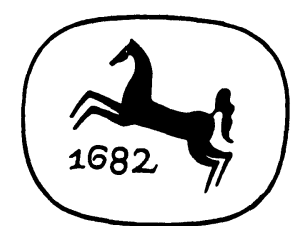

Repertorien

zur Deutschen Literaturgeschichte

Herausgegeben

von Paul Raabe

Band 8

Erster Teilband 
Michael Winter

Compendium Utopiarum

Typologie und Bibliographie literarischer Utopien

Erster Teilband

Von der Antike bis zur deutschen Frühaufklärung

J. B. Metzlersche Verlagsbuchhandlung

Stuttgart 
Die Typologie der utopischen Literatur liegt hier in ihrem ersten Teil vor, der die utopischen Texte bis zur Mitte des I 8. Jahrhunderts erfaßt. Ein zweiter Teil, der die utopischen Texte des I8. Jahrhunderts und des I9. Jahrhunderts bis zur Revolution von 1848 und die Utopien der zweiten Hälfte des 19. und der ersten Hälfte des 20. Jahrhunderts behandelt, folgt in einem zweiten Band. (Alle Verweise im I. Teilband auf Texte, die nach I73 I erschienen sind, beziehen sich auf den 2. Teilband)

Für die Genehmigung des Abdrucks der Titelblätter und Abbildungen aus den Originalen danke ich sehr herzlich der Herzog August Bibliothek in Wolfenbüttel.

Cip-Kurztitelaufnahme der Deutschen Bibliothek

Winter, Michael

Compendium Utopiarum: Typologie u. Bibliogr. literar. Utopien / Michael Winter. - Stuttgart: Metzler. Teilbd. I. Von der Antike bis zur deutschen Frühaufklärung. - 1978.

(Repertorien zur deutschen Literaturgeschichte; Bd. 8)

ISBN 978-3-476-00396-6

ISBN 978-3-476-03101-3 (eBook)

DOI 10.1007/978-3-476-03101-3

(C) 1978 Springer-Verlag GmbH Deutschland Ursprünglich erschienen bei J. B. Metzlersche Verlagsbuchhandlung und Carl Ernst Poeschel Verlag GmbH in Stuttgart 1978 
Meinen Eltern 
Die Literatur hat im radikalen Fortdenken des Möglichen ein eigenes Genre geschaffen: die Utopie. Ihre Geschichtlichkeit und ihre Erscheinungsformen sind bibliographisch und typologisch erfaßbar. Ihre mythische Dimension als ursprüngliche Einheit von Mensch, Göttern und Natur ist in der antiken Literatur noch erkennbar; in der Moderne tritt sie seit der Renaissance nur noch als Nachschein oder als beschworener Vorschein ins Bewußtsein.

Der Weg der wissenschaftlichen Diskussion über den "Staatsroman" im 19. Jahrhundert bis zur Erörterung einer Soziologie des utopischen Denkens im 20. Jahrhundert, einer durch Literatur vermittelten prognostischen Orientierung, ist indessen nicht identisch mit der Begriffsgeschichte und der Literaturgeschichte von "Utopie". Die Begriffsgeschichte ist die Geschichte von Zirkelschlüssen gemäß dem herbeigerufenen oder jeweils bekannten Material; die Literaturgeschichte ist die Geschichte einer "Subliteratur" in verschiedenen Formen, vom Traktat über die "Schlaraffia Politica" bis zur Science Fiction. Robinsonade und voyage imaginaire, Reiseroman und Bildungsroman haben utopische Elemente, die geeignet erscheinen, epische Gattungen differenzierter zu bestimmen. Diese Elemente begründen aber noch keine "Utopie". Wie also ist das "ungeheure utopische Vorkommen in der Welt" (B1och), soweit es literarisch ist, kategorial zu erfassen?

Zweifellos entzieht sich die Utopie der öfter behaupteten Relation zwischen jeweils auftretenden gese11schaft1ichen Mißständen und der Rückbesinnung auf das Vergangene. Sie eliminiert vielmehr das Vergangene und schlägt einen Bogen von der aetas aurea zur chiliastischen Hoffnung. In ihrer Wirkungsabsicht, in ihrem appellativen Charakter, widersetzt sie sich der Geschichte und verspricht eine zukunft, die doch immer vom jeweiligen historischen Ort des utopischen Entwurfs bedingt ist. Dieser Widerspruch bestimmt das Nachdenken über die "Utopie", solange nur wissenssoziologisch oder nur bibliographisch-antiquarisch vorgegangen wird.

Das hier vorliegende Kompendium stellt sich diesem Widerspruch und hebt ihn auf, über seinen bibliographisch-typologischen Informationswert hinaus. Es ist im Wortsinne ein zusammenfassender Abriß einer 1iterarischen
Gattung, ein historisches Verzeichnis utopischer Werke nach Autoren, Druckfassungen und Bibliotheks-Standorten, und es nimmt eine typologische Neuordnung nach bestimmten Deskriptoren vor.Darüber hinaus ist es eine kritische Phänomenologie und eine Analyse der utopischen Artikulationsformen überhaupt bis hin $z u$ einer Bedeutungslehre utopischer Sprache. Es schließt keinen heuristisch einengenden Kompromiß zwischen der umfassenden Bestandsaufnahme und der einebnenden Typenlehre. Es zeigt vielmehr, folgt man den Intentionen und der Leseanleitung des Verfassers, neue Zusammenhänge zwischen der historisch genauen Analyse und der Entstehung einer literarischen Formensprache, die ihre gesellschaftskritischen Inhalte anderen und jeweils eigenen Erwartungshaltungen von Publikum und Autor verdankt. Wie Campane1la in einem scientistischen orbis pictus an den Wänden und Mauern seines Sonnenstaates das Wissen seiner Utopie zu pädagogischen Zwecken versammelt hat, wie Bacon in seinem Hause Salomons die wissenschaftlichen Ergebnisse und Projekte in Neu-Atlantis katalogartig aufzähli - so erscheint in diesem Kompendium, auf die Gattung der Utopie überhaupt bezogen, der Thesaurus eines neu erarbeiteten und erweiterten Wissensstandes zur utopischen Literatur, einschließ1ich mancher Neuentdeckungen oder Wiederentdeckungen aus europäischen Bibliotheken, gewiß noch lückenhaft, aber umfassender und genauer als bisher vorliegende Sammlungen und Darstellungen.

Dieses Kompendium ist zugleich die Vorstufe und Vorbedingung zu einer geplanten kommentierten Dokumentation der utopischen Literatur, in der alle typologisch wichtigen Zeugnisse neu versammelt und in einem neuen $\mathrm{Zu}-$ sammenhange gezeigt werden sollen. Die verfälschte und verleumdete Utopie kann erst dann ihren eigentlichen Begriffs- und Wertbereich erlangen, wenn sie in ihrer eigenen $\mathrm{Ge}-$ schichte sichtbar wird. Kafkas Aphorismus ist in diesem Sinne zugleich ein utopisches Epimythion: "Wenn das, was im Paradies zerstört worden sein soll, zerstörbar war, dann war es nicht entscheidend; war es aber unzerstörbar, dann leben wir in einem falschen Glauben". 
Der Streit um die Standpunkte von konservativ UND PROGRESSIV IST ZUR 7.EIT AKTUELL. REZEPTE FÜR EINE BESSERE GESELLSCHAFT HALTEN BEIDE BEReit, Sie Reichen Von Reformen oder VerhindeRUNGEN VON REFORMEN BIS ZU DEN NICHT MEHR LEgaLen AKTIONEN VON TERROR UND GEgenterRoR. Die Diskussion UM DiE SOZIale Utopie hat Sich ZU EINZELFRAGEN KOMPLIZIERTER WIRTSCHAFTLICHER UND GESELLSCHAFTLICHER ABLÄUfE, ZU EINZELFRAGEN IN WISSENSCHAFT, TECHNIK UND TECHNOLOgie Versachlicht. Sie bleibt im Anfangsstadium von DetailfrRagen SteCKen. Gegenüber GLOBALEN Programmen, WIE SIE NOCH BIS ZUM ENDE DER ERSTEN HÄLFTE UNSERES JAHRHUNDERTS VERKÜNDET WURDEN, SIND WIR MIT RECHT SKEPTISCH GEWORDEN, DiE KLAREN GEgenSÄTZE VON GUT UND BöSE, VON UTOPISCHER MÖGLICHKEIT UND REALER WIRKLICHKEIT HABEN SICH VERWISCHT. DER Konservative IST ZUWeilen der Progressive und der Progressive zUWEILEN DER Konservative GANZ NACH LAGE DER HISTORISCHEN UND GESELLSCHAFTLICHEN UMSTÄNDE. WiR Sind AUF DER SUCHE NACH NEUEN BEgRifFEN, UnSERE HOFFnUngen aUSZUDRÜCKEN. UNSERE SPRACHE HINKT HINTER DER WIRKLICHKEIT HER, ANSTATT IHR VORAUSZUEILEN, WIE IN UTOPIEN.

Der Prozess der Zivilisation ist derart voranGESCHRITTEN, DASS IHN EIN ROBINSON NICHT MEHR IN WENIGEN JAHREN, NICHT IN EINEM GANZEN LEBEN NACHVOLLZiehen KönNTE. Utopische PeRspektiven JENSEITS DER ALTERNATIVE VON PROGRESSIV UND KONSERVATIV TUN SICH AUF. DiE ENTWICKLUNG UNSERER ZIVILISATION HAT SICH NIE NACH IHREN UTOPIEN GERICHTET, WEDER NACH IHREN GLÜCKSVORSTELLUNGEN NOCH NACH IHREN SCHRECKENSVISIONEN, SONDERN ALLEIN NACH DEN HISTORISCHEN SACHZWÄngen. DenNoCH WAREN die GLÜCKSVORSTELLUNGEN WEGWEISER NICHT SO SEHR FÜR DIE KÜNFTIGE TATSÄCHLICHE ENTWICKLUNG DER ZIVILISATION, SONDERN EHER FÜR DIE ZEITGENÖSSISCHEN ERWARTUNGEN IN I IRRE ZUKUNFT. SOLCHE EINDEUTIGEN, KOMPAKTEN INDIKATOREN FÜR UTOPISCHES BEWUSSTSEIN HABEN WIR HEUTE NICHT MEHR. DASS ES SIE DAGEGEN FÜR ALLE FRÜHEREN ZEITEN IN LITERARISCHEN ZEUGNISSEN, DEN UTOPIEN, ODER AUSSERLITERARISCH DOKUMENTIERT, IN ZEUGNISSEN UTOPISCHEN ODER REVOLUTIONÄREN DENKENS UND HANDELNS GAB, ZEIGT, WIE STÄNDIG IN DER KULTURGESCHICHTE ÜBER DEN FORTSCHRITT DER ZIVILISA-
TION REFLEKTIERT WURDE. ENTWICKLUNG, TeleOLOGIE, FORTSCHRITT SIND CHARAKTERISTISCHE GRUNDBEGRIFFE EUROPÄISCHEN DENKENS, NICHT ERST SEIT DEM BEgINN DER InDUSTRIEgESELLSCHAFT. AUCH HEUTE WIRD STÄNDIG ÜBER DIE UTOPISCHEN PERSPEKTIVEN UNSERER ZIVILISATION NACHGEDACHT, NUR NICHT MEHR - WIE EINST - IN ROMANEN. MIT DER SÄKULARISIERUNG DER ZiVILISATION HAT AUCH DeR Niedergang Der Utopischen Mythen begonnen. NICHT, DASS SIE NICHT MEHR AUFFINDBAR WÄREN, ERNST BLOCH HAT SIE JA ÜBERALL IN UNSERER WELT AUFGESPÜRT. ABER SIE SIND NICHT MEHR EINDEUTIG IN LITERARISCHEN GATTUNGEN FASSBAR.

Die neue Entwicklung des utopischen Denkens WIRD ERST KLAR, WENN MAN DIE UTOPIEN DURCH DIE JAHRHUNDERTE DES ZIVILISATIONSPROZESSES HINDURCh Verfolgt. Die Grundlagen und Materialien DAFÜr SOLL Diese ARBeit LIEfERn. Die hieR ZUSAMMENGETRAGENEN ZeUgnisSE DES UTOPISCHEN DENKENS MACHEN DEUTLICH, DASS ES DIE UNZUFRIEDENHEIT MIT DEN GEGEBENEN UMSTÄNDEN SCHON IMMER GEGEBEN HAT UND DASS DIE KRITISCHE UNZUFRIEDENHEIT ZU DEN WEITESTEN UND HARTNÄCKIGSTEN AUSbLicken der Vernunft geHört. Auf SPREngsätze UND SinNLOSE Zerstörung hat EIN SOLCHES DenKen NIE GEBAUT, UND DORT, WO UTOPISCHES DENKEN REVOLUTIONEN BEGLEITET HAT, BEFAND ES SICH IMMER IM EINKLANG MIT DEM MEHRHEITLICHEN BEWUSSTSEIN EINER HISTORISCHEN WENDE, ZU UNTERSCHEIDEN IST ZWISCHEN UTOPISCHEM, D.H, VORWÄRTS- UND ZIELGERICHTETEM DENKEN UND ANARCHISCHEM, D.H. ZIELLOS NEGATIVEM DENKEN .

Das Zustandekommen dieser Arbeit verdanke ich DER Hilfsbereitschaft DER MitaRBEITER VERSCHIEDENER BIBLIOTHEKEN, HIER VOR ALLEM DER Herzog-August Bibliothek in WolfenbütTel, DeR BibliotheK DES BRITISH-MUSEUM, DER BibLIOTHËQUe Nationale UND DER Niedersächsischen StaATSUND UNIVERSITÄTSBIBLIOTHEK IN GÖTTINGEN.

FÜR SEINE WISSENSCHAFTLICHE UND PERSÖNLICHE geduldige Betreuung danke ich Herrn Prof. Dr. Gerhard SCHMidt-Henkel, SaArbrücken, für Viele Anregungen ebenso Herro Prof.Dr.Wilhelm Vosskamp, Bielefeld. Für die herausgeberische Betreuung danke ich Herrn Prof.Dr. Paul RaAbe, Wolfenbüttel, und dem Lektorat des MetzlerVerLAGEs,

SAARBRÜCKEN, IM MärZ 1978 


\section{I, EINLEITUNGSTEIL}

Utopie als Roman und Utopie als Aktionsprogramm

Zwei Grundformen utopischen Denkens

1. "Utopia" als Grundstruktur der 1iterarischen Utopien

2. Von der Revolution der Theologie zur Theologie der Revolution. Die Utopie Thomas Müntzers

3. Anmerkungen

2. Hinweise zur Benutzung des chronologischtypologischen Teils

\section{TYPOLOGISCH-CHRONOLOGISCH-BIBLIOGRAPHISCHER TEIL}

Chronologische Bibliographie der utopischen Literatur und typologische Kommentare

1. Von der Antike bis zur deutschen Frühaufklärung

\section{I , ANHANG}

Typologische Zusammenfassung

1. Typologische Tabellen

2. Typologische Register

3. Ergebnisse und Zusammenfassung

1. Bibliographie der biblio- und biographischen Hilfsmitte 1

2. Spezialbibliographien zur utopischen Literatur

3. Anthologien und Textsammlungen

4. Bibliographie der neueren Literatur zu Utopie und Utopisten

5. Bibliographie der erwähnten Sekundärliteratur

\section{IV, REGISTER}
1. Autorenregister
2. Titelregister
3. Namenregister
4. Sachregister
5. Verzeichnis der Abkürzungen 


\section{De optimo Reipublicz Statu, Libellus verè̀ aureus.}

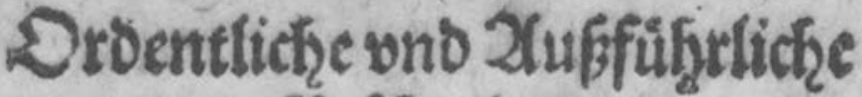

Befchreibung

Der vberaus fertlichen ono ganis munberbarlichen 1 , bock wenigen bibsero befanderen Inful

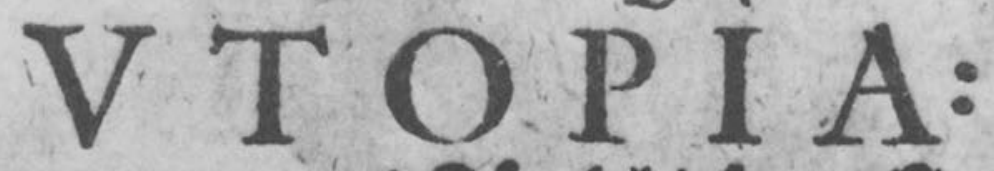

Gampt bmbitanslicher Gusefy

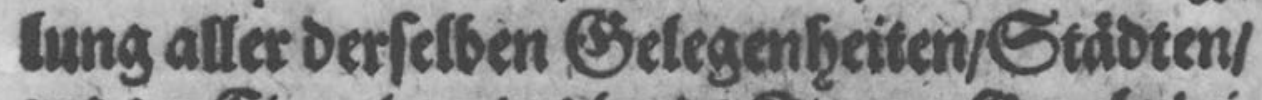

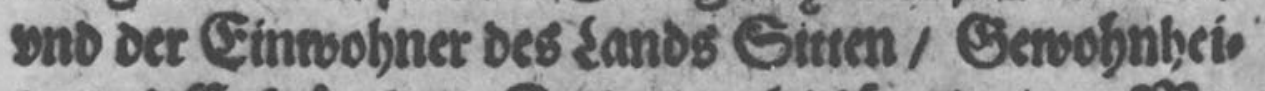

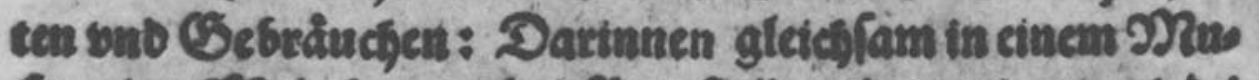

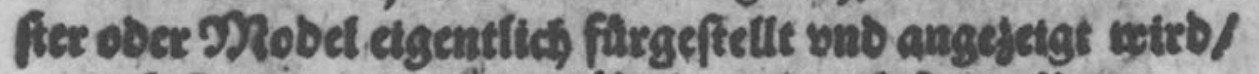

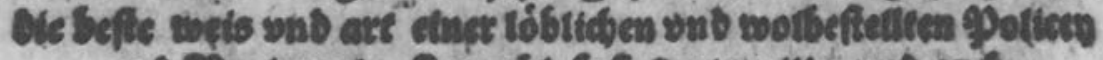

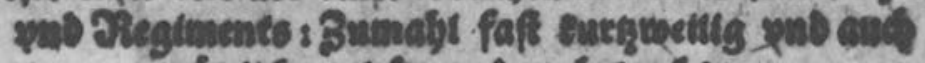

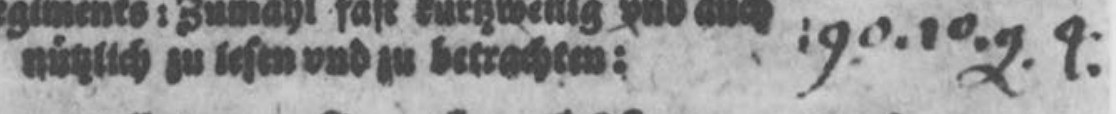
Erfitich ourch Den Soctigelährten bno 2Beitberimpeten Serrn Thomam Morum,

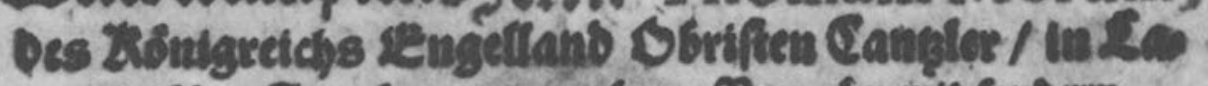

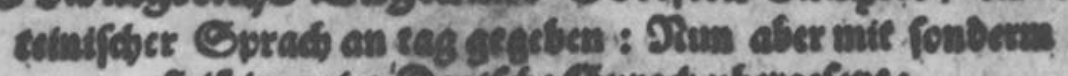

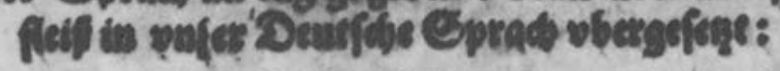

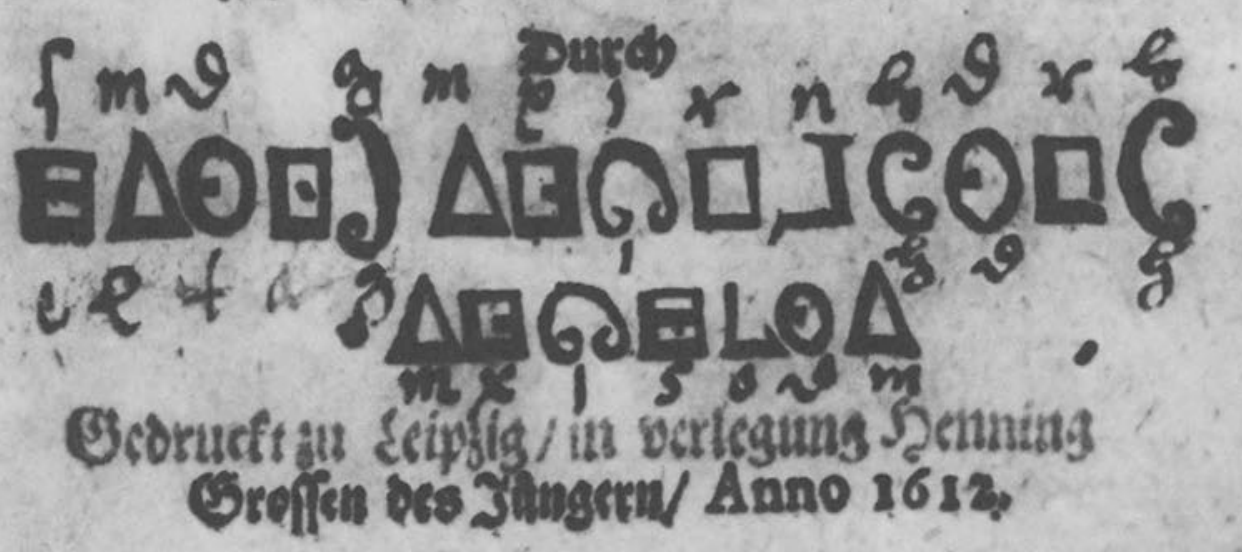

Thomas Morus: De optimo Reipublicae Statu, Libellus verè aureus. Ordentliche vnd Außfürliche Beschreibung Der vberaus herrlichen vnd gantz wunderbarlichen I...I Insul Vtopia. Leipzig 1612. - Bibl.: 23: 139.Pol.: Titelblatt. - Vgl.S.28,1 


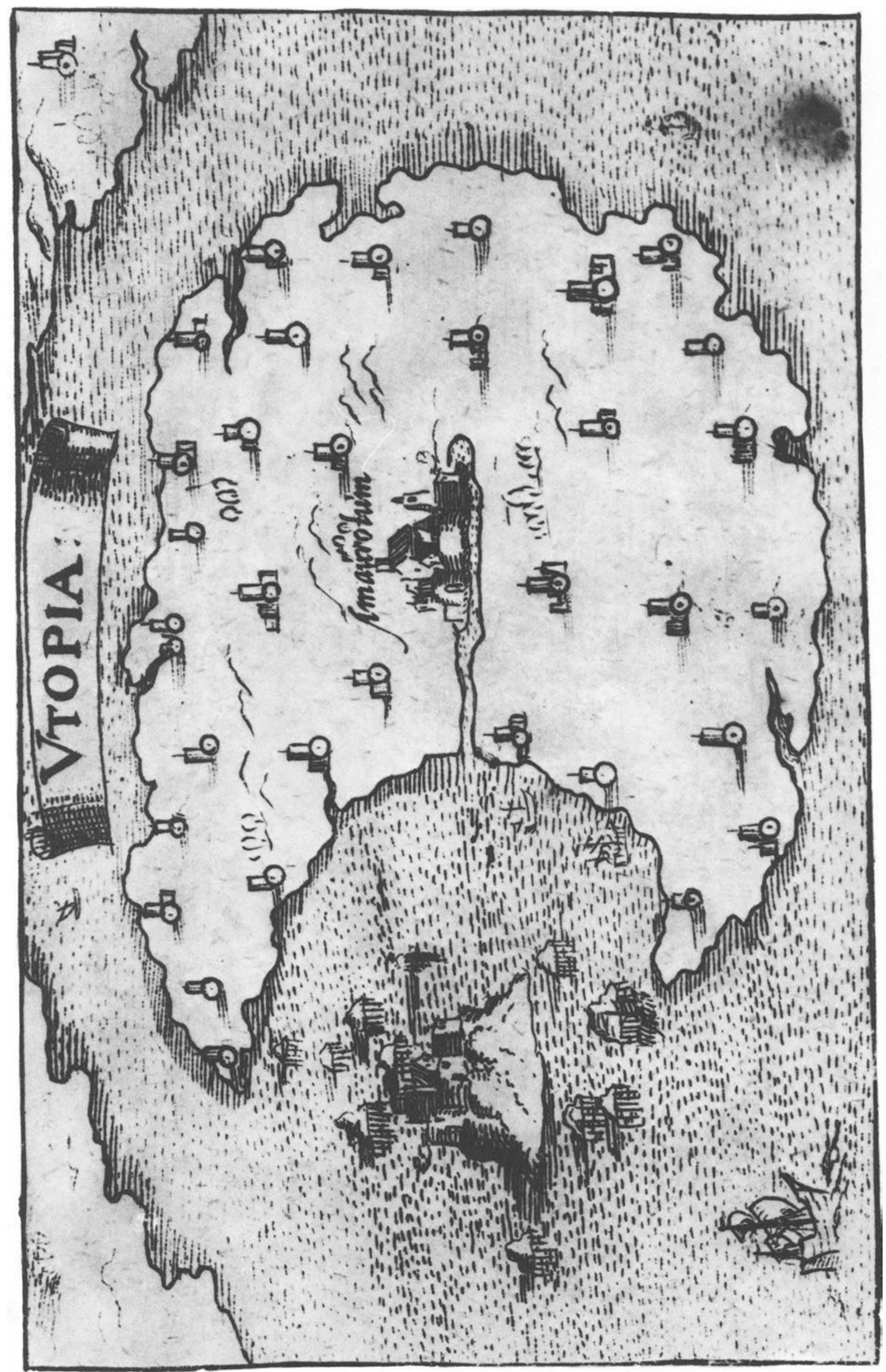

Thomas Morus: Utopia. Leipzig 1612. - Bibl.: 23: 139.Pol.: Abbildung der Insel Utopia (Bl.6r) 


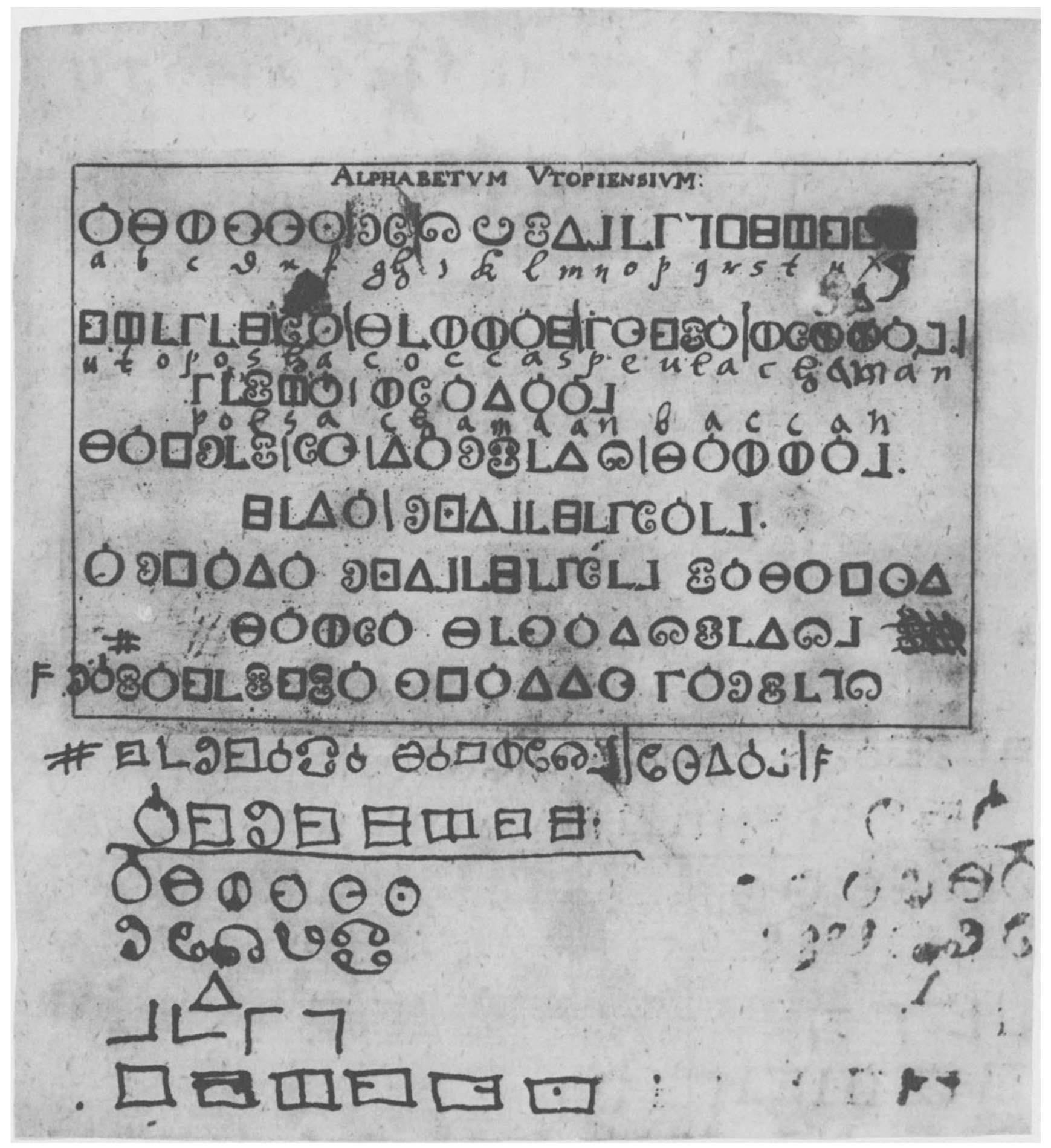

Thomas Morus: Utopia. Leipzig 1612. - Bibl.: 23: 139.Pol.: Utopisches Alphabet (Bl.7V). - Vgl. dazu S.XXIV,1 
Einleitungsteil 


\author{
UTOPIE ALS ROMAN \\ UND \\ UTOPIE ALS AKTIONSPROGRAMM \\ ZWEI GRUNDFORMEN \\ UTOPISCHEN DENKENS \\ (MORUS UND MÜNTZER)
}

I. UTOPIA als Grundstruktur der literarischen Utopien.

Der Traum vom besten Staat findet nicht nur im Roman statt. Durch die Geschichte des utopischen Denkens seit der Renaissance zieht sich ein ständiger Wechsel in den Präsentationsformen dieses Traumes. Er schwankt in seinen äußersten Begrenzungen zwischen dem "als ob" der literarischen Fiktion und der Hektik revolutionären Handelns. Modellbeschreibung auf der einen, revolutionäres Aktionsprogramm auf der anderen Seite, beide Formen utopischen Denkens treten in der Geschichte der Utopie immer wieder nebeneinander und nacheinander auf. Das führt zu der Frage nach dem Verhältnis von Utopie als Roman und Utopie als revolutionäre Handlungsanweisung. Utopie als Roman und Utopie als Pamphlet und revolutionäres Programm sind komplementäre Gattungstypen, die immer wieder in Zeiten zusammen auftreten, in denen die traditionellen sozialen Strukturen einer Gesellschaft in Bewegung geraten sind, so zur Zeit der Reformation bei Thomas Morus und Thomas Müntzer, zur Zeit des englischen Bürgerkrieges und der Cromwellherrschaft bei Samuel Gott (s.u.Nr.78) und Gerrard Winstanley (s.u.Nr.80 u.82), später in der Zeit der Französischen Revolution, der 1848er Revolution und der russischen Oktoberrevolution. Beide Formen, Utopie als Roman oder als Programm, sind Ausdruck des Unbehagens an den bestehenden gesellschaftlichen Verhältnissen. Beide aber beruhen auf einer völlig unterschiedlichen
Vieles fiele leichter, könnte man Gras essen. Hierin hat es der Arme, sonst als Vieh gehalten, nicht so gut wie dieses. Nur die Luft ist ohne weiteres da, aber der Acker muß erst bestellt werden, immer wieder. In gebückter, mühsamer Haltung, nicht so, wie man feines Obst aufrecht an der Mauer zieht. Sammeln von Beeren, Frichten, freie Jagd sind lange vorbei, wenige Reiche leben von vielen Armen. Bestöndiger Hunger zieht durch das Leben, nur er zwingt zur Fron, dann erst zwingt die Peitsche. Wöre der tägliche Bissen so sicher wie die Luft, dann gäbe es kein Elend. So aber wächst nur im Traum das Brot wie Laub auf den Boumen. Vorhanden ist nichts dergleichen, das Leben ist hart, und trotzdem war stets ein Gefuhl des Auswegs da, und daß er möglich sei. Da er so lange nicht gefunden wurde, schwärmte tröumerischer Mut nach überallhin aus.

(Ernst Bloch: Das Prinzip Hoffnung.)

Auffassung von Wirklichkeit und Mög1ichkeit utopischer Veränderung. Der Utopist, der Autor utopischer Romane, resigniert von vornherein im Hinblick auf eine unmittelbare Realisation seines Ideals - obwohl er sie immer im Auge hat -, indem er seinen utopischen Staat in den Bereich der poetischen Wahrscheinlichkeit verlegt, aber er zeichnet sein Gegenbild zu der von ihm kritisierten Gesellschaft a1s Modell konkret in allen Einzelheiten. Die unzulänglichen Verhältnisse der realen Welt und die idealen Verhältnisse der utopischen We1t werden dem Leser als ein literarisch deutlich gestalteter Kontrast vorgeführt. Den Weg aber vom einen zum anderen Zustand einer Gese11schaft, den Weg von der Realität in die Utopie liefert der utopische Roman nicht. Gerade auf diesen Aspekt konzentriert sich jedoch das utopische Aktionsprogramm einer revolutionären Bewegung. Das "Wie" des Weges von der unzulänglichen Realität zur Utopie rückt hier in den Vordergrund. Dafür bleibt zwar nicht immer das Ziel der Revolution, aber der gesellschaftliche Zustand danach unklar. Das utopische Programm in Form des Pamphlets, der Flugschrift oder der Programmschrift, vor allem der Rede, der Predigt, ist hier Begleiterscheinung utopischen Handelns in der historischen Wirklichkeit. Winstanleys wie Müntzers utopisches Denken beschränkt sich nicht auf schriftliche Äußerungen, sondern 
geht darüber hinaus in historischem Handeln auf. Insofern ist dieser Typ der utopischen Literatur immer $z u$ einem Teil nur außerhalb ästhetischer Zusammenhänge in historischen Zeugnissen erfaßbar. Die UTOPIA des Thomas Morus wäre auch ohne die historischen Umstände ihres Autors, allerdings nicht ohne die Kenntnis des historischen Hintergrundes des Textes als utopisch-kritisches Mode11 erfaßbar. Müntzers oder Winstanleys Schriften sind dagegen nicht ohne den Bauernkrieg oder die Digger-Bewegung und ohne den Anteil der Autoren an diesen historischen Ereignissen $z u$ verstehen. Die Utopie als Roman hat für sich die Gewißheit, den best möglichen staat gefunden $z u$ haben, aber seine Gründer sind literarische Figuren. Das utopische Aktionsprogramm dagegen steht bei seinen Initiatoren in der Gewißheit des geeigneten historischen Augenblicks, sei es in der Hoffnung auf die Parusie oder auf die Vernunft des menschlichen Geistes, die endlich allgemein hervorbrechen wird. Das revolutionäre utopische Handeln betrügt sich in der Einschätzung der historischen Situation und oft der tatsächlichen historischen Machtverhăltnisse. Daß die Mächtigen der jeweiligen Gegenwart, die es zu bekehren oder zu bekämpfen gilt, letztlich auch in der Zukunft die Măchtigen bleiben, schätzt der Romanutopist realistischer ein. Darunter leidet die revolutionäre Potenz seines Textes. Dort aber, wo geschrieben und gehandelt wird, wo utopisches Programm und revolutionäres Tun Hand in Hand gehen, leidet oft der antizipatorische Weitb1ick.

Die Romanutopie konstruiert und schildert ein gese11schaft1iches Ideal, das in der Wirklichkeit bis dahin nicht existiert hat und das als Wunschbild der vom Utopisten als fehlerhaft kritisierten gesellschaftlichen Realität gegenübergeste11t wird. Aus der "Negation" der vom Autor als schlecht empfundenen Rea1ität entsteht die Kritik an den jeweils herrschenden gesel1schaft1ichen Verhä1tnissen. Aus dieser Kritik heraus konstruiert der Utopist ein gese11schaftliches "Gegenmode11", in dem die als negativ empfundenen gesellschaft1ichen Verhältnisse durch ihr positives Gegenteil ersetzt werden. Jedem utopischen Mode11staat liegt also direkt oder indirekt die Kritik an der zeitgenössischen, bestehenden Gesellschaft zugrunde. ${ }^{l}$ Als Grundstruktur der Sozialutopie besteht so die Spannung zwischen der Negation der negativen Realität und der Affirmation der positiven Möglichkeit einer besseren Zukunft, die in der Fiktion des Romans zunächst nicht als zeitliches, sondern als örtliches Entrückt-sein von der Realität dargeste11t wird. Gese11schaftskritik und utopisches Mode11 verhalten sich innerhalb der Utopie zueinander wie Negativ und Positiv ein und desselben Bildes. Die Fiktionsstruktur der Romanerzählung - in der frühen Utopie, des Reiseberichts - hat dabei die Aufgabe, zwischen abgebildeter gesellschaftlicher Wirk1ichkeit und konstruierter gesellschaft1icher Möglichkeit zu vermitteln. Im Roman müssen also Wirklichkeit und Möglichkeit so in literarische Bilder gekleidet werden, daß sie wie zwei reale Welten miteinander verglichen werden können, wobei jede bis ins kleinste Detail das Gegenteil der anderen ist. Die Kontinuität der Betrachtung gewăhrleistet in jedem Fall die Person des Reisenden, ohne den der utopische Roman erzähltechnisch nicht möglich wăre. 2 Die Romanutopie lebt also grundsätzlich aus zwei strukturbestimmenden Bereichen: Aus der Abbildung der Realität und aus der Abbildung der Idealität. Aus dem ersten ergibt sich ihre gesellschaftskritische, aus dem zweiten ihre antizipatorische Dimension. Daraus ergibt sich folgendes strukturmode11 für das utopische Denken bzw. für den utopischen Roman:

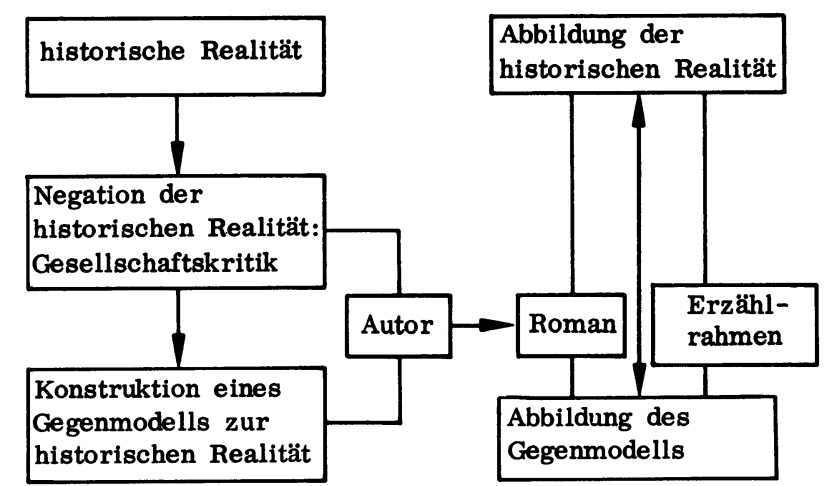

Am deutlichsten tritt diese Grundstruktur des utopischen Romans in dem Text hervor, der für die gesamte Gattung bestimmend wurde, in Thomas Morus' 1516 erschienenem Buch von der Insel Utopia: LIBELLUS VERE AUREUS DE OPTIMO REIPUBLICAE STATU, DEQUE NOVA INSULA UTOPIA (s.u. Nr.37). Bis auf sprachlich-semantische Details ist Morus' utopischer Modellstaat das genaue Gegenbild des zeitgenössischen England. Die beiden Grundkomponenten des utopischen Romans, Kritik an der historischen Realität und Gegenmode11, stehen hier deutlich im ersten und zweiten Buch der UTOPIA einander gegenüber. Das erste Buch berichtet zunächst von einer Gesandtschaft des Autors im Dienst Heinrichs 
VIII. nach Antwerpen, die historische Tatsache ist. Bei dieser Gelegenheit trifft Morus seinen Freund Peter Aegid, ebenfalls eine historische Gestalt. Erst dieser stellt ihm den Weltreisenden und Begleiter Amerigo Vespuccis, Raphael Hythlodaeus, vor. Die literarische Figur, Raphael Hythlodaeus, ist von Morus so geschickt in die realen historischen Beziehungen eingebaut, wie es erforderlich erscheint, um bereits den Gewährsmann der Utopie, den Reisenden und Erzähler, so wahrscheinlich wie möglich zu gestalten. So beginnt dieser "Roman" vollkommen auf der Ebene des Berichts wirklicher Begebenheiten. Von dieser Ausgangsposition aus ist es für den Autor kein Problem mehr, alle Erzählungen des Reisenden als wahrscheinlich hinzustellen. Nur mit dem Namen "Hythlodaeus" verweist Morus satirisch auf den fiktiven Charakter der Person und der Erzählung. Denn der humanistisch gebildete zeitgenössische Leser konnte diesen Namen mit "Schwätzer","Auf-

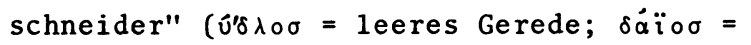
erfahren, von $\left.\delta \alpha \tilde{n} v \alpha_{\imath}\right)^{3}$ übersetzen. So wird satirisch der Anspruch auf Wahrscheinlichkeit zurückgenommen und das Bemühen um die 1iterarische Wahrschein1ichkeit bloßgestellt.

Raphael Hythlodaeus, der philosophische Seefahrer und "Meister im Garnspinnen" ist das Sprachrohr der utopischen Welt und der Vermittler zwischen Utopia und Europa, zwischen Idealität und Realität. Die äußere "Handlung" der UTOPIA besteht lediglich aus der Diskussion der beiden Humanisten, Aegid und Morus, mit dem Utopia-Besucher in einem Antwerpener Garten. Nicht persön1iche Schicksale und Reiseabenteuer sind der Gesprächsstoff, sondern man kommt sehr bald auf ein Hauptanliegen, das, wie es heißt, der Zweck dieser Schrift ist ${ }^{4}$ und eigentlich der einzige Diskussionsgegenstand $z$ wischen einem weltreisenden Philosophen und einem humanistischen Gelehrten im Staatsdienst sein kann: Staatsformen, fremde und eigene. Auch das, was Morus von den einleitenden Gesprächen nur zusammenfassend wiedergibt, dreht sich um dieses Thema. Noch wichtiger aber ist für den pädagogisch und staatstheoretisch engagierten Philosophen die Frage nach der Realisierbarkeit seiner Ideen. Was nützen die einleuchtenden Beispiele von einer glücklichen Gesellschaft, wenn nicht die Aussicht besteht, in ihrem Sinne realpolitisch wirken zu können? Das ist das entscheidende Problem des Autors und seiner Gesprächspartner, und deshalb eröffnet Aegid die Diskussion mit der Empfehlung, Hythlodaeus, der Staats- und
We1tweise, solle seine heilsamen Ansichten und Erfahrungen in den Dienst der herrschenden Fürsten stellen, um dort, wo sich die Staatsmacht konzentriert, durch Oberzeugung und Einfluß verăndernd zu wirken. Aus diesem Vorschlag entwickelt sich ein Gespräch um die Möglichkeit oder Unmöglichkeit, durch Ratschläge, besonders an Königshöfen etwas $z u$ verbessern. Die Frage nach dem Erfolg der Fürstenerziehung oder Umerziehung durch den Philosophen ist ein Grundgedanke der UTOPIA. Hier knüpft Morus an eine Problematik an, die bereits bei Platon auftaucht, der in seiner POLITEIA (s.u.Nr.6) die Realisierung utopischer Vorstellungen davon abhängig macht, daß entweder die Könige Philosophen oder die Philosophen Könige würden. ${ }^{5}$ In dieses Diskussionsgerüst schieben sich nun drei bzw. zwei längere Erläuterungs- oder Erzăhlpassagen Raphaels ein, von denen die letzte fast den gesamten Teil von Buch II einnimmt und inhaltlich die Beschreibung der Insula Utopia enthält. Danach kehrt Hythlodaeus sofort zu seiner anfänglichen Argumentation im unterbrochenen Streitgespräch zurück, und der Dialog zwischen Morus und Raphael wird mit einem Fazit des Geprächspartners und Autors abgeschlossen.

Nachdem Raphael seinen Zuhörern mit zwei ausführlichen, hypothetischen Beispielen ${ }^{6}$ nachgewiesen hat, daß es für ihn unmöglich sein würde, mit seinen gegen alle Machtpolitik gerichteten Ansichten unter fürstichen Ratgebern jemals etwas zu bewirken, verweist Morus auf die Notwendigkeit der Kompromißbereitschaft. Dagegen verwehrt sich Hythlodaeus entschieden: Ein Philosoph müsse seinen Oberzeugungen treu bleiben und dürfe keine Rücksichten auf halbe Wahrheiten und Kompromisse nehmen, sonst sei die eigene Sache erst recht verraten und eine gute Absicht in die schlechteste verwandelt. Auch Platon habe schließlich gesagt, der Philosoph solle sich fern und seinen Blick rein halten von Staatsgeschäften, da er ja doch nichts ausrichten könne, solange die Könige nicht selber Philosophen seien oder die Philosophen Könige. ${ }^{7}$ Hier sind wir mitten im Zentrum einer Diskussion um die Oberzeugungskraft der Rede und um das Verhältnis von Philosophie und Rhetorik, die die gesamte humanistische Renaissance-Philosophie durchzieht. Dabei ging man von zwei klassischen Positionen aus: Platon bestätigt dem Philosophen die Unabhängigkeit von rhetorischen Zwängen. Seine Sache sei es, die Wahrheit zu sagen - sei sie auch noch so unbequem und abseitig - und nicht, sich um das Oberzeugen zu 
kümmern, auch nicht in Staatsangelegenheiten. ${ }^{8}$ "Wenn wir die Wahrheit auf unserer Seite haben, denkst du, wir sollten uns viel um die Meinung anderer kümmern?"9 Dagegen verteidigt Isokrates den Rhetoriker und verlangt für das öffentliche Gespräch: "Wir sollten nicht nach Neuheiten trachten, denn in diesen Gesprächen ist es nicht möglich, von Paradoxem oder Unglaubwürdigem $z u$ reden oder Dinge zu erwähnen, die außerhalb der anerkannten Meinung stehen."10 Hier liegt nicht nur das Problem von Raphaels Utopia-Schilderung, sondern überhaupt des utopischen Romans; dieser muß das Unglaubwürdige so glaubwürdig wie möglich schildern, um nicht a1s Lügengeschichte abgestempe1t und wirkungslos zu werden. Für den Gesprächspartner Morus sind jedoch ideale politische Verhältnisse nicht nur eine Frage der richtigen Oberzeugung. Deshalb stellt sich ihm darüber hinaus das Problem, ob die gesellschaftlichen Verhältnisse überhaupt ideal sein können - seien sie nun auf regierende Könige oder Philosophen zurückzuführen -, solange nicht alle Menschen gut sind. Dagegen argumentiert Hythlodaeus umgekehrt, daß erst alle Verhältnisse gut sein müssen, ehe es der Mensch werden kann. Das Haupthindernis dafür aber ist das Privateigentum.

Freilich, mein lieber Morus, wenn ich dir meine letzte tberzeugung offen sagen soll, so dünkt mich in der Tat: wo es noch Privatbesitz gibt, wo alle Menschen alle Werte am Maßstab des Geldes messen, da wird es kaum jemals möglich sein, eine gerechte und glūckliche Politik zu treiben. I... I So bin ich denn fest überzeugt, daB der Besitz durchaus nicht auf irgendeine billige oder gerechte Weise verteilt und überhaupt das Glück der Sterblichen nicht begründet werden kann, solange nicht vorher das Eigentum aufgehoben ist; I...I. 11

Hier liegt der Kern der utopischen Argumentation, auf dem sich alles weitere aufbaut. Die Entscheidung gegen das Privateigentum und die Konstruktion einer utopischen We1t ohne Privatbesitz ist innerhalb der Literatur zur UTOPIA immer wieder gegensätzlich gedeutet worden: einmal als das eigentliche antizipatorische Moment der Morusschen Utopie, der Vorausblick auf den kommunistischen Staat, zum anderen als eine eher zurückschauende Idealisierung "vorkapitalistischer" kollektivistischer, mittelalterlicher oder antiker Gesellschaftsformen (z.B. das Urchristentum) angesichts der Entwicklung der frühen Privatund Geldwirtschaft mit ihren verheerenden Folgen im England des beginnenden 16. Jahrhunderts. 12 Ein funktionierendes Gemeinwesen, das nicht auf privaten Besitzverhältnissen aufgebaut ist, können sich jedenfalls die Gesprächspartner des Hythlodaeus nicht vorstellen. Das ist der Punkt, von dem aus Raphael seine Utopia ausführlich ins Bild setzen kann, und jetzt warten seine Zuhörer mit Spannung darauf, was er woh1 zu erzählen habe.

Hythlodaeus schildert zuerst die geographische Gestalt der Insel Utopia, er beschreibt die liegende Siche1-Barke mit den Hörnern des wiederwachsenden, sich wiedergebärenden Mondes (1una renascens).13 Utopia ist nicht nur Nirgendwo (Nusquama, oi $\tau$ ómoo) oder glücklicher Ort $(\varepsilon \tilde{u} \tau o ́ \pi \circ \sigma)^{14}$, es ist vor allem auch neuer Anfang. Später schildert Raphael die MithrasVerehrung in Utopia als einen der dort herrschenden religiösen Hauptkulte. Mithras wird das höchste Wesen genannt, an das alle Utopier glauben und dem sie die Schöpfung des Weltalls zuschreiben. ${ }^{15}$ Mithra ist in der altorientalischen Mythologie, z.B. im Avesta, dem heiligen Buch der Perser, der Kämpfer für die gerechte Ordnung und gegen das Böse. In anderen antiken, auch europäischen Mythen ist er der Stiertöter, Sonnengott, Schöpfer und Erretter der Menschheit, dem Prometheus ähnlich, manchmal auch Herrscher über den gesamten Kosmos. Er hält die mondförmigen Hörner des Stiers, den er tötet und dadurch die Natur von neuem erweckt. Porphyrios zufolge ist der Stier identisch mit dem Mond, dem "Ernährer der Kreatur". 16 Der neu erstehende Mond (-Stier) ist die Erneuerung des Lebens und Mithras der Bewirker des neuen Anfangs. Aus dem Blut des Stiers sprießen Ähren, und aus seinem Schwanz wächst ein Ährenbünde1.16a Das Zeichen der Fürstenwürde in Utopia ist eine Getreidegarbe. In diesem mythologischen Zusammenhang ist Utopia ein neuer Anfang glücklicher Menschheit. Morus knüpft gleich zu Beginn seiner Utopia-Schilderung an antike Mythen an und gestaltet über Satire und Sozialkritik hinaus seine Utopie zu einem neuen Mythos. Dem strahlenden Mythos vom Staat ohne Sünde, der im 2.Teil beschrieben wird, setzt Morus im 1. Buch die Schilderung der düsteren Verhältnisse im zeitgenössischen England gegenüber. Hythlodaeus erinnert sich auf die Frage, ob er jemals in England gewesen sei, an eine Tafelrunde im Haus Kardinal Mortons - ebenfalls eine historische Person - bei der er in eine Diskussion über das englische Strafrecht verwickelt wurde. Zunächst kritisiert er die Härte der Strafen und analysiert anschließend die Gründe für die allseits beklagte,wachsende Kriminalität. Es sitze eine große Anzah1 müßiger Edelleute auf ihren Ländereien und presse Pächter und Bauern aus, um ein verschwenderisches Leben führen zu können. Dazu halten sie sich ein Heer von 
Dienern und Hofbeamten, die niemals ein nützliches Handwerk erlernt haben. Wer von diesen Leuten wegen Krankheit, Alter, oder weil er nicht mehr bezah1t werden kann, entlassen wird, muß sich und seine Familie durch Betteln oder Rauben ernähren. Die Bauern aber vertreibt die Schafzucht von ihren Äckern. Denn wo der größte Teil der Felder in Weideland verwandelt wird, um so viel profitbringende Wolle wie möglich $z u$ produzieren, bedarf es nur noch einiger Hirten. Die vertriebenen und obdachlosen Familien lungern in den Städten und Dörfern herum und werden mit dem Tod bestraft, wenn man sie beim Stehlen erwischt. Durch den Rückgang der Landwirtschaft verteuern sich die Lebensmittel, und die Stoffe, wo die Schafe von Seuchen befallen werden. Daneben werden die Preise vom Monopol der Reichen durch verminderte Produktion oder Abgabe von Produkten künstlich in die Höhe getrieben. Kein Wunder also, daß viele Haushaltungen ihre Dienerschaft entlassen müssen. Hier schließt sich der Kreis. Das vagabundierende "Proletariat" wird vermehrt durch brotlose Kriegsveteranen, die schon immer - legal - vom Räuberhandwerk gelebt haben.17 Daraus zieht Hythlodaeus den Schluß:Ehe man Diebe aufknüpft, sollte man gegen das Monopol der Reichen und gegen die neuen Wirtschaftsformen (Schafzucht - Wo11spinnerei) einschreiten.

Kämpfet an gegen all diese lebensgefährlichen Seuchen! Verordnet, daß die Gehöfte und Dörfer von denen wieder aufgebaut werden, die sie zerstört haben, oder aber laBt sie den Leuten einräumen, die zum Wiederaufbau bereit sind! Setzt Schranken gegen die Aufkäufe der reichen Besitzer und gegen die Freiheit gleichsam ihres Monopols! Sorgt, daB nicht so viele vom MüBiggang leben! Ruft den Ackerbau wieder ins Leben, erneuert die Wollspinnerei; das gäbe ein recht ehrsames Geschäft, in dem sich mit Nutzen jener Schwarm von Tagedieben betătigen könnte, die bisher die Not zu Dieben gemacht hat I... I Soviel ist gewiB: solange ihr diese Ubel nicht heilt, rühmt ihr euch vergebens eurer gerechten Strafen gegen den Diebstahl! Sie nehmen sich gut aus, aber gerecht und nützlich sind sie nicht. Denn wenn ihr die Menschen in jämmerlicher Erziehung aufwachsen, ihren Charakter von zarter Jugend an verderben laßt, um sie dann hinterher zu bestrafen - wenn sie nämlich als Erwachsene eben die Laster an den Tag legen, für die sie von Kindheit an die besten Anlagen zeigten: ich bitte euch, was tut ihr anderes, als daß ihr selber sie erst zu Dieben macht und dann den Richter spielt. 18

Thomas Morus liefert hier aus dem Munde seines Protagonisten eine sehr genaue Analyse der wirtschaftlichen Umwälzung, von der das zeitgenössische England auf der Schwelle zu frühen "kapitalistischen" Produktionsformen, die die alte feudale Ordnung vollkommen zerstörten, betroffen wurde. Die Änderungsvorschläge, die Hythlodaeus seiner Kritik entgegenstel1t, haben durchaus einen "revolutionären" Ton. Es ist aber zu bedenken, daß diese Töne auch in vielen englischen Parlaments- akten der Zeit wiederzufinden sind. Darüber hinaus bleibt es fraglich, ob Morus mit diesen Vorschlägen und mit seinem utopischen Staat, der ja als Gegenmodell zu England konstruiert wurde, tatsächlich einen revolutionären Schritt nach vorn träumt. Gegen die Kriminalität in England hä1t Hythlodaeus später als Antithese die Zustände in Utopia:

Welche Last von VerdrieBlichkeit ist in diesem Staate abgeschüttelt, welche gewaltige saat von verbrechen mit der Wurzel ausgerottet, seit dort mit dem Gebrauch des Geldes zugleich die Geldgier gănzlich beseitigt ist! Denn wer sieht nicht, daß Betrug, Diebstahl, Raub, Streit, Aufruhr, Zank, Aufstand, Mord, Verrat und Giftmischerei, jetzt durch tägliche Bestrafung mehr nur geahndet als eingedämmt, mit der Beseitigung des Geldes alle zusammen absterben müssen, I...I. 19

Die plausibelste Lösung, die die Utopier vorexerzieren, scheint die Abschaffung des Geldes und des Privateigentums $z u$ sein, ehe sich in der historischen Realität überhaupt eine spezifisch kapitalistische Gesellschaftsform, die auf Geldwirtschaft und Privateigentum aufbaut, entwickeln konnte. Auf alle Fä1le ist Morus' Gesellschaftskritik von einem vorbürgerlichen, vorkapitalistischen Standpunkt geprägt, da er die Formen und die Entwicklung einer bürgerlich-kapitalistischen Wirtschaft und Gesellschaft überhaupt noch nicht übersehen konnte. So bleibt als Alternative zu einer beginnenden frühkapitalistischen Wirtschaft in England nicht ein nachkapitalistischer kommunistischer Staat, sondern nur eine rückgewandte agrarisch-güterkommunistische archaische Urgemeinschaft. Bei allen Spekulationen über Morus als Vorläufer des modernen Sozialismus ist zu betonen, daß der spätere Lordkanzler als utopische Lösung aller sozialen Probleme seiner Zeit immer nur eine Zurücknahme der begonnen Entwicklung im Hinblick auf vorkapitalistische Wirtschafts- und Gemeinschaftsformen im Auge haben konnte. Ohne Zweifel weist sein Staat ohne Privatbesitz, weit vorausschauend, antizipatorische Elemente auf, die auch auf zukünftige Staatsformen zielen. Konkrete Vorbilder waren allerdings für Morus das Urchristentum, ideale Klostergemeinschaften und Berichte über exotische Staats- und Gemeinschaftsformen aus dem neu entdeckten amerikanischen Kontinent. Trotzdem meint es Morus mit seinen Reformen, die er in Utopia als realisiert darstellt, ernst, und gerade in der Grundfrage der Utopia-Schrift nach den Grundlagen des besten Staates: ob private Besitzverhältnisse oder kommunistische Gütergemeinschaften, ist kein ironisches Augenzwinkern des Humanisten festzustellen. Eher die Zweifel, die der Gesprächspartner Morus an der Beschreibung und den Meinungen 
Hythlodaeus' äußert, sind als Ironie zu interpretieren. 20 Die sozialkritischen und "revolutionären" Impulse der UTOPIA können trotz der unbestreitbar satirischen Passagen des Textes nicht geleugnet werden. Gerade aber der sozialkritische Impuls des Textes wurde von der literatur, die den Heiligen nicht mit dem Sozialrevolutionär vereinigen konnte oder mochte, stets abgeschwächt. Man versuchte hier häufig Satire und sozialkritisches Engagement a1s einen Gegensatz aufzufassen und nur das eine oder nur das andere $z u$ sehen, ohne $z u$ beachten, daß gerade Satire und Sozialkritik in der utopischen Literatur eng zusammengehören (vgl. dazu den Kommentar zu Swifts "Gulliver", s.u.Nr.144). Die UTOPIA ist beides: ein satirischer Humanistenspaß auf die Zeit im Sinne von Erasmus' LAUS STULTITIAE ${ }^{21}$ und zugleich das ernste sozialkritische Engagement eines humanistischen Renaissance-Gelehrten in der Zeit der europäischen Reformationsbewegung.

Durch die Utopia-Schrift zieht sich kontinuierlich die Konfrontation $z$ wischen Realität und Idealität. Nicht nur der inhaltliche Gegensatz von Buch 1 und Buch 2 unterstreicht diesen Kontrast. Auch während Hythlodaeus den utopischen Staat beschreibt, blickt er ständig "zurück" auf die englischen Verhältnisse. So entsteht ein fortwährender Wechsel in der Perspektive, auch während der Model1schilderung im zweiten Teil. Aus diesem permanenten Perspektivenwechsel entsteht die innere Spannung des utopischen Romans. Dahinter ist deutlich seine anfangs skizzierte Struktur erkennbar.

Was ist das aber für ein Staat, den Hythlodaeus schildert? "Aller Ade1, alle Pracht, aller Glanz, alle Würde und Majestät, alle wahre Zierde und aller Schmuck des staatiichen Lebens" sind von Grund auf umgestürzt.22 Man darf nicht reisen ohne Erlaubnis der Behörden. Zwar braucht jeder nur sechs Stunden am Tag zu arbeiten, aber es gibt keine freie Berufswahl und eine al1gemeine Arbeitspflicht. Es gibt zwar keine Todesstrafe außer für Aufruhr und politische Diskussionen außerhalb des Senats, aber es gibt eine Sklavenkaste, deren Angehörige alle niederen Arbeiten verrichten müssen. Es gibt keinen Privatbesitz. Alle Häuser und Wohnungen, alle Städte sind gleich ausgestattet. Wohnungswechsel ist häufig. Alle Utopier eines Stadtviertels essen gemeinsam in großen Sälen. Die Verwaltungspyramide wird demokratisch gewäh1t bis zur höchsten Spitze der Republik. Jeder ist wahlberechtigt. Es herrscht Glaubensfreiheit.
Atheismus allerdings ist verboten. Geldwirtschaft ist unbekannt. Jeder bekommt aus staatlichen Magazinen, was er zum Leben braucht. Unnötiger Luxus und Moden sind unbekannt. Schmuck, Gold und andere Wertgegenstände werden a1s lächerlicher Kindertand angesehen. Auf dem Land, das gleichmäßig jeder Stadt zugeordnet ist, arbeiten alle Bürger wechselweise für eine gewisse Zeit. Vielehen sind verboten. Die Kinder werden früh aus dem Elternhaus genommen und staatlicher Aufsicht und Erziehung übergeben. Die Hauptmasse der Bevölkerung besteht aus Handwerkern und Bauern. Mit der Leitung des Staates sind die Gebildeten (1iterati) betraut. Jeder, der die intellektuellen Fähigkeiten besitzt, erhält eine wissenschaft1iche und philosophische Ausbildung. Der humanistische Traum von den Philosophen als Königen wird hier zweifellos deutlich. Aber ist die Insel Utopia ein intellektueller Terrorstaat? Als totalitärer Albtraum ist sie schon deshalb nicht interpretierbar, weil historisch jede Erfahrung moderner totalitärer Regime feh1t. Was uns an diesem Staat fremdartig oder bedenklich vorkommen mag, sind lediglich Projektionen der historischen Realität auf die Idealităt des Mode11s. So weist die Sklaverei in Utopia eher auf die Verhältnisse in England zurück, im Vergleich zu denen das utopianische Strafrecht noch als höchstes Maß an Humanität gelten kann. Empfindlich reagiert der utopische Staat allerdings auf alle Umsturzbestrebungen, denn kann es einen besseren Staat als den besten geben? Die Utopie hält sich für das Ziel aller gesellschaftlichen Veränderungen, in ihr ist also jede weitere Veränderung eine Verschlechterung. Deshalb steht auf Aufruhr in Utopia die Todesstrafe. Entgegen ihrer sonstigen demokratischen Mobilität reagiert die Utopie auf Revolutionen genauso hysterisch wie reale Staaten. Gegen den Verdacht des Totalitarismus spricht vor allem auch die epikuräische Lebensphilosophie der Utopier, die Edward Surtz zuerst deutlich herausgestellt und beschrieben hat. ${ }^{23}$ In Utopia wird viel gelacht. Das kann man von wenigen utopischen Staaten der Weltliteratur behaupten. Bei den Humanisten und ihren antiken Vorbildern herrschte offenbar eine grundsätzlich andere Bewertung von staatlichen Zwängen als sie wesentlich im bürgerlichen Liberalismus entwickelt wurde. Die Kultivierung des Vergnügens in Utopia scheint beinahe noch erstaunlicher als die ökonomischen Strukturen dieses Gegenmodells, denn Lustgewinn ist das höchste Lebensziel der Utopier. Tatsächlich ist hier nicht ein ideales Wirtschafts- 
system an sich schon der glückliche Zustand, sondern nur dessen materielle Grundlage. Die zweitlängste thematisch zusammenhängende Passage in Raphaels Beschreibung befaßt sich mit der Philosophie des Vergnügens. Die Utopier unterscheiden zwischen echten und falschen Vergnügungen und rechnen $z u$ den letzten alle, die auch in Europa hoch geschätzt werden.

Keine Abendmahlzeit verläuft ohne Musik; auch fehlen zum Nachtisch nicht allerhand Leckereien. Man zündet wohlriechende Răucherkerzen an, sprengt duftende Essenzen und versäumt nichts, um die Tischgesellschaft zu erheitern. Sie neigen sämtlich viel zu sehr zu solcher fröhlichen Stimmung, um irgendein Vergnügen für unerlaubt zu halten, das keinen Schaden bringt. 24

Schaden aber bringt es, wenn man Scheinvergnügungen nachjagt, alles daran gibt, in prunkvollen Gewändern herumzulaufen, Edelsteine zu horten und Schätze zu vergraben, von denen man unter der Erde erst recht nichts hat, oder wenn man stundenlang Würfel auf ein Spielbrett fallen $1 a ̈ ß t$ und allerhand Tiere aufeinanderhetzt oder hintereinander herjagt.

Und wie kann es Gefallen erwecken und nicht vielmehr Widerwillen, das Gekläff und Geheul der Hunde zu hören? oder wieso macht es größeres Vergnügen, wenn der Hund hinter dem Hasen, als wenn der eine Hund hinter dem anderen herjagt? Handelt es sich doch in beiden Fällen um den gleichen Vorgang: es wird gerannt. 25

Glückseligkeit besteht für die Utopier zuerst im Vergnügen. Vergnügen aber bedeutet, naturgemäß leben, der Vernunft gehorchen, den Kummer der Mitmenschen lindern und ihre Traurigkeit aufheitern. Vergnügen ist neben angenehmem Leben, Freude, Heiterkeit, Genuß, aber vor allem die Ausbildung des Geistes.

Zu den Freuden der Seele rechnen sie die Verstandestätigkeit und die süße Empfindung, die der Betrachtung der Wahrheit entspringt. Dazu kommt das angenehme $\mathrm{Be}-$ wußtsein eines rechtschaffenen Lebenswandels und die gewisse Hoffnung auf das künftige Heil. 26

$\mathrm{Zu}$ den Freuden des Körpers gehören Nahrungsaufnahme und -ausscheidung, Geschlechtsverkehr, körperliche Schönheit und in erster Linie allgemeine Gesundheit, der sie alle anderen Empfindungen unterordnen.

Denn den Wohlgeschmack des Essens und Trinkens und alles, was zu derselben Art von Leibesfreuden gehört, erklären sie zwar für erstrebenswert, aber nur um der Gesundheit willen. Denn das alles sei nicht an und für sich erfreulich, sondern nur insofern es einen widerstand bildet gegen das unvermerkte Aufkommen von Gesundheitsstörungen. 27

Alle finsteren Kasteiungen und humorlosen Fanatismus verachten sie aufs höchste.

Dagegen halten sie es allerdings für geradezu wahnwitzig, den Reiz körperlicher Schönheit zu verachten, die Kräfte des Körpers zu zermürben, Gelenkigkeit in Trägheit zu verkehren, den Leib durch Fasten zu erschöpfen, die Gesundheit zu vergewaltigen und auch sonst die Lockungen der Natur $\mathrm{zu}$ verschmähen I...I dagegen sich selber aufreiben, ohne irgendeinem Menschen zu nützen, bloß um des nichtigen Schattens von Tugend willen, oder bloB um sich gegen künftige Widerwärtigkeiten abzuhärten, die sich vielleicht niemals ereignen werden - das erscheint ihnen ganz unsinnig 1 ...I.28 Die Utopier sind keine Stoiker, schon gar keine
Puritaner. Aber Epikuräer im klassischen Sinn sind sie auch nicht, besonders nicht in bezug auf ihr kommunistisches Staatsideal. 29 Für sie ist beides wichtig, dauerhafte Gesundheit und Schmerzlosigkeit als Voraussetzung für die bedeutendere Verstandestätigkeit.

Von Campane11as "Sonnenstaat" her (s.u.Nr.64) durchzieht ein schwerer Vorwurf die Literatur zur Utopie: sie sei menschenfeindlich, der beste Staat beherberge die traurigsten Menschen. Seit jeher wurde versucht von konservativer Seite aus, mit diesem Argument den jeweiligen gesellschaftiichen status quo $z u$ rechtfertigen und Veränderungen $z u$ verhindern. Oberdies haben uns die Erfahrungen mit totalitären Regimen gegenüber gese11schaftlichen "Idea1lösungen" skeptisch gemacht. Die Antiutopien des 20. Jahrhunderts, z.B. Orwe11s Terrorstaat, haben dazu nicht wenig beigetragen. Wievie1 humaner Optimismus dagegen den Ursprungstext der gesamten Gattung durchzieht,zeigen die angeführten Zitate. In Utopia sch1ießen nicht die idealen, geplanten staatlichen Institutionen das vergnügte, he11e Leben des Einzelnen aus. Aus der Philosophie des Vergnügens entspringt in Utopia erst die den europäischen Völkern so konträre Einstellung $z u$ Besitz und Luxus, die die Grundlage des utopischen Kollektivismus ist.

Deshalb meinen auch die Utopier, die Natur selbst habe uns vielmehr ein angenehmes Leben, d.h. eben das Vergnügen, als ziel aller unserer Handlungen vorgezeichnet, und nach ihrer Vorschrift leben, nennen sie Tugend. Aber zugleich lädt die Natur die Menschen ein zu gegenseitiger Hilfe bei dem Versuch, das Leben f $r o \mathrm{~h}-$ I i c h IHervorh.v.Verf.I zu gestalten I...I und eben deshalb heiBt sie dich wieder und wieder achtgeben, $\mathrm{da} B$ du nicht deinem eigenen Vorteil in einer Weise nachgehst, die anderen Leuten Schaden bringen könnte. Darauf beruht auch nach ihrer Ansicht die Heiligkeit nicht bloB der Privatverträge, sondern auch der öffentlichen Bestimmungen über die Teilung der Lebensgüter, d.h. eben der materiellen Grundlage des Vergnügens. 30

Im Zustand des Goldenen Zeitalters stehen sich Lustprinzip und Leistungsprinzip einander nicht mehr im Wege. Als Voraussetzung für einen solchen Zustand nennt Marcuse "die Verkürzung der Arbeitszeit bis zu dem Punkt, wo das b1oße Arbeitsquantum die menschliche Entwicklung nicht mehr behindert".31 Das ist für den Gesel1schaftskritiker des 20. Jahrhunderts nur auf der Stufe höchster Industrialisierung denkbar. Aber auch der Renaissancephilosoph Thomas Morus drängte in seiner Utopie von einem grundsätzlich anderen, vorindustriellen Standpunkt aus auf ein Minimum an notwendiger Arbeitszeit. Vielleicht liegt hier, eher als in den Einzelheiten von staatlichen Institutionen und Wirtschaftsformen, das eigentliche antizipatorische Moment der Morusschen Utopie. 
In Utopia scheint nicht nur die Okonomie, sondern auch die Philosophie Europas auf den Kopf gestellt. Die Utopier sind völlig andere Wesen, aber sie sind keine anthropologischen Entartungen, sondern völlig normale, vernünftig denkende Menschen, die allerdings in einem fernen, unbekannten Kontinent leben. Es ist das Problem des utopischen Romans, seine Fiktion von der anthropologischen Entdeckungsreise wahrscheinlich zu machen. Wie kann der europäische Leser jener Zeit von diesen antipodischen Wesen lernen - aus anderen Verhältnissen für die eigenen $z$ lernen, ist die pädagogische Absicht der Utopie - , die mit ihm nicht das geringste gemein haben und die noch dazu lexikalisch und semantisch eine völlig andere Sprache sprechen? Das ist das erzähltechnische Problem des utopischen Romans überhaupt. Er muß versuchen, seine idealen und zugleich fremdartigen Gesellschaften, deren Menschen mit einer außerhalb der gewohnten Semantik liegenden Begrifflichkeit operieren, trotzdem so glaubwürdig wie möglich zu gestalten. Dabei sient sich die Utopie vor der Schwierigkeit, eine völlig fremde Welt, die $z u$ der bestehenden ein kritisches Gegenbild auch in Sprache und Begrifflichkeit darstellen sol1, eben in der kritisierten realen Begrifflichkeit des Lesers zu vermitteln, d.h. reale Semantik mit der vielleicht gerade gegenteiligen des utopischen Zustandes zu überlagern. Dichtungslogisch konsequent wäre es, die Utopier selbst in ihrer fiktiven Sprache sprechen $\mathrm{zu}$ lassen. Es hat auch nicht an Versuchen gefeh1t, in der utopischen Literatur eine utopische Sprache zu konstruieren. Schon die erste Ausgabe der UTOPIA (1516) stellt an den Beginn im Anschluß an das Titelblatt ein utopisches Alphabet mit den entsprechenden 1ateinischen Buchstaben und ein Tetrastichon in utopischer Sprache und Schrift mit lateinischer Obersetzung, die beide von Peter Giles (Petrus Aegidius), dem Humanisten und Freund des Autors, hinzugefügt worden waren. Jedoch müssen alle derartigen Versuche fehlschlagen, denn der Utopist ist eben kein Utopier. Die Charakterisierung aber dieser "utopischen" Sprache ist in allen Utopien ähnlich: Es besteht keinerlei Widerspruch und Mißverständlichkeit zwischen Wort und Bedeutung, zwischen der Aussage des Sprechenden und seinen Gedanken und Absichten. Es gibt keine semantischen Vieldeutigkeiten und keine Möglichkeit zur Lüge. Hythlodaeus sagt von der Sprache der Utopier, daß sie "die treueste Dolmetscherin der Gedanken" sei.32 Die utopische Sprache, die sich einer Verständigung ohne Worte anzunähern versucht, ist die Sprache der Engel, die schon im Mittelalter in derselben Art charakterisiert wurde. Sprachlich und begrifflich hat die Utopie also zwei Seiten: einmal die fiktive, ideale Sprache, in der sie sich jedoch, wenn sie rezipierbar bleiben will, nicht präsentieren darf, und zum anderen die Sprache ihrer Vermittlung, die die utopische Semantik mit Wörtern realer zeitgenössischer Sprache erklärt und somit eine spezielle "Sprache der Utopie" entwickelt, die eigentlich immer fiktive Obersetzung ist. Das Erlernen utopischer Semantik in den Begriffen der tatsächlichen Welt ist ein wesentlicher Prozeß, den die Utopie ihren Lesern zumutet. Erleichtert wird dieser Prozeß durch die Einführung eines Mittelsmannes - bei Morus ist es Hythlodaeus -, der nicht nur als Weltreisender die Kunde vom irdischen Paradies nach Europa bringt, sondern der zugleich auch die Funktion des Obersetzers übernimmt. Indem er seinen eigenen Lernprozeß schildert, füllt er im Laufe seiner Erzählung nach und nach die realen wörter der Sprache des Lesers mit der utopischen Semantik an. Somit spricht die Utopie zwei Sprachen, die sich in ihrem Text überlagern: die der Realität und die der utopischen Möglichkeit. Aber nicht das Erlernen einer konstruierten,fremden Semantik ist das Ziel des Spiels mit den Sprachen von Wirk1ichkeit und Möglichkeit, sondern die Demonstration der Unzulänglichkeit der realen Sprache und Begriffe, hinter denen sich die Unzulänglichkeiten der realen gesellschaftlichen Verhältnisse verbergen. Dabei geht es nicht allein um die Oberfläche gesprochener Sprache, sondern um das, woraus Sprachgewohnheiten und ihr Bedeutungshintergrund entstehen, näm1ich um den inneren Bewertungszusammenhang von Daseinsformen und die moralischen Kategorien eines fremden Gemeinwesens, die in Utopia bewußt auf einer den Konventionen des Leserbewußtseins konträren ökonomischen Grundlage beruhen. Die Utopier, so berichtet Raphael, haben als ökonomische Grundlage ihres Gemeinwesens eine Art Güterkommunismus, aufgrund dessen jeder das vom Staat erhält, was $z u$ seinem Lebensunterhalt erforderlich ist. Es gibt also, wie wir bereits gesehen haben, keinerlei Privatbesitz (possessiones privatae). Allein auf diese Tatsache und auf die Einsichtigkeit der Utopier in die weisen Maximen ihres Staates gründet sich eine der europäisch-englischen Realität völlig konträre Moral und Einstellung zu Ge1d- oder Goldwert, die sich in der kon- 
sequenten Darstellung des Autors natürlich bis in die Begrifflichkeit ihrer Sprache und in die Semantik ihrer Wörter auswirkt. Nicht

ihre Sprache, aber diese, gegenüber der Realität veränderte und, wie sich herausstellt, konträre Bedeutung ein und desselben Gegenstandes wird dem Leser durch die Schilderung ihrer Sitten und Ansichten eindringlich veranschaulicht: Da die Utopier aufgrund ihrer Besitzverhältnisse für sich und untereinander kein Geld brauchen, legen sie keinerlei Wert auf Gold oder Silber, aber auch nicht auf irgendwelche anderen Wertgegenstände und Edelsteine, die bei ihnen lediglich als Kinderspielzeug beliebt sind. Um jedoch, wenn es notwendig erscheint, auch außerhalb ihres Staates, wo eben Reichtum etwas gilt, anderen Staaten überlegen zu sein, haben sie sich einen ungeheuren Staatsschatz, der im Bedarfsfall sofort eingeschmolzen werden kann, in einer ungewöhnlichen Form zugelegt, die - so schildert es Hythlodaeus - "ihren sonstigen Einrichtungen ebenso entspricht, wie es uns, die wir das Gold so hoch schätzen, I...I unverständlich und daher nur erfahrenen Leuten glaubhaft erscheint."

Während sie nämlich aus zwar sehr geschmackvollen, aber billigen Ton- und Glasgeschirren essen und trinken, stellen sie aus Gold und Silber I...I allerorts Nachtgeschirre Imatellas! und lauter GefäBe für schmutzige Zwecke I sordidissimal her. Zudem werden die Ketten und schweren Fußfesseln, in die sie die Sklaven schließen, aus denselben Metallen geschmiedet. SchlieBlich tragen alle, die irgendein Verbrechen ehrlos gemacht hat Iquoscunque aliquod crimen infames facit $I$, goldene Ringe an den Ohren, Goldringe an den Fingern, Goldketten um den Hals I...I So sorgen sie auf jede Art und Weise dafür, daB Gold und Silber bei ihnen in Verruf I in ignominial stehen. I... I Ein wie verschiedenes Empfinden aber diese von den übrigen Völkern so abweichenden Einrichtungen hervorgerufen haben, ist mir niemals so klar geworden wie gelegentlich einer Gesandtschaft der Anemolier I...I, Idie beschlossenI, sich selbst so groBartig wie Götter aufzumachen und die Augen der armseligen Utopier durch den Glanz ihres Schmuckes zu blenden. Also zogen die drei Gesandten mit hundert Begleitern ein I... I in goldstrotzenden Mänteln, mit schweren goldenen Halsketten und Ohrgehāngen, dazu mit goldenen Ringen an den Händen I... I kurz mit all den Dingen geschmückt, die bei den Utopiern entweder Strafmittel für die Sklaven, Schandmäler für die Ehrlosen oder Tand für die Kinder waren I servorum supplicia, infamium dedecora, puerorum nugamental. I...I den Augen der Utopier I... schien dieser ganze glanzvolle Aufwand schandbar IpudendusI; sie grüßten gerade die Niedrigsten an stelle der Herren ehrerbietig, und die Gesandten selbst, die sie wegen ihrer goldenen Ketten für Sklaven hielten, ließen sie ohne jegliche Ehrenbezeigung vorüberziehen. 33 Die Schilderung dieses ethnologischen Mißverständnisses zwischen Anemoliern, die ebensogut auch für ein reales europäisches Volk stehen könnten, und Utopiern gehört zu den glänzendsten satirisch-utopischen Passagen des gesamten Textes. Allerdings ist das geschilderte Ereignis nicht ganz und gar Fiktion. Denn im Hintergrund dieses bedeutsamen gegenseitigen Mißverständnisses zweier Vö1ker steht ein noch bedeutsameres, tatsächliches ethnologisches Mißverständnis, das die zeitgenössischen Reisebeschreibungen aus der Neuen We1t dokumentieren. Amerigo Vespucci, den Hythlodaeus als Gewährsmann für seine Reisen nennt, beschreibt in seinen QUATUOR NAVIGATIONES, ${ }^{34}$ daß tatsächlich die Ureinwohner Amerikas ein vollkommen anderes Wertbewußtsein in bezug auf Edelmetalle und -steine hätten und das für Verarbeitungen aller Art wichtigere Eisen höher einschätzten. "Sie legen keinen Wert auf Gold, Perlen oder andere Gegenstände, die wir hier in Europa für wertvoll halten. Und tatsächlich verachten sie sie sogar und geben sich keinerlei Mühe, danach zu streben."35 Ähnliches berichtet Pietro Martire d'Anghiera in seiner Schrift $D E$ ORBE NOVO. "Die Verachtung der Indianer für Gold steht in absolutem Gegensatz zur Gier der Spanier danach." 36 In welchem Maße diese Berichte in bezug auf die mitte1- und südamerikanischen vorkolumbianischen Kulturen und vereinzelte Indianerstämme zutreffen, soll hier nicht überprüft werden. Denn folgenschwerer war wohl das ethnologische Mißverständnis von Seiten der amerikanischen Ureinwohner, die ihre Schätze dem weißen "Wundermann" ohne Argwohn zeigten. ${ }^{37}$ Eben hier in der Realität war dieses Mißverständnis wie bei Morus ein sprachliches, nur nicht satirisch geplant.

Das wesentliche Merkmal an dem zitierten Abschnitt ist der Prozeß einer Oberlagerung von europäisch-anemolischer und utopischer Semantik. Der Leser wird von Raphael Hythlodaeus zunächst informiert über die Sitten der Utopier, über die ökonomischen Grundlagen ihres Staates, über ihre darauf beruhende Philosophie und schließlich über die auf allem sich begründende Semantik der Wörter Gold, Goldschmuck, Prunk, Reichtum. Es stellt sich dabei heraus, daß zwar das Wort, das die Utopier für Gold (aurum) gebrauchen, eben dasselbe Metall bezeichnet, das auch die entsprechenden Wörter der europäischen Sprachen meinen, aber im Zusammenhang mit dem utopianischen Mora1codex verbindet sich im weiteren semantischen Umfeld dieses Wort mit genau den entgegengesetzten Bedeutungen und Wertungen wie im europäischen Sprachgebrauch. Setzen wir für den Morusschen Kontext nun theoretisch vereinfachend in der utopianischen Semantik einmal die Gleichung Gold=Tand/ehrlos/Narrheit (aurum =nugae/infamis/stultitia) und für den europäischen Bereich die Gleichung Gold=Wert/ehrenvol1/Erhabenheit (aurum=pretium/nobilis/nobilitas) ${ }^{38}$, so erhä1t, da Morus ja nicht in uto- 
pischer Sprache, sondern durch Hythlodaeus übersetzt, in lateinischer Sprache berichten läßt, der Begriff "aurum" den paradoxen Beigeschmack von Tand/Wert, Schande/Ehre, Narrheit/Erhabenheit. Das Wort bleibt damit nicht mehr gesicherter Bestandteil ein und derselben Semantik, sondern muß immer wieder von neuem in bezug auf seinen Kontext, d.h. in bezug auf den jeweils gemeinten gesellschaftlichen Kontext (Europa-Utopia) überprüft werden. Ein utopischer Staat, der sich auf der Negation der realen Verhältnisse aufbaut, kann nicht deren Sprache teilen. Die Utopie aber muß, um rezipierbar $z u$ bleiben, dieselbe Sprache sprechen wie ihre Leser. In diesem Dilemma bleibt der Utopie der Weg, die dem Leser gewohnte Semantik der Begriffe zu unterhöhlen und sie mit einer gerade entgegengesetzten, aber doch wahrscheinlichen, einer konstruierten utopischen Gesellschaft zu überlagern. Das erfordert vom Leser einen Lernprozeß. Er wird bei Morus noch vom Erzähler vorgeführt. So gerät der Leser selbst nicht in Verlegenheit. Die Erfahrung des Mißverständnisses beim $\mathrm{Zu}-$ sammentreffen mit fremdartiger, hier utopischer Weltsicht macht zunächst der Erzähler. So wird auch nicht direkt der Europäer der Blamage ausgeliefert, sondern ein fiktives Volk. Die vermutliche Ăhnlichkeit anemolischer und europäischer Gebräuche und Reaktionen aber setzt europäisches Verhalten im satirischen Spiegel nur umso deutlicher der Kritik aus, und zwar einer Kritik, der der Leser von dem Standpunkt aus, in den er durch die Erzählperspektive hineinmanövriert wurde, zustimmen muß. Die Auflösung, d.h. die Obersetzung des "utopischen Codes", wird vom Erzähler vorgeliefert, so daß der Leser von vornherein schon in der besseren Position ist als jene Anemolier und Utopier in der zitierten Episode. Die Paradoxie von "utopischem Code" und "Wirklichkeitsbedeutung" ein und derselben Begriffe hat in der UTOPIA ohne Zweifel satirische Qualität. Nicht allein aber der Prozeß der Oberlagerung ist dabei entscheidend, sondern ebenso die Erzählperspektive. Der Leser oder die Zuhörer des Hythlodaeus bekommen einen Bericht aus Utopia, der letztlich den Sinn hat, ihre eigene Realität kritisch zu beleuchten. Ist dem Leser der utopische Code einmal geläufig, so wird er sich den Anemoliern überlegen fühlen, die sich durch ihren blinden Stolz in seinen Augen lächerlich machen. Es ist das aber gerade die eigene Lächerlichkeit europäischer Prunksucht, die er nun belächelt. Ober die Utopier, deren durchaus nicht als absurd geschilderte Sichtweise von Wert und Unwert ihm eindringlich vertraut gemacht worden ist, wird er weniger lachen als über die, die weniger klug als er unvorbereitet in utopianische Fettnäpfchen treten. Daß die Utopier die Niedrigsten mit Achtung, die Höchsten aber als Sklaven ansehen, erscheint dem über die utopischen Verhältnisse aufgeklärten Zuhörer weniger lächerlich als die Blamage der Unwissenden. Der Erzähler aber wahrt Distanz $z u$ beiden Seiten und läßt den Leser mit der Kenntnis beider Verstehensmöglichkeiten schließlich über das Mißverständnis überhaupt lachen. Die Berechtigung fremder Kulturen, und eben gerade utopischer, die Dinge anders zu bewerten, die fatale Vergewaltigung fremder Semantik durch die bekannte, die auch die Utopier zuweilen angesichts ihrer eigenen "Kolonialgeschichte" betreiben, ist eines der entscheidenden kritischen Themen des utopischen Romans. In der UTOPIA hat er gleich am Beginn seiner neuzeitlichen Geschichte aus dem Dilemma, von etwas zu sprechen, das es nicht gibt, und aus dem Zwang zum Realismus in der Darstellung erzähltechnisch seine Konsequenzen gezogen. Er hat zwar keine utopische Sprache schaffen können, wohl aber eine Sprache der Utopie realisiert. Die "Sprache der Utopie" konstruiert für bestimmte zentrale gesellschaftliche Begriffe eine der Realität kritisch entgegengesetzte Semantik und gibt diese der Sprache des Lesers als entlarvenden Unterton bei. Damit zielt die utopische Literatur, hier die UTOPIA, die mit ihren Erzählungen und 1iterarischen Bildern Revolutionen meist überspringt, mit ihrer Sprache auf die Grundlagen revolutionären Denkens.

Wir haben gesehen, Utopie kommt aus dem Mythos. Bei Morus ist es der Mythos vom neuen Anfang. Sein Symbol ist der wiederaufgehende Mond. Aber die UTOPIA enthä1t noch andere utopische Symbole, der Weg vom Dunkel ins Licht, von der Ode zum üppigen Garten, vom Wilden zum Kultur- und Obermenschen, sie enthält den Traum vom Goldenen Zeitalter und vom Paradies. Auch dort, wo dieser Traum seine mythologischen Grundlagen verläßt und zur rationalen, sozialen Konstruktion wird, bleiben die mythischen Bilder und Symbole ein wesentliches literarisches Vermittlungselement zwischen Autor und Leser. Der Traum vom Staat ohne Sünde entspricht dem menschlichen Urwunsch nach dem irdischen Paradies und nach dem Schlaraffen1and der Märchen, der in den Mythen aller alten Kulturen bereits wach war.

Also hatte das Staatsmärchen vor allem Bezug auf die uralten Volkstrăume selber schon utopischer Art, darauf aus, 'das Glũck zu suchen'. Aber nun, vom Mărchen her, als phantasievollem: noch eine andere Beziehung uto- 
pischer Art zu sozusagen praelogischen Formen besteht.Es ist eine erst recht bildreiche und 'dennoch' dem späteren Begriff und seinem Licht I...I keinesfalls abgewandte. Gemeint ist die Beziehung $z$ erworbenen 'Grundbildern' der Phantasie oder den oft erwähnten Archetypen. Freilich: wăhrend das Märchenhafte, zum Unterschied von der Sage, keineswegs herabgesunkener Mythos ist I...I blieb das archetypische Bildmaterial weithin im Mythischen, prägte sich darin aus. Daher auch wurde das Archetypische nicht nur als praelogisch, sondern wiederum grundfalsch - als schlechthin irrational pointiert; so bei C.G.Jung. Er steckte es in ein kopflos 'UnbewuBtes vor fünfhunderttausend Jahren', lieB es von daher - ganz zukunftslos, ganz Regressio - nur 'emergieren'. Statt dessen aber sind nicht nur archetypische Bilder immer wieder neu in der Geschichte entsprungen I... I sondern auch die wirklich alten zeigen oft mitten im Mythischen einen völlig hellen, drängendutopischen Sinn (Man denke an die verklärte Erinnerung: goldenes Zeitalter, als verschüttetes oder aber von der zukunft noch zukommendes gedacht). Letztere Art Archetypen ist an sich also schon deutlich utopisch I...I Nicht aber verweigern sich die verkapselt, gar offen humanen Archetypen dem utopischen Begriff, auch brüten diese keineswegs im hintersten UnbewuBten, diluvial, mysterisch. Jeder kennt sie vielmehr aus seinem gegenwärtigen Dasein, aus der nicht nur zündenden, sondern erhellenden Kraft schlagender Bilder. Kennt sie aus Kunstwerken und ihren ausgetragenen Situationen, Konflikts- und Lösungs-Formen, aus der unabnutzbaren Kraft eindeutiger Symbole, selbst vieldeutiger Allegorien. I...I Archetypisch sind alle Szenen der Anagnorisis als blitzartiger Wiedererkennung (Elektra und Orest, Josef und seine Brüder), archetypisch ist der Weg aus Nacht zum Licht (Zug aus Ägypten nach Kanaan). Und letzteres Grundbild eben ist bereits 'archetypische Utopie' selber. 39

Die Utopie zieht ihre mythischen Wunschbilder aus ihrer ursprünglichen religiösen Verknüpfung in die historische Realität und Sozialität. Ihre Symbolsprache bleibt auch dort einsichtig, wo sie nur verkürzt erscheint und nur andeutend wirkt. Die utopischen Symbole, die auf archetypische utopische Mythen verweisen (Goldenes Zeitalter, Nacht zum Licht: Weg nach Kanaan, neuer Anfang: aufgehender Mond, Säulen des Herakles), erwecken Assoziationen zu alten Sehnsuchtsbildern von einer We1t ohne Sünde, die in den Mythen und Religionen aller Kulturen verbreitet sind. Der utopische Roman, der mit diesen Bildern arbeitet, keilt seine utopisch-rationale Konstruktion so in utopisch-mythische Symbole ein, daß das zunächst Unbekannte a1s A1t-bekanntes wiedererkannt wird. So ist die Rezeption von utopischen Romanen selbst ein Prozeß der Anagnorisis als blitzartiger Wiedererkennung. Insel, Garten, sorgloses Leben, Entkräftung der Todesangst rufen Vertrautheit hervor und produzieren praelogisch direkt Sehnsucht, die auf der Ebene der Reflexion sich zur Gese11schaftskritik konkretisiert. Nicht nur das Fremdartige lockt also am utopischen Modell, sondern gerade auch das schon immer Bekannte. Damit erscheint das utopische Gegeneinander von Antizipation und Tradition nicht mehr als ein unüberwindbarer Kontrast, sondern es gibt eine Brücke vom einen zum anderen. Die Antizipation selbst hat mythisch ihre Tradition.
Hythlodaeus ist Enthüller von Neuem und Vermittler von Vertrautem zugleich. Er ist rationalistischer Kritiker, und doch bleibt ein Rest von der Aura des Mythos-Verkünders. "Utopos, der Herrscher, hat mich von einer Halbinsel zur Insel gemacht", heißt es in Aegids Tetrastichon am Beginn. "Als einzige unter allen Ländern habe ich den Menschen ohne die Hilfe der abstrakten Philosophie die philosophische Stadt gebracht. Gern teile ich meine Wohltaten, und nicht ungern lasse ich mich von allem, was besser ist, überzeugen." 40 Utopia ist eine künstliche Gründung. Inse1 und Stadt sind auf dem Reißbrett geplant. Aber auch hier, wie schon immer, ist die Stadtgründung mit utopischen Symbolen belastet. 01ymp, Götterburg, himmlisches Jerusalem, Stadt und Höhe sind $z u$ Anfang noch eng miteinander verknüpft (Akropolis $=$ Hochstadt). Wehranlage und Kultstätte, die Sicherheit vor dem Irdischen und die Nähe zum Göttlichen liegen hier dicht beieinander. Die Stadt aber ist zugleich Ratio in ihrer geplanten Symmetrie, spätestens seit Hippodamus von Milet (s.u.Nr.2). Utopia ist geplante Inse1, geplante Stadt, geplante Natur, geplanter Mythos.41 Das Bild des noch nicht geschlossenen Halbmondkreises verweist auf das Streben nach Vervollkommnung. Auch diese Vervollkommnung des Menschen, des Staates ist geplant in den Institutionen Utopias. Das Ziel wäre dann Utopia a1s ökonomische und soziale Weltordnung. Hier vermischt sich mythische mit rationaler, geplanter Vervollkommnung. So ist Utopia beides, mythisches Bild und rationale Konstruktion. Sonnen- und Mithras-Kult und die persischen Züge der utopianischen Sprache ${ }^{42}$ verweisen deutlich auf die Spuren der alten Mythen, der neue, geplante aber führt ständig über in die rationalen Gesetzmäßigkeiten der besten Staatsverfassung. Alle utopischen Symbole der UtopiaSchrift halten ihre Verbindung zum Mythischen, sind aber zugleich Bestandteil rationaler Planung: so hat das utopische Paradies seine wirtschafts- und sozialpolitischen Grundlagen, und doch bleibt der Garten Eden in Erinnerung. Die Teilnehmer an der Expedition Raphaels durch Südamerika durchmessen auf ihrem Weg nach Utopia Stationen einer Entwicklungsgeschichte zur menschlichen Kultur. Zunächst wird erzählt von"wüsten Einöden im beständigen, dörrenden Sonnenbrand: ringsum trostlose Wüstenei, abschreckend, gänzlich unkultiviert". Man begegnet anschließend erst wilden Tieren und Schlangen, dann wilden Menschen, "die weder an Rohheit noch an Gefährlichkeit den Tieren etwas nachgeben". Dann entwickelt sich langsam 
alles zu kultivierteren Daseinsformen. "Das Klima wird erträglicher, die Erde schimmert im Grün, zahmer werden die Tiere." Der Wilde wird zum Kulturwesen. "Städte, feste Plätze tun sich auf." Es gibt Handelsverkehr, und schließlich wird von "trefflichen und klugen politischen Maßnahmen gesitteter Völker" und von der Seltenheit "heilsamer und weiser" Staatsverfassungen gesprochen. ${ }^{43}$ Am Endpunkt dieser Entwicklungsleiter stehen die "Sitten und Einrichtungen der Utopier". Die Entwicklung läuft von der Einöde zum Garten, von der Bestie und Schlange zum Haustier, vom Wilden zum homo politicus und zum homo utopicus. Das Zie1 dieser optimistischen Entwicklungslinie und der Reise Raphaels ist der Utopier. Erst in Utopia scheint der Schöpfungsakt vollendet mit einem von Menschenhand neu geschaffenen Paradies. Die Reise hat, wie später häufiger im utopischen Reiseroman des 17. und 18. Jahrhunderts, nicht nur geographischen Expeditionscharakter, sondern sie ist zugleich auch Reise durch die Zeit, durch die Entwicklungsphasen der Natur- und Kulturgeschichte, bei Morus nur bildhaft angedeutet, später bei Restif de 1a Bretonne (s.u.1781) 44 ausführlich beschrieben. Die Zeitreise ist also implizit schon immer im Bildervorrat des utopischen Romans vorhanden und tritt nicht völlig unvorbereitet erst bei Mercier (s.u. 1770) 45 auf. Das künst1iche Paradies, das Raphael entdeckt, ist durch folgende Merkmale charakterisiert: Geborgenheit, Planung, Regelmäßigkeit des Lebens, kein Müßiggang, aber Befreiung von der größten Arbeitslast, allgemeiner Wohlstand, aber kein Privateigentum und Geringschätzung von materiellem Reichtum, Oberfluß an allen Lebensprodukten, vergnügtes, frohes Leben ohne Sorgen und Todesangst, ewiger Friede, Gesundheit, langes Leben, höchste Toleranz. Einige dieser "Bilder" vom kollektiven Glück sind nicht unbekannt. Der Oberfluß taucht als gebratenes Huhn, das einem in den Mund fliegt, immer wieder in den Volksmärchen vom Schlaraffenland oder Cocagne 46 auf oder in der Bibel als Land, in dem Milch und Honig fließen. Diese Bilder sind als Essenz in allen Tagträumen vom Menschenglück, den kollektiven wie den individuellen, vorhanden. Mit ihnen baut die Utopie das Unbekannte, noch nicht Erfahrene aus und füllt damit allgemeine Bezeichnungen wie Inse1, Stadt, Staat, die dadurch einen ganz anderen, utopischen Begriffshintergrund bekommen. Die Lesererfahrung ruft beim Lesen so mit utopischem Sinn unterlegter Begriffe nicht gespeicherte erlebte Bilder, sondern archetypische, die sich hier neu bilden, ab. Das Vokabular utopischer Symbole und Bilder hebt den gesamten Zusammenhang der Utopia-Beschreibung aus seiner alltäglichen Bedeutung heraus in den Bereich einer allgemeinen utopischen Hoffnung auf das bessere Leben. Das Symbolrepertoir ist begrenzt und die Bedeutung der einzelnen Symbole intersubjektiv festgelegt. Daher bedarf es nur weniger Wendungen, um Beschreibungen und Argumentationen plötzlich in einen weit über ihren unmittelbaren Inhalt hinausreichenden Zusammenhang zu stellen. Der Beginn der Raphaelschen Inselbeschreibung gleicht jeder beliebigen geographischen Studie, bis plötzlich das Element der Planmäßigkeit, Gleichmäßigkeit und Wiederholung auftritt. Die Insel hat vierundfünfzig Städte. Auch England und Wales hatten zur Zeit Morus' eine gleiche Anzahl von großen Städten. ${ }^{47}$ Die Städte Utopias sind "aile geräumig und prächtig, in Sprache, Sitten, Einrichtungen, Gesetzen genau übereinstimmend. Sie haben alle dieselbe Anlage und, soweit das die lokalen Verhältnisse gestatten, dasselbe Ausssehen." 48 Die kurz zuvor von Hythlodaeus erwähnte Künstlichkeit der Inse $1^{49}$ erscheint jetzt nicht mehr als absonderliche Eigenart, sondern als Teil einer groß angelegten Planung. Auf diesem durchgeplanten Eiland nun gibt es weder Armut noch Hunger, weder Neid noch Mißgunst. Es sammeln sich hier a1le Träume vom menschlichen Zusammenleben, die dort geträumt werden, wo tägliche Unsicherheit an Leib und Besitz und die Aussicht auf eine hoffnungslose Zukunft den Wunsch erzeugen, sich einer alle Verantwortung übernehmenden Planung und Regelung des gesellschaftiichen Zusammenlebens anvertrauen $z u$ können. In diesem Moment ist die Insel nicht länger ein bloßer geographischer Begriff, sondern sie erscheint als fiktiver Ort mit ihren charakteristischen Eigenschaften 50 weit allgemeiner in den Hoffnungen derer als utopisches Symbol angesiede1t, die einen Schutzraum vor den unübersehbaren Gefahren des realen Lebens suchen. Auch deshalb ist die Utopie ein Charakteristikum der Unsicherheit historischer Umwälzperioden. Die Umgestaltung von der wilden zur geplanten Natur ist ein Menschheitstraum, der aus Angst entsteht, seit der Mensch gegen unbeherrschbare Naturwiderstände zu kämpfen hatte. Planung ist ein Teil vom Schöpfungsmythos, zugleich Domestizierung der wilden Natur. Der neue Anfang, den die Inselgestalt symbolisiert, ist unbelastet und rein von Fehlern und kapselt sich ab auf begrenztem Raum, der vollständig und ohne Widerstände beherrscht wird, prometheisch, in mühelosem Spiel und virtuosem Gestalten. So sind die Begriffe Planung und 
Inse1 im utopischen Kontext zu utopischen Symbolen geworden, allerdings nicht direkt das Abstraktum "Planung", sondern alle Bilder, denen direkt der Begriff Planung zugeordnet werden kann.

Das System der utopischen Symbole und Bilder bieibt unabhängig von jedem grammatischen Regelsystem. In Anlehnung an Paul Watzlawicks terminologische Unterscheidung von "digitaler" und "analoger" Kommunikation 51 entwickelt Hans Ulrich Söffner die Theorie von der "analogen Informationsübermittlung" utopischer und mythischer Symbole und Bilder.

Mit 'digitaler' Kommunikation ist ein aus definierten Begriffssprachen bekannter Sachverhalt gemeint: Die 'willkürliche', bewußte Setzung einer eindeutigen semantischen Relation zwischen objekt (designatum) und sprachlichem Zeichen (Wort). In den 'analogen' Zeichen dagegen kommt eine Ähnlichkeitsbeziehung, eine strukturelle Übereinstimmung mit dem Objekt zum Ausdruck. 52 Diese Ähnlichkeitsbeziehungen oder Analogien bestehen zwischen gemalten Bildern und der abgebildeten Realität, genauso zwischen sprach1ichen Bildern und den bezeichneten objekten, vorausgesetzt, daß die sprachlichen Zeichen eine Entsprechung in den in der Erinnerung des Lesers gespeicherten Bildern finden. Da dieser Bildervorrat in der Erinnerung subjektiv variiert, entstehen im Vorstellungsbereich von Leser zu Leser verschiedene semantische Realisationsvarianten der gelesenen Zeichen, die umso geringer sind, je größer die Intersubjektivität des Bildgehaltes ist.

Voraussetzung einer intersubjektiven Semantik ist u.a. ein 'gemeinsamer' - sprich: 'intersubjektiver' Bildervorrat und intersubjektive Erfahrung. Eben diese Voraussetzung hat bei Symbolen und 'bildhaften' Formeln ihre besondere Bedeutung, denn die intersubjektive Erfahrung und deren quasi-bildhafter Ausdruck spielen in diesen eine so tragende Rolle, daB sie ohne Verlust semantischer Informationen in nahezu jede Sprache übersetzt werden können, und ihre Wirkung in sehr vielen Sprachen dieselbe ist. 53

Die Wirkung utopisch-mythischer Symbole ist umso größer, je eindeutiger und verbreiteter ihr Bedeutungshintergrund festliegt. Der Leser hat die Erfahrung, die diese analoge Mitteilung beinhaltet, bereits als einen Gesamtkomplex gespeichert. Es genügt der Appell, so Söffner, und sie wird rekapituliert und aktualisiert, ohne daß umfangreiche, erklärende Konstruktionen nötig sind. Dabei ist natürlich zu beachten, daß sprachliche Bilder mit festgelegter Symbolbedeutung eine wesentlich stärkere, vor allem komplexere, intersubjektive Analogiewirkung haben als beliebige Bilder ähnlichen Inhalts. Die Kombination Säulen und Parthenon 1öst für das Wort Säule völlig andere semantische Informationsdaten aus als die Kombination Säulen und Herakles. Beide Begriffskombinationen haben einen hohen Bildanteil, der intersubjektiv festgelegt ist. Die erste ist real existent, die zweite literarisch belegt. Die erste ist selbst kein Mythos, die zweite Teil eines Mythos. Die Säulen des Parthenontempe1s der Athener Akropolis sind aus direkter Anschauung oder von Abbildungen her in der Erinnerung als Bild sofort rekonstruierbar. Das Erinnerungsbild kann an der Realität überprüft und korrigiert werden. Die Intersubjektivität dieser analogen Mitteilung wird eingeschränkt durch die historische und psychische Determiniertheit des betrachtenden Individuums. Schon das nähere Assoziationsfeld des Bildes bleibt vollkommen subjektiv. Für den Informationswert der Heraklessäulen ist es dagegen gleichgültig, ob sie als Bild festgelegt sind oder nicht.54 Wichtig ist allein ihr Signa1charakter, d.h. ihre auslösende Funktion für die Aktivierung ihres Bedeutungshintergrundes und dessen spezifischen Assoziationsfeldes. Während im ersten Fal1 nur das äußere Bild als intersubjektiv funktionierende, analoge Mitteilung gewertet werden kann, spielt im zweiten Fal1 die äußere Erscheinung überhaupt keine Rolle. Die Säule ist Signal für eine Kette von festgelegten Assoziationen, von Geschichten und Bedeutungen, deren Informationsgehalt vom Mythos festgelegt ist und für alle Fä1le konstant bleibt. In einem Textzusammenhang 1ösen nun beide Bilder Verschiedenes aus: Die Athener Tempelsäulen und ihre Umgebung bleiben als in der Erinnerung rekonstruiertes Bild - subjektiv gestaltet Kulisse für den Textinha1t. Darüber hinaus assoziiert der Leser nichts, was den Text direkt und vom Autor vorgeplant ergänzen könnte. Die Haltung des Lesers dem Text gegenüber bleibt konsumierend, höchstens illustrierend. Die Herakles-Säulen dagegen geben einem Textzusammenhang (etwa in Bacons INSTAURATIO $M A G N A^{55}$ ) eine neue Dimension und eine bestimmte hintergründige Bedeutung, die der Leser, vorausgesetzt, er hat die entsprechenden Informationen gespeichert, jetzt selbst aktivieren muß. Diese Aktivierungsfunktion analoger Mitteilungsträger mit festgelegten semantischen Assoziationsketten macht sich die Utopie für ihren eigenen Wirkungsbereich zunutze. Das mythische Symbol wird in der 1iterarischen Utopie ersetzt durch ein symbolartiges Signal oder utopisches Bild, das (hier funktionieren Symbole sozialer Tagträume genauso wie Traumsymbole) bestimmte soziale Wunschvorstellungen im Leser als erfüllt reproduziert. Die Intersubjektivität solcher Symbole und Wunschbilder entspringt aus dem bereits erwähnten arche- 
typischen utopischen Symbolrepertoir, das die Mythen aller Kulturen aufweisen. Die selbständige Aktivierung der als erfüllt gedachten sozialen Wunschvorstellungen erzeugt im Leser eine Spannung $z$ wischen bestehender oder dargestellter realer und utopischer ordnung. Daraus kann sich dann eine Neigung zum Verändern der Realität entwicke1n. Daß aber diese Neigung auch wirklich in historisches Handeln übergeht, ist vom utopischen Text nicht mehr $z u$ beeinflussen. Der Obergang von utopischem Denken zu revolutionärem Handeln vollzieht sich, wie wir später bei Thomas Müntzer sehen, nicht im Bereich der Rezeption literarischer Utopien, sondern schon vor- oder außerliterarisch mit der Entscheidung, Denken nicht in literarische Bilder, sondern in Handeln umzusetzen.

Wenn der Tagtraum des humanistischen Unterhändlers Heinrichs VIII. beginnt, so stehen wir vor der Wortkombination Insel und Utopier (Utopiensium Insula) und haben noch aus dem ersten Teil jene andere, bekanntere Kombination von Insel und England im Gedächtnis, semantisches Festland für uns, historisch und geographisch fest abgesteckt. Die Unmöglichkeit, alle im Lauf der Geschichte erfahrbaren, halbwegs intersubjektiven Assoziationsmöglichkeiten zu dem Begriff "Englische Inse1" auszuschöpfen, legt die Beschränkung auf die im Text gelieferten Informationen nahe. Trotzdem bleibt $z u$ bedenken, daß dieser ausgewählte Informationsanteil immer auf einen breiten, bereits vorhandenen, intersubjektiv fixierten oder subjektiv ausgeprägten und historisch variierenden Bildervorrat im Leser trifft und von ihm ergänzt, illustriert oder umgewertet werden kann. Im gleichen Maße stoßen die gelieferten Informationen zur Inse1 Utopia zunächst auf kein Echo beim Leser. Ihre Analogiebeziehungen liegen in einem anderen Erfahrungsbereich. Ihre Intersubjektivität ist von einer anderen semantischen Qualität. Die Insel Utopia stellt sich als utopisches Symbol heraus, als rationale Gestaltung eines archetypischen utopischen Bildes. Im literarischen Kontext des Morusschen Romans verhält sich das Bild von der "Insula Anglia" zum Bild von der "Insula Utopia" wie in dem erwähnten Beispiel die Säulen des Parthenon zu den Säulen des Herakles. Die englische Inse1 ist weder von ihrer geographischen Gestalt und Lage, noch von ihrer Geschichte her symbolbelegt. Keine der gegebenen Informationen eröffnet einen über die Tatsachen selbst hinausweisenden Hintergrund. Die Tatsachen sind erschreckende Fakten, keine Tag- träume, nicht Symbole für eine bessere Welt, sondern Beweise für die Existenz einer schlechten. Aber auch diese schlechte We1t hat bei Morus ihr über sich hinausweisendes, allerdings nicht utopisches, man könnte sagen, dystopisches Symbol. Dem Bild vom gezähmten Tier und Menschen und vom blühenden Garten steht die Vision vom reißenden Schaf gegenüber. Das zahmste aller Tiere wird zum Wolf und frißt Menschen und Länder und verwandelt die Inse1 in eine Einöde.

Eigentlich gelten sie Idie englischen SchafeI als recht zahm und genügsam; jetzt aber haben sie, wie man hört, auf einmal angefangen, so gefräBig und wild zu werden, daB sie sogar Menschen fressen, Länder, Häuser, Stădte verwüsten und entvölkern. 56

Wo sich auf dem Weg nach Utopia die Einöde in Fruchtbarkeit verwandelt, wird hier in England umgekehrt alle Fruchtbarkeit zur Einöde. Dem Schöpfungsmythos steht das Bild der Zerstörung gegenüber. Die englische Realität wird im Bild vom reißenden Schaf zur apokalyptischen We1t, die utopische im Bild von der beherrschten Natur zum Paradies. So bleibt auch in den Symbolen und Bildern der UTOPIA wie in ihrer Wortsemantik die anfangs schematisierte Grundstruktur des utopischen Romans, Möglichkeit als konstruierte absolute Gegenwelt zur Wirklichkeit, konsequent erhalten. Die reine Sprache der Utopier kann nicht vorgeführt werden, aber sie muß ähnlich funktionieren wie die der utopischen Symbole. Utopische Sprachkritik funktioniert hier als Konfrontation von sprachlichen Bildern der Hoffnung mit Bildern der Hoffnungslosigkeit. Die Wirkung der UTOPIA liegt in der groß angelegten Gegenüberstellung der beiden Inseln, wobei die Spuren der einen jeweils immer schon oder noch in der anderen $z u$ finden sind. Die gedachte Inse1 bleibt ein Positivabdruck der erlebten, aber nur in der kann der Mythos vom besseren Leben als pädagogischer Impuls angesiedelt werden. Deshalb ist gerade der Utopist von allen Schriftstellern am meisten auf die Rezeption seiner Texte angewiesen. 
"Wenn die Religionen sich wenden", sagt Keller, und er will voll Bürgergrimm die Töufer malen, "so ist es, wie wenn die Berge sich auftun; zwischen den großen Zauberschlangen, Golddrachen und Kristallgeistern des menschlichen Gemüts, die ans Licht steigen, fahren alle häßlichen Tazzelwïrmer und das Heer der Ratten und Möuse hervor"; - Mützer aber fuhr mit, das Heer der dunklen Ratten und Möuse zu entzaubern, I... I seine eigene Seele bedenkend und die Heimkehr der Gefährten, wie odysseus, wie Christus.

(Ernst Bloch: Thomas Müntzer als Theologe der Revolution.)
II. Von der Revolution der Theologie zur Theologie der Revolution. Die Utopie Thomas Müntzers.

Ungehorsam erzeugt die Wut der Mächtigen. Ende 1533 setzt das englische Parlament die Suprematsakte in Kraft. ${ }^{1}$ In ihrem wesentlichen Wortlaut erklärt sie Heinrich VIII. zum Oberhaupt der englischen Kirche und besiegelt damit den Bruch mit Rom. Der englische Lordkanzler Thomas Morus weigert sich, den Eid auf diese Akte zu leisten. Nachdem die fast einjährige Towerhaft den Entschluß des unbeugsamen Mannes nicht ändern konnte, wird ihm der Prozeß gemacht. Heinrich begnadigt seinen ehemaligen Berater zur Enthauptung. Nicht viel besser ergeht es Thomas Müntzer, und die Moral von der Bestrafung des aufrührerischen Theologen liefert Philipp Melanchton in seiner HISTORI THOME MUNTZERS gleich mit.

Dis endt Thome Muntzers ist wol zubedencken / vff das ein jeder dabey lern / das man nicht soll glewben denen die sich rumen gotlicher offenbarung I...I Auch sollen wir lernen / wie hart Got straffe vngehorsam vnd auffrur wider die oberkeit I...I. ${ }^{2}$

Weder die Opfer, Morus und Müntzer, noch ihre Richter, noch die näheren Gründe für ihren Tod sind auf irgendeine Weise vergleichbar. Als einzig Verbindendes bleibt der Ungehorsam, und auch der hat bei Morus eine andere Bedeutung als bei Müntzer. Das Schimpfwort von "lousy Luther's abominable bitchery", wie Thomas Morus die Reformation nannte ${ }^{3}$, läßt auf das Verhältnis des englischen Humanisten zu dem deutschen Reformator schließen. Weder Luther noch Tyndale, der englische Reformator, erst recht nicht Müntzer, hätten in Utopia die Chance, unbestraft zu bleiben. Denn Religionsstreitigkeiten darf es dort nicht geben. Reformatorischer Eifer wird in Utopia nicht als Ketzerei, sondern als Aufruhr aufgefaßt und jede Gewaltanwendung wird bestraft. Von hier aus gesehen würde Morus woh1 auch die Worte Melanchtons unterschreiben. Die Staatsmacht in Utopia bestimmt nicht über Glaubensinhalte, aber über die Spielregeln der Toleranz, eine Einstellung, die, noch bevor Europa durch Reformation und Gegenreformation zerspalten wird, dem Toleranzgedanken des späten
18. Jahrhunderts nahe kommt. Aber auch Utopus, der Gründer und Herrscher, kam als Eroberer und mußte erst einmal seine Gegner besiegen, ehe er eine neue Ordnung errichten konnte. Das ist das Dilemma des Humanisten. Mit den Grundsätzen des humanistischen Idealstaates ist ein Utopia nicht realisierbar. Morus selbst müßte als Gründer seiner Utopie zum Schwert greifen. Damit wäre er Thomas Müntzer um ein beträchtliches Stück näher gerückt. Bezeichnenderweise träumt er sich aber in einem Brief an Erasmus nicht als Utopus, sondern als König des bereits lange bestehenden Inselstaates. ${ }^{4}$ So umgeht er die Frage, wie er sich als Eroberer oder Revolutionär verhalten hätte. Müntzer dagegen umgeht nicht die Frage nach dem Wie der Utopie, sondern gerade nach dem was, nach den Inhalten des utopischen Zustandes, die Morus so eindringlich schildert. Hier liegen die Voraussetzungen für den Unterschied zwischen Utopie als Roman und Utopie als Aktion. Was Utopus gelingt, die Erschaffung einer neuen Welt mit dem Schwert, muß seinem Autor Wunschtraum bleiben. Müntzer aber steht als Beispiel dafür, was einem historischen Utopus im Europa des 16. Jahrhunderts passiert wäre. Denn der Kampf gelingt nur in der Fiktion, und auch dort, in der Erzählung Raphaels 1iegt er weit zurück und wird in fast mythische Vorzeit verdrängt. Morus und der utopische Roman bis zum 18. Jahrhundert schildern den Zustand nach der Revolution. Gerade das bleibt uns Müntzer schuldig. Ich fahr daher, mit dem Schwert Gideons, droht er am 12. Mai 1525 dem Grafen Albrecht von Mansfeld, 5 und wenig später macht er seine Drohung wahr, um das Reich Gottes anbrechen zu lassen, in dem alle gleich sein sollen und dem sich die Fürsten nur um ihr Leben widersetzen können.

Dye entporunge habe er dorumb gemacht, das dye christenheyt solt alle gleych werden und das die fursten und herrn, dye dem ewangelio nit wolten beystehen, solten vortriben und totgeschlagen werden I... I Ist ir artigkel gewest und habens uff dye wege richten wollen: Omnis sunt communis, und sollten eynem idern nach seyner not- 
dorft ausgeteylt werden nach gelegenheyt. Welcher furst, graff oder herre das nit hette thun wollen und des erstlich erinnert, den solt man dye koppe abschlahen ader hengen. 6

Nur an dieser Stelle, aus seinem BEKENNTNIS UND WIDERRUF vom 16. Mai 1525,7 erfahren wir unsicher über Müntzers Absichten, unsicher, weil seine Aussagen durch die Tortur erpreßt und später von seinen Feinden überliefert wurden. Trotzdem kommt hinter dem Schleier uns ungewohnter Sprache und Gestik, aus der die Emotion des Augenblicks spricht, und aus dem fieberhaften Predigen das eigentliche Ziel der Müntzerschen Existenz im urchrist1ich gemeinten omnia sunt communia zum Vorschein. Müntzers "Maximalprogramm", das im praktischen Kampf allerdings keine Rolle spielte, ${ }^{8}$ kann so umrissen werden: eine neue Gemeinschaft auserwählter Christen, die - urchrist1ich allen Besitz ohne Unterschied miteinander teilen. Urchrist1icher Güterkommunismus ist also die Grundlage der humanistischen wie der reformatorischen Utopie. Das rückwärtsgewandte Mönchsideal steht, bei Müntzer stärker als bei Morus, hinter beiden Träumen. Diejenigen, die gegen die Feinde Gottes kämpfen, sind Auserwählte. Die Feinde sind der römische Klerus, die Fürsten und Grundherren und deren Diener, $z u$ denen Müntzer auch Luther rechnet. Nichts ist Menschenwerk in diesem Kampf. "Ihr sol1t diese große Menge Ivon FeindenI nit scheuen, es ist nit euer, sondern des Herrn Streit. Ihr seid nit, die da streiten", 9 schreibt Müntzer an die Allstedter und die Berggese11en aus Mansfeld. Es ist nicht nur Zweckoptimismus, der hier einer Minderheit Mut zum Aufstand zusprechen wi11. Die Legitimationslogik Müntzerschen Streitens liegt in der für uns kaum noch nachvol1ziehbaren reformatorisch erneuerten Autorität des biblischen Textes, die für die gesamte "frühbürgerliche Revolutionsbewegung" nicht unterschätzt werden darf, da sie jede Art von sozialen Konflikt in dieser Zeit begleitet.

Müntzers utopisches Programm ist theoretisch nicht belegt, aber die Anstrengungen, es in die Wege zu leiten, liegen deutlich als historische Zeugnisse vor uns. Zwar wird kein ausgefeiltes Bild von einer paradiesischen Gesellschaft als utopisches Symbol beschworen, aber Müntzers Sprache, die die Revolution betreibt, ist voller utopischer Symbole. Sehnsucht nach der besseren Welt wird bei ihm nicht durch die fiktive Darstellung des erfül1ten Traums erweckt, sondern durch die Gewißheit ihrer nahen Ankunft. Ob Müntzers "omnia sunt communia" allerdings die Tagesbe- dürfnisse der Kleinbürger, Handwerker und Bauern aus der Zeit des Bauernkriegs trifft, bleibt fraglich.10 Mythisches ist jedenfalls auch hier im Spie1. Wo Morus seinen neuen, geplanten Mythos vom Staat ohne Sünde literarisch ins Bild setzt, macht sich Müntzer selbst zur mythischen Gestalt und droht mit überirdischer Macht. Die mythische Substanz seiner Sprache zieht er aus den prophetischen Büchern des alten Testaments, und er selbst scheut nicht, sich in die Reihe der Propheten zu stellen. So schreibt er an Graf Ernst von Mansfeld:

Das du auch wissest, das wyrs gestrackten bevell haben, sage ich: Der ewigke lebendige Got hatz geheissen, dich von dem stull mit gewalt uns gegeben zu stossen; dann du bist der christenheit nichts nutze, du bist ein schadlicher staubbessem der freunde Gottis. Got hat von dir und von deines gleichen gesagt, Ezechielis am 34. und am 39., Danielis 7. Michee 3. Abdias der prophet sagit dein nest muß zerrischen und zerschmettert werden. 11

Die Beziehungen von biblischer Mythologie, historischer Gegenwart und eigener Person stellt Müntzer in allen seinen Texten her, dabei wird eine Parallelität von alttestamentarischem Mythos und historischer Realität, so wie sie der Reformator sieht, rhetorisch eindringlich suggeriert. Die Attribute aus der christlichen Mythologie, mit denen Müntzer sich schmückt, geben tiefere Einblicke in die Progression seines revolutionären Bewußtseins. Sie funktionieren ähnlich wie die utopischen Symbole, die Morus verwendet, aber ihre Funktion im rezeptionellen Vorgang ist eine andere. In beiden Fällen wird mit einem Zeichen auf größere Zusammenhänge verwiesen. Bei Morus sind es Bilder sozialer Wünsche, bei Müntzer sind es Hinweise auf Geschichten des siegreichen Kampfes gegen alt- und neutestament1iche Formen von Häresie und Heidentum, die letztlich auch auf die Utopie nach dem Sieg zielen.

Ende Juli 1524 bezeichnet sich Müntzer in seiner AUSGEDRUCKTEN ENTBLOSSUNG DES FALSCHEN GLAUBENS 12 als "Thomas Muntzer, mit dem hammer". Der Hammer verweist auf eine Stelle bei Jeremias, in der es heißt: "Ist mein Wort nicht wie ein Fewer, spricht der HERR, vnd wie ein Hammer der Felsen zuschmeist?" 13 Kurz nach seiner FURSTENPREDIGT ${ }^{4}$, deren Tite1 er mit "Thomam Muntzer, diener des wordt gottes" unterschreibt, vertraut Müntzer noch ganz auf die Oberzeugungskraft seiner rhetorischen Fähigkeiten und darauf, die sächsischen Herzöge und ihre Untertanen für seinen Kampf gegen die römische Geistlichkeit und den "Kompromißkurs" Luthers zu gewinnen. Aber bereits die Fürstenpredigt und die nicht zur 
Zensur gegebene Fassung der "Ausgedrückten Entblößung"15, die im Titel den Hammer erwähnt und zwei weitere Jeremiaszitate, frei von Müntzer übersetzt, nachfolgen läßt, enthalten auch Drohungen anderer Art. In der "Fürstenpredigt" war die Rolle des revolutionären Subjekts noch den der Reformation nahe stehenden Fürsten zugedacht mit einer ungewissen Drohung, man werde ihnen das Schwert nehmen, falls sie es nicht gegen die römischen Feinde und deren weltliche Diener gebrauchten.

Also nottlich ist auch das schwerdt, die gotlosen zu vertilgen, Rom. am 13. Das aber dasselbige nw redlicher weyse und fuglich geschehe, so sollen das unser thewren veter, die fursten, thun, die Christum mit uns bekennen. Wo sie aber das nicht thun, so wirt yhn das schwerdt genommen werden, Danielis am 7. capitel, I $\cdots I .{ }^{16}$ Wer den Fürsten die Macht aus der Hand nimmt, erfahren wir durch den Hinweis auf das Danie1Kapite1: "Königtum, Herrschaft und Obermacht über alle Reiche unter dem Himmel wird dem Volke der Heiligen des Höchsten verliehen." 17 Für Müntzer wird allerdings schon im Brief an Friedrich den Weisen vom 4. Oktober 1523 und in zwei weiteren Briefen vom 22. Juli 1524 und vom 9. Mai $1525^{18}$ dieses Volk der Heiligen identisch mit dem realen Volk seiner Umgebung, den Bürgern, Handwerkern und Bauern Allstedts und Müh1hausens, mit denen er schließlich gegen die Fürsten zieht. So verweben sich Mythos und Realität immer mehr in seinem Streben nach der Realisierung der Utopie.

Deutlicher wird Müntzer in den Jeremiaszitaten der "Entb1ößung". Er selbst dekoriert sich mit dem Hammer, dem Wort Gottes, das physische Kraft besitzt und Felsen zerschmettert. Damit ist die Verbindung von Autor und Mythos hergeste1lt, und das mythische Geschehen reaktiviert sich für die historische Gegenwart in Müntzers Sprache. Werden auch die weiteren Zitate aus Jeremias im Zusammenhang mit der Beziehung Autor - Mythos gesehen, so erhalten sie einen radikaleren revolutionären Sinn, a1s das in einem "neutralen" Zitatzusammenhang mög1ich wäre. Nicht mehr die Fürsten, sondern der Autor selber wird, wie jener Jeremias, zur Umgestaltung der Welt aufgerufen.

Jeremie am ersten: "Nym wahr, ich hab meyne wortt in deynen mundt gesetzt; ich hab dich heüt tber die lefitt und liber die reych gesetzt, auff das du außwurtzelest, zurbrechst, zurstrawest, und verwustest und bawest und pflanzest." 19

Die Gegenüberstellung von auswurzeln und pflanzen, verwüsten und bauen bleibt über die innermythologische Bedeutung hinaus ein unverbindliches Wortspiel. Erst im Müntzerschen Kontext von Schrift und historischem Handeln wird daraus ein utopisches Programm für die Neugestaltung oder Umgestaltung der We1t. Rhetorik und revolutionäres Handeln gehen hier Hand in Hand.Die Verbindung von Schrift und Schwert, sagt Helmut Brackert, bedeutet im Bauernkrieg "Anspruch auf legitime Ausübung der Gewalt und umfaßt im Zusammenhang des Bauerkrieges die ganze Dimension der Legitimierbarkeit des bäuerlichen Aufstandes einerseits, der radikalen Niederschlagung dieses Aufstandes durch die Fürsten andererseits."

Nimmt man die Bezeichnung "literarisch" nicht als Wertbegriff I...I sondern versteht man sie in einer weitgefaBten Bedeutung als Kennzeichnung von Texten uberhaupt, d.h. von regelhaft-festen situationsbestimmten Formen von Sprachhandlungen, so wird man vom Bauernkrieg sagen dürfen, daß kein Krieg vorher und kaum ein Krieg nachher so stark auch "literarisch" bestimmt war, kein Krieg so sehr auf einer auch literarischen Ebene geführt wurde, in keinem Krieg Literatur als Motivationshilfe, als Agitationsimpuls, als Argumentationsinstrument und eben auch und vor allem als Transportmittel der Selbstund Fremddarstellung sowie der Interessenvertretung eine vergleichbare Rolle spielte. 20

Verwüsten und bauen, das ist die Grundforme1 und Konsequenz jener Sozialutopie, die ihren neuen Anfang nicht als Lehr- und Gegenbild zur Realität, nicht als Antizipation von neuer Ordnung versteht, sondern als die Einführung der neuen Ordnung durch die Zerstörung der bestehenden jetzt und hier. Was Thomas Morus nur in der Vergangenheit einer räumlichen und zeitlichen Fiktion anzusiede1n wagt, in der Hoffnung auf eine pädagogische Wirkung des Bildes, wird bei Müntzer zu einer kompromißlosen realpolitischen Forderung, die er auch sofort in der Gewißheit der nahenden Parusie einzulösen versucht. Wo Utopie direkt erfahren und nicht im Rezeptionsvorgang vorgeste11t wird, ist ihre literarische Inszenierung nicht mehr ausschlaggebend. Auch das mag ein Grund dafür sein, daß Müntzer keine "konkrete" Utopie entwickelte. Rekonstruktionsversuche solcher historischen utopischen Stimmungen müssen allerdings lückenhaft bleiben, da ihre Substanz, die konkrete Erfahrung des historischen Augenblicks, verloren gegangen ist. Es bleiben Reste von Sprache wie Müntzers Manifest an die Bergknappen ${ }^{21}$, aus dessen semantischem Hintergrund, der von uns jedoch nicht mehr restlos nachvollzogen werden kann, die Erfahrung der kurz vor der Erfüllung stehenden Utopie spricht. Müntzers Aufstand, der schon am Beginn an seinen historischen Widerständen scheiterte, bleibt ein utopischer Torso, und wir sind verwiesen auf Dokumente, Sprache und Symbole, die nur das Gerüst umreißen können. Es bleiben der Hammer und das Schwert Gideons, der atemlose Aufruf, das sich mehrfach wiederholende "dran, dran" im Brief an die Allstedter kurz vor der Schlacht bei Frankenhausen. Es bleibt auf der einen Seite der Mythos vom 
kampflosen Sieg der gottgeführten Dreihundertschar des Gideon gegen die Midianiter ${ }^{22}$ und auf der anderen die katastrophale Niederlage des Müntzerschen Haufens bei Frankenhausen. Schon in seiner "Ausgedrückten Entblößung" baut Müntzer auf das Bild vom Kampf Gideons und auf die Stärke seines Glaubens.

Gedeon hett eynen solchen festen, starcken glauben, das er mit im ein unzelige grosse welt durch dreyhundert man liberwant. 23

Seine Bereitschaft zum Kampf, auch seine Oberschätzung sind hier schon ganz deutlich. Trotzdem kalkuliert er in diesem Augenblick noch mit der Wirkung der anderen Fassung der "Entblößung", die den Fürsten vorliegt und in der die Formel vom auswurzeln und bauen und weitere Anspielungen auf die Fürsten vermieden wurden. ${ }^{24}$ Erst nach seiner Flucht aus Allstedt gibt Müntzer den Gedanken auf, die Fürsten auf die Seite seines Bundes zu bringen.25 Der prophetische Führer der revolutionären Christenheit ist jetzt Thomas Müntzer selber, wie es bereits das unrezensierte Exemplar seiner "Entblößung" andeutet.

So die heylig kirch sol durch die bitter warheit vernewt werden, so muß ein gnadenreycher knecht Gottes herfür treten im geyst Helie I... I und mbB alle ding in den rechten schwanck bringen. Warlich, ir wirt vil mussen erweckt werden, auff das sie mit dem allerhơchsten eyfer durch brüstigen ernst die christenheyt fegen von den gotlosen regenten. 26

Thomas Morus symbolisiert seinen neuen Anfang durch die Sichelform seiner künstlichen Insel und durch den Mythos der Wiedergeburt im MithrasKult. Wiedergeburt wird hier jedoch nicht nur in ihrem spezifisch mythologischen Sinn verwendet, sondern zugleich auch aus der Sicht des Renaissancehumanismus als Wiederbelebung antiker Sprache, Wissenschaft und Lebensformen in christlichem Gewand. Müntzer richtet seine Aufmerksamkeit ausschließ1ich auf den Kampf, der vor der Utopie liegt. Seine Symbole des neuen Anfangs, einer Renaissance oder militanten Wiedergeburt urchristlicher Lebensformen sind Werkzeuge der Zerstörung, der Hammer, das Schwert und die Siche1, letztere in einem anderen Sinn, als Morus sie verwendet. Beide, Morus und Müntzer, greifen bei der Vermittlung ihres utopischen Denkens entsprechend dem Rezeptionshorizont ihres Publikums und den von ihnen verfolgten, unterschiedlichen Wirkungsabsichten auf griechisch-römische bzw. jüdisch-alttestamentliche Mythen zurück. Morus' neuer Mythos vom besseren Leben korrespondiert deutlich mit dem alten Mythos vom Paradies und Goldenen Zeitalter. Müntzers Kampf um eine gerechte Sozialordnung und chiliastisch erwartete neue christliche Gesellschaft beschwört immer wieder den biblischen Mythos vom Kampf Israels. So kaschiert sich die Antizipation mit der Legitimität des Traditionellen. Revolution ist unter diesem Aspekt nichts "Unerhörtes", sondern Erneuerung von Bekanntem.

Müntzer reaktiviert den siegreichen Kampf Gideons nicht nur literarisch für das Bewußtsein seiner Rezipienten, sondern auch in der Realität, indem er mit dreihundert Ausgewäh1ten aus seinem Allstedter Bund und einem Haufen von Bauern in die Schlacht zieht. Die Herausforderung, mythisches Geschehen in der Realität $z u$ wiederholen und dadurch die Utopie einzurichten, stellt sich dem Risiko des historischen Scheiterns und damit dem für jede Utopie tödlichen Verdikt, unrealistisch zu sein. Nicht so die Fiktion von der irgendwo und irgendwann bestehenden Utopie, die immer wieder als Literatur rezipiert werden kann und deren antizipatorische Elemente über den historischen Augenblick hinaus a1s Denkansätze gegenüber einer bestimmten gesellschaftlichen Konstellation wirksam bleiben können. So gesehen besteht der Vorteil der 1iterarischen Utopie gegenüber dem historischen Versuch gerade in der Mehrschichtigkeit der 1iterarischen Formulierung, in ihrem ästhetischen "Mehrwert" 27, der über ihre aktue1le Bedeutung hinaus variierende, in verschiedenen Epochen sogar konträre Rezeptionsmöglichkeiten zuläßt. Das trifft für den gescheiterten Realisierungsversuch nur in bezug auf eine Beurteilung der beteiligten historischen Personen und deren Handlungen, weniger auf die vorliegenden Dokumente zu. Die UTOPIA ist in größerem Maß unabhängig von ihrem Autor und dessen historischer Existenz rezipierbar als die Predigten und Briefe Müntzers, die ausschließlich im Zusammenhang mit dessen historischem Handeln gesehen werden müssen. Der Utopia-Text handelt sich unter Umständen den Vorwurf der Aktionslosigkeit und melancholischen Träumerei ein, während es andererseits gerade die gescheiterten Versuche, Utopien einzurichten, sind, die der gesamten Gattung zuweilen den Ruf einbrachten, unrealistisch zu sein. Zur Entlarvung der gesellschaftlichen Verhä1tnisse ihrer Epoche tragen beide Formen der Utopie bei, die eine deutlicher in ihren 1iterarischen Gegenbildern, die andere deutlicher in der Art und Intensität der Gegenreaktionen.

Umgestaltung ist für Müntzer zuerst auch eine Sache der Sprache.

Derhalben ist meine ernstliche wolmaynung noch diesen heutigen tag, der armen zurfallenden christenheyt also zu helffen mit Deutschen ampten I...I das ein itlicher gutherziger mensch sehn, horen und vornemen mag, wie 
die vorzcweyffelten beptischen bôsewicht die heylge biblien der armen christenheit zu großem nachteyl gestollen und yren rechten vorstandt vorhalten haben, und doch gleichwol armer leuthe gtiter daruber bôBlich vorschlungen haben 1 ... I Weyl aber nw der arme gemeyne man seinen glauben auf eyttel larven gestellet hat I...I ist billich und zymlich I...I das man der schwachen schonen soll 1.Corin.3; so wil sich kein vorschonen besser odder fûglicher finden lassen, dann die selbige lobgesenge im Deutschen zu handeln, auff das die armen, schwachen gewissen I...I mit voranderung des Lateins ins Deutsch, mit psalmen und gesengen zum wort Gottis und rechtem vorstand der biblien I...I kommen moggen. I... I Es soll sich ein prister stellen I...I er sol das wueten der tyrannen nicht ansehn, sonder das testament Christi offenbar handeln und deutsch singen und erkleren, uff das die menschen mûgen christformig werden. Roma 8. Als dann so wirt aller geitz, wucher und hinterlistige tûck der pfaffen, mônchen und nonnen mit aller yrer wortzeln hernidder fallen, die itzdt in guttem scheyn den glauben vorhyndern. Das helff uns gott allen. Amen. 28

Müntzers Kampf für die Erneuerung des christlichen Glaubens ist ein Kampf gegen die Sprache der durch Besitz und Bildung Privilegierten. Nicht mehr geheimnisvolle Zeremonien lateinischen Gemurmels sollen eingeschüchterte, blinde Gläubigkeit erzeugen, sondern biblische Inhalte sollen in neuer aktueller Bedeutung allen verständlich vermittelt werden. Diejenigen, die aus der Wundergläubigkeit und Unkenntnis der Analphabeten Kapital schlugen, mußten die allgemeine Zugänglichkeit der Bibeltexte in den Volkssprachen fürchten, noch dazu, wenn solchen Obersetzungen des Wortes Gottes, das uneingeschränkte Autorität genoß, ein revolutionärer Sinn beigegeben wurde. Unter diesem Aspekt kann die Obersetzungstätigkeit mehr oder weniger aller Reformatoren als eine über den 1iterarischen Bereich weit hinausgehende sozialrevolutionäre Leistung angesehen werden. Für Thomas Müntzer ist die Reformierung der Sprache der Ausgangspunkt zur Reformation des christlichen Lebens, und aus seiner eigenen Sprache ist seine Utopie herauszuhören.

Wo sich die als Wort Gottes geglaubte Schrift, jeder Verstehensbeschränkung enthoben, selbst als Aufruf zum Kampf gegen die bestehende Ordnung erschließen $1 a ̈ ß t$, muß die Wirkung einer interpretierenden Bibelübersetzung stärker als alle revolutionären Aufrufe, Pamphlete und Flugschriften sein. Soweit folgt auch Luther einem allgemeinen reformatorischen Trend. Müntzer geht allerdings noch einen Schritt weiter als Luther mit seiner Bibelübersetzung. Eine gedruckte Ausgabe des gesamten deutschen Bibeltextes 1äßt die große Masse der deutschsprachigen Analphabeten unberücksichtigt. Wer deutsch lesen und schreiben konnte, beherrschte meist auch von seinem Bildungsgang her die lateinische Sprache. Eine deutschsprachige Bibel erschloß somit von der sozialen Schichtung her gesehen, direkt keine neue Leserschaft.
Dazu kommt, daß in der Zeit des frühen Buchdrucks Bücher für die Masse des Volkes unerschwingliche und fremdartige Gegenstände waren. Somit ist der Besitz von Luthers Bibel noch lange Zeit ein Privileg adliger und intellektueller Kreise. Während Luther seine Bibe1übersetzung obendrein entschärft, indem er ihre als sozialrevolutionär interpretierbaren Inhalte in seiner Theologie ausschließlich auf eine Reformierung der geistlichen Ordnung bezieht, verzichtet Müntzer auf eine Gesamtübersetzung und konzentriert sich in der Hauptsache auf den Vortrag einzelner Teile der Schrift während des Gottesdienstes, hier traditionsgemäß vorzüglich der Psalmen. So konnte er auch den Analphabeten wichtige Inhalte der Bibel leicht und eindringlich zugänglich machen. Die Tatsache allein, deutsche Messen und ein deutsches Kirchenamt einzuführen und $z u$ praktizieren, ist allerdings noch nicht entscheidend für das müntzersche Problem von Revolution und Sprache. Denn auch Luther hatte eine deutsche Gottesdienstordnung eingeführt, und die Tradition deutscher Teilübersetzungen der Bibel (Zainer-Bibel) und des mündichen Vortrags von Bibelstellen in deutscher Sprache geht bis weit ins Mittelalter zurück.29 In seinem SERMON VON DER HEILIGEN MESSE ${ }^{30}$, 1520, verlangt Luther, ähnlich wie Müntzer in dem oben zitierten Vorwort $z u$ seiner DEUTSCH-EVANGELISCHEN MESSE, 1524, die Einführung einer deutschsprachigen Messordnung für die Laien und wendet sich gegen die Ausbeutung der Gläubigen durch die römische Priesterschaft. Die Betonung der Abendmah1shandlung als Kernstück der Messe und die Teilnahme aller Gemeindemitglieder an dieser Handlung sowie die Erklärung ihrer Bedeutung lassen dem Opfercharakter der römischen Messe, die mit umfangreichen Geldeinnahmen verbunden war, keinen Raum mehr. ${ }^{31}$ Darüber hinaus betont auch Luther das Erklären, Vorlesen und Lernen von deutschen Bibe1stellen und Psalmen, um den Informationsstand und die selbständige Urteilskraft der Laien über ihren G1auben $z u$ fördern. ${ }^{32}$ Allerdings beschränkt sich seine Reformation auf die Demokratisierung des Gottesdienstes und die Mitbestimmung der Gemeinde bei der Gestaltung des geistlichen Lebens. Dabei schränkt er jedoch die von ihm zunächst empfohlene Variationsfreiheit in den einzelnen Teilen seiner Messordnung, die 1526 nach den Bauernaufständen erschien, ${ }^{33}$ in einem entscheidenden Punkt ein: Die freie Predigt und Auslegung von Bibelstellen durch den Prediger soll möglichst nach festgelegten Beispielen gehalten werden, um die Verbreitung 
revolutionärer Gedanken gegen die weltliche Ordnung zu verhindern. Die freie Predigt aber war ein Hauptmedium Müntzerscher Utopie.

Darnach gehet die predigt vom Euangelio des Sontags odder fests. Vnd mich dunckt / wo man die deudsche postillen gar hette durchs iar / Es were das beste / das man verordente / die postillen des tages / gantz odder eyn stucke / aus dem buch dem volck fur zu lesen / nicht alleyne vmb der prediger willen / die es nicht besser kunden / sondern auch vmb der schwermer vnd secten willen zuuerhüten I...I. ${ }^{34}$

Nicht erst nach dem Bauernaufstand vom Mai 1525 zeigt sich der gegenutopische Zug der Lutherschen Reformation. Deutlich wird seine Ste1lung zur Revolution schon in seinen Schriften über das Verhältnis von Untertan und Obrigkeit von 1520, 1522 und 1523 und in den Schriften zum Bauernkrieg von 1525.35 In dieser Studie geht es allerdings nicht um die allgemeine Darstellung der gegensätzlichen Positionen von Luther und Müntzer, ${ }^{36}$ sondern darum, eine utopische Sprache von ihrem zeitgenössischen Hintergrund abzuheben. Der Unterschied zwischen der Sprache Luthers, die eine sich etab1ierende Ordnung unterstützt, und der Sprache Müntzers, die auf eine andere zukünftige Ordnung gerichtet ist, $1 a ̈ ß t$ sich weder an der lexikalischen, noch an der allgemeinen grammatischen Form, sondern allein an ihrer speziellen Semantik ablesen. Die Charakterisierung der "praktischen", nicht einer ästhetischen Konstruktion dienenden utopischen Sprache Müntzers auf dem Hintergrund der dem historischen Augenblick angepaßten lutherischen Sprache ist insofern problematisch, als sich semantische Nuancierungen über Jahrhunderte hinweg nur in wenigen Sonderfällen sicher erschließen lassen. Die wichtigsten Hinweise zur Markierung der entscheidenden semantischen Unterschiede von müntzerscher und lutherischer Sprache und damit von der "verbotenen" Sprache der Utopie zu der "offiziell sanktionierten" Sprache der deutschen Reformation erhalten wir nur durch die abweichende Obersetzungs- und Interpretationstätigkeit der beiden Reformatoren.

Man halte dazu, daß Münzer, der als erster deutsch singen und predigen lieB, dies tat, damit das Volk nicht den dunklen lateinischen Worten weiter Kraft zuschreibe. So bildhaft und geformt sich die Abfolge dieses deutschen Amtes auch gibt: selbst die Psalmen sind darin "verdolmetscht mehr nach dem Sinn als nach den Worten", und nirgends ist die 'Schrift' entschiedener als hier in sich selbst gesprengt. Freilich, an mehreren Stellen ist Müntzers Ubertragung einfach nur dem niederen Volk angemessen und aufreizend; so sieht sich vor allem das Tun, das Sein der Gottlosen sehr viel breiter, exemplifizierender ausgeführt als bei Luther oder in der gleichfalls wortgetreuen I...I Vulgata.

Dennoch, so sagt Bloch,

hat Münzer I...I eine Glut und Rhythmik empfindender Sprache erreicht, die dem hohen Lutherdeutsch gleichkommt, wo nicht, aus tiefster Selbstbetroffenheit, dieses Orts uberlegen wirkt und von einer wenigstens dem Erlebnisinhalt des Psalms konformen Figur. 37

Auf dem Hintergrund des 1utherischen Bibe1textes erscheinen die müntzerschen Interpretationen alttestamentlicher Verse als mythische Zitatstücke einer utopischen Verheißung, die den Sieg verspricht, wo revolutionäre Gewalt nicht gescheut wird.

Schließlich also paraphrasiert Münzer den gegebenen Text nirgends nur aus agitatorischer Erregung, sondern darüber aus reinerem Wucher des Geistes, aus dem tiefen Realisierungs-, Identitätsverlangen des verzweifelten Christen, aus 'rein tăuferisch spiritualer Einbeziehung' also, die das Außere der Schrift und alles Äußere lediglich als Hinweis, als Gelegenheit, als Zeugnis, als Sollizitation, als Ermahnung des inneren Schatzes wertet. Hier wirkt eine andere Art Theologie, als welche nicht nur, lutherisch, die Sakramente, sondern zugleich auch täuferisch, den Bibeltext zum bloBen Instrument herabsetzt, auf dem der Geist zum Ziel seiner eigenen Umfassung spielt. ${ }^{38}$

Nicht bloße Obersetzung der Meßpsalmen ins Deutsche macht das Revolutionäre in Müntzers Meßordnung aus, sondern die Obertragung der lateinischen oder hebräischen Worte in einen revolutionären utopischen Sinn, der an der bestehenden weltichen Ordnung zweifelt.

Beweis dafür sei ein Obersetzungsvergleich des zweiten Psalms, der gleich zu Beginn in Müntzers Deutschem Kirchenamt auf das Osterfest gesungen wird, mit der lutherischen Obersetzung von $1531 / 1545$ und dessen Kommentar von 1519.39
Psalm 2 (Text):

Müntzer-, Luther-übersetzung 40

1. Worumb beyssen die leut ire zen ubereinander

1. Warumb toben die Heiden /

und das volck bekưmmert sich mit uppigen dingen.

Vnd die Leute reden so vergeblich.
Lutherkommentar zu Psalm 2:41

warum empören sich die Heiden und die Völker nehmen vor, was umsonst ist? die Könige der Erde treten zusammen und die Fürsten versammeln sich zuhauf wider den Herrn und wider seinen Christus. ... So läBt Gott das Toben Trachten und Raten der Gottlosen gegen die Frommen zu, aber das alles sind nur schäumende Wasserwogen I...I eh sie ans Ufer kommen, brechen sie in sich selbst zusammen I...I. 


\section{Psalmtext :}

2. Die kûnge und fursten der erden haben sich mit-

2. Die Konige im Lande Zehnen sich auff / vnd die eynander vortragen wider Got und seynen

Herrn ratschlagen miteinander / Wider den

gesalbten. 42

HERRN vnd seinen Gesalbeten.

3. Wir w8llien zurbrechen yren bundt und wôllen von

3. Lasset vns zureissen jre Bande / Vnd von vns sochen unbeschwert bleyben. werffen jre seize.

4. Der im hymel ist, wirt sie belachen und wirt

4. Aber der im Himel wonet lachet jr / Vnd der yrer in die backen spotten.

HERR spottet jr.

5. Er wirt yn zusprechen in seynem zorne,

5. Er wird einest mit jnen reden in seinem zorn/ und in seynem grym wirt er sie vorstrawen./ Vnd mit seinem grim wird er sie schrecken. /I

\section{Ich IChristusI byn zum kûnge von ym IGottI}

6. Aber ich IGottI habe meinen Konig eingesetzt/ verordnet auff dem berge seyner IGottI heyligkeit. Auff meinen IGottI heiligen berg Zion.

7. Zur erfullung werd ich IChristusI predigen

7. Ich IChristusI wil von einer solchen Weise presein IGottI gesetze, dann er IGottI hat zu digen / Das der HERR zu mir IChristusI ge-
LaBt uns zerreiBen ihre Bande und von uns werfen ihre Seile. Diesen Vers muB man mit den Worten toben, reden, sich auflehnen in Beziehung setzen, so daB der Sinn ist: dazu toben und schwatzen sie, das beratschlagen und beschliessen sie, ihre Hălse nicht unter Gottes und Christi Joch zu beugen, die Seile zu zerreiBen und zu sagen: wir wollen nicht, daB dieser über uns herrsche $(\mathrm{Lk} .19,14)$ I...I Andern scheint dieser Vers anders $z u$ verstehen, aber ich halte mich an diesen Sinn ... I... I Beachte: den Verkehrten ist alles verkehrt I... I Das Gesetz Christi I... I heiBen sie Bande und Joch und haltens für Knechtschaft und schwer. Ihr Gesetz aber, das die wahre Knechtschaft und Schwachheit ist, halten sie für Freiheit und leicht.

I... I damit die Zuversicht der Angefochtenen desto sicherer werde, heiBt es mit Betonung: er lacht, er spottet ihrer I...I er lacht und spottet dessen wie einer Nichtigkeit, wie er auch Ps.37 (12f.) dieselbe Redeweise gebraucht: der Gottlose droht dem Gerechten und beiBt seine $\mathrm{zahhne}$ zusammen, aber der Herr lacht sein, denn er sieht, daB sein Tag kommt. I...I Was aber meinen die Worte: "der im Himmel wohnt"? I...I Auf Erden, in den Wassern und bei allen Kreaturen leidest du, allenthalben und in allen Dingen ist dir die Hoffnung auf Hilfe genommen, bis daB du in Glauben und Hoffnung alles überspringst und dich an den hălst, der im Himmel wohnt. Denn dann bist auch du im Himmel, aber im Glauben und in der Hoffnung. Dahin muB unser Herz in allen Anfechtungen seinen Anker werfen. Dann werden die Ubel der Welt nicht allein leicht, sondern auch lăcherlich sein.

Er wird mit ihnen reden in seinem zorn und mit seinem Grimm wird er sie schrecken ... Dies Wort "reden" muß man in betontem Sinne nehmen d.h. er wird mit seinem Wort beschlieBen gebieten und verordnen, aber nicht, was für sie, sondern was gegen sie ist, nicht in Barmherzigkeit, sondern im Zorn. I...I Wenn man die Präposition "mit" verăndert in "gegen" und das Wort "reden" in "gebieten", wird der Sinn klarer: er wird gegen sie gebieten in seinem zorn. Aber er wird sie nicht allein vernichten und verderben, sondern auch ängstigen, denn äuBerlich wird er sie im Kampf, innerlich durch Furcht verzehren.

Ich habe meinen König eingesetzt auf meinen heiligen Berg zion ... Der Sinn ist: jene wollten freilich nicht, daB er über sie herrsche und haben sich wider mich und meinen König verbunden. Aber mein Rat wird bestehen und mein Wille wird geschehen I...I.

ILuthers Randkommentar zur Bibelausgabe von $1545:^{43}$ "a) Act.13., Ebre.1.5. (Weise): Von einer newen weise/ Das ist die newe Lere des Euangelij von Christo Gottes Son." I

Ich will von einer solchen Weise predigen, daß der Herr zu mir gesagt hat: du bist mein Sohn, heute hab ich dich gezeugt ... Man könnte sagen: warum 


\section{Psalmtext :}

mir IChr.I gesagt: du IChr.I bist mein IG.I son, sagt hat / a Du IChr.I bist mein IG.I Son /

heut von $\operatorname{mir}$ IG.I geboren.

Heute hab ich IG.I dich gezeuget.

8. Fodder IG.I von mir IChr.I die v8̂lcker, dein IG.I

8. Heissche von mir IG.I / So wil ich IG.I dir IChr.I

erbe, dann du IG.I bist ein besitzer uber alle

die Heiden zum Erbe geben / Vnd der Welt ende

grentze der erden.

zum Eigenthum.

9. Du IGott!I salt sie zurbrechen mit einer eysern

9. Du IChristus!I solt sie mit einem eisern Scepter stangen wie ein geschirr des topffers zuschlahen / Wie Topffen soltu IChr.I sie wirst du IG.I sie zurknirschen. zeschmeissen.
Lutherkommentar:

hat der heilige Geist diese Worte nicht klarer gesetzt, etwa so: ich will das Gebot Gottes verkündigen, daB ich sein Sohn bin und er mich heute gezeugt hat? Antwort: der heilige Geist ist sich immer gleich. $\overline{\text { Denn }}$ im Johannesevangelium macht er es ebenso: wenn Christus da von sich und seiner Gottheit spricht, hat er immer darauf acht, die Autorität des Vaters anzuführen und alles, was er selbst ist, auf den Vater zurückzuführen. I ... I So führt er auch hier, da er sagt, er werde auf Befehl des Vaters verkündigen, daB er der Sohn Gottes sei, zuerst den Vater redend an. Wir sollen eben im Sohne mehr den Vater hören, der vom Sohne spricht, als den Sohn, der von sich selber spricht. Der Sinn ist also der: ich will Gottes $\mathrm{Ge}-$ bot verkündigen, daB ich Gottes Sohn bin, aber ich wills nicht auf meine eigene Autorităt tun I...I vielmehr, was der Vater von mir gesagt hat, das will ich euch verkündigen, ihn selber sollt ihr von mir sprechen hören.

Heische von mir, so will ich dir die Heiden zum Erbe geben und der Welt Ende zum Eigentum. Was will das bedeuten, $d a B$ es bei der Einsetzung des Königs auf den Berg Zion nicht heiBt, er solle das Reich auf dem Berg Zion heischen, das Erbe aber über die Heiden wird vom Heischen, ja vom Befehl zum Heischen abhängig gemacht? Vielleicht deswegen, weil der Segen und das Reich Christi dem Volk Israel in Abraham verheiBen, den Heiden aber ohne VerheiBung rein aus Barmherzigkeit geschenkt worden ist I... I Darum also wird Zion Christus als Reich übergeben, ohne dab er es heischt, das Erbe der Heiden aber nur, wenn er es heischt, gleichsam als ein Geschenk für Christus, weil ihnen nichts verheiBen war.

Du sollst sie mit einem eisernen zepter zerschlagen, wie Töpfe sollst du sie zerschmeißen. Hier muß man wiederum die Träume des Fleisches weit weg tun, daB nicht jemand sich einbilde, das Reich Christi könne mit Eisen und Waffen bereitet oder erhalten werden, wo doch geschrieben steht I...I 2.Kor.10 (4): unsre Waffen sind nicht fleischlich. I...I Oder warum verfolgen wir dann nicht auch die Bösen in unsern eigenen Reihen mit dem Schwert, vor allem die großen Hansen unter den Völkern? Aber das sei ferne! Das Reich Christi besteht in Gerechtigkeit Wahrheit und Frieden; mit diesen dreien ward es gewonnen, mit diesen muB mans auch schützen. I...I Dieser Vers ist nu auch wieder ganz allegorisch zu verstehen. I...I Denn weil das Wort Christi ein Wort des Heils und Friedens I...I ist, aber nicht im Fleisch, sondern im Geist wirkt, so muB es notwendig Heil Frieden Leben und Gnade des Fleisches drücken und austreiben. I ... I Das Zepter ist das allerheiligste Evangelium Christi,denn dies ist das Zepter seines Reichs, wie I...I geschrieben steht I...I Jes.11(4): er wird mit dem stab seines Mundes die Erde schlagen mit dem Odem seiner Lippen den Gottlosen töten. ${ }^{44}$ Was ist aber das Zepter des Mundes Christi anders als das Wort Gottes, mit dem Gott die Erde d.h. die, die nach Irdischem trachten, schlägt? Und was ist der Geist seiner Lippen anders als dasselbe Wort des Geistes, mit dem er den Gottlosen tötet, damit er der Gottseligkeit lebe und der Gottlosigkeit tot sei? I...I Eisern aber heiBt es wie gesagt um des Fleisches willen, denn dem Fleisch ist das Gesetz Christi sehr hart I...I Denn all unsern Wünschen legt es Kreuz und Tod auf, nämlich Armut, Demut und Geduld. I...I die Armut zerstört die Begierde der Augen und die Habsucht, die Demut zerstört den Hochmut und den Ehrgeiz, die Geduld zerstört die Begierde des Fleisches und die Lust. I...I Zum dritten, gleichwie Eisen alles zermalmt und zerschlägt, wie es Dan. 2 (40) heiBt, so zermalmt auch das Wort Christi alles Große d.h. es demütigt die Stolzen, bringt alles verdrehte zurecht d.h. züchtigt die Zuchtlosen, biegt alles Starre d.h. beugt die Hocherhabenen, glättet alles Rauhe d.h. beschwichtigt die Zornigen I...I Summa, es zerstört jede schlechte Gestalt und wandelt sie in eine Gott wohlgefällige Gestalt I...I. 
10. Do wirt sichs dann gehören, euch kưnigen, clug

10. So lasst euch nu weisen jr Könige /

zu sein und vorsichtig recht urteil fellen auff erden. Vnd lasst euch züchtigen jr Richter auff Erden.

11. Dienet Got mit forcht, und mit ewrem entsetzen

11. Dienet dem HERRN mit furcht / Vnd frewet euch solt ir yhm wunsam sein.

mit zittern.

12. Das der Herr uber euch nit zorne, ergreyfft die

12. Küsset ${ }^{\mathrm{b}}$ den Son / Das ex IChr.I nicht zürne / zucht, anderst werdet ir den rechten weg nit vnd jr vmbkomet cauffm wege / IDenn ... treffen. IAbsatz: es folgt Vers 13.I das folgende wird ohne Absatz direkt an V.12 angeschlossen.I

13. Wann er IG.I mit kurtzem zorm wirt inbrunstig sein,

(12.)Denn sein IChr.I zorn wird bald anbrennen / selig seint alle, die sich do auff Got vorlassen. Aber wol allen die auff Jn IChr.I trawen.
So laßt euch nu weisen, ihr Könige, und laßt euch züchtigen, ihr Richter auf Erden ... Wie kühn und, wie man heutzutage sagt, wie aufrührerisch und ärgerlich ist doch dieser überaus freche Prophet, der seinen Mund gegen den Himmel auftut, der nicht die kleinen und den Pöbel, sondern die höchsten Häupter und die Könige anzugehen wagt I...I Aber soll man das ertragen, wenn die Könige und Richter auf Erden I...I mit dem Pöbel auf eine Stufe gestellt und trotz ihrem langgeübten Lehrund Herrscheramt in die Reihe der Schüler gestellt werden I...I? I...I Wer sollte hier nicht zittern, I...I auf $\mathrm{da} B$ alle Gerechtigkeit erfüllt werde, indem, der hoch ist, sich unter den Niedrigsten demütigt und der Niedrige bebt vor der Demut der Hoheit ... Für das Wort "laBt euch weisen" steht im Hebrăischen "hascilu" I...I. In unserer Sprache sagen wir dafür: seid weise und verständig. I...I seid verständig, d.h. macht, daB ihr verständig seid, sorgt, daß ihr gläubig werdet.

ILuthers Randkommentar v. 1545, a.a.0., S.969,2:"(Dienet) Seid gehorsam vnterthenig."I

ILuthers Randkommentar, ebd.: "b) Oder also / Huldet dem Sone. c) (Auffm wege) Das ist / in ewr weise vnd wesen."I

Lernet Zucht, daß der Herr nicht einmal zürne und ihr abkommt vom rechten Weg (Vulgataübersetzung von Vers 12). Im Hebräischen sind die Worte "Herr" und "rechten" nicht vorhanden, aber das tut nichts. Fast von allen wird die Ubersetzung "lernet zucht" verworfen. Das hebräische "nasscu bar" hat Hieronymus übertragen mit "betet rein an!" I ... I betet den Sohn an! Denn "bar" heiBt auch Sohn. I .... I Der Bischof von Burgos und Lyra übersetzen: küsset den Sohn. Nirgends aber liest man, daB "bar" Zucht bedeutet. I...I Wir wollen versuchen, alles miteinander zu vereinigen. Der KuB ist erstlich ein Zeichen der Ehrerbietung und Anbetung I...I. Zum zweiten ist der $\mathrm{KuB}$ ein Zeichen der Anerkennung und der Treue I...I. Zum dritten ist der Kuß ein Zeichen der höchsten Freundschaft und Liebe ... Nu können wir jenes "bar", das man mit Sohn oder rein oder Zucht übersetzt hat, so auslegen, daB der Glaube an Christus unsere wahre Zucht ist. I... I Denn sein Zorn wird bald entbrennen; aber wohl allen, die auf ihn trauen. Dieses Stück gehört im Hebräischen zum vorangehenden Vers, der dann vollständig so zu ordnen ist: küsset den Sohn, daB er nicht zürne und ihr auf dem Wege umkommt, denn sein Zorn wird bald entbrennen. I... Der Sinn ist also: betet Christus eilend und schnell an, damit ihr nicht durch seinen Zorn vergeht und euch nicht selber tãuschet, als wäre er noch weit entfernt; I...I.
Luther übersetzt in Psalm 2, Vers 3-4: "Die Könige im Lande lehnen sich auf, und die Herrn ratschlagen miteinander wider den Herrn und seinen Gesalbten." Den nächsten Vers schließt er im Sinne eines Doppelpunktes an: "Laßt uns zerreißen ihre Bande und von uns werfen ihre Seile." Ausdrücklich faßt Luther in seinem Kommentar den 3. Vers als Aufstand der Könige und Herrn gegen die Lehre Gottes und Christi auf und interpretiert "Bande" und "Seile" als "Gesetz Christi", das von den "Widersachern
Gottes" als "Knechtschaft" aufgefaßt wird. Nach Luther ist Vers 3 eine nähere Erläuterung zum Aufstand der Könige. Bei Müntzer aber ergibt sich eine vollkommen andere Interpretationsmöglichkeit dieser Verse. Er übersetzt: "Die Könige und Fürsten der Erde haben sich miteinander vertragen", d.h. nach der zeitgenössischen Bedeutung: haben ein Bündnis miteinander geschlossen, "wider Gott und seinen Gesalbten".45 Im nächsten Vers fährt Müntzer direkt fort: "Wir wollen zerbrechen ihren Bund 
und wollen von solchen (Dingen, Leuten) unbeschwert bleiben", d.h. wir wollen von solchen Dingen unbelastet bleiben, oder: wir wollen von solchen Leuten nicht unterdrückt werden (beschweren = Last auflegen, unterdrücken). 46 Nicht die gegen Gott Verschworenen reden hier, sondern diejenigen, die gegen die gottlosen Könige und Fürsten kämpfen wollen. Diese aktuel1 politische Interpretation der Verse verdeutlicht Müntzer in seiner "Ausgedrückten Entblößung", indem er sich auf den zitierten Psalmtext bezieht.

Wie bey unsern zeyten nu Gott seyn liecht in die welt schickt, wirt beweyset IdurchI der gottlosen, unsinnigen Menschen regiment und öberkeyt nach allem mîtwillen mit allem eusserlichem toben und witten auffs allerhôchst wider Got und alle seyne gesalbten, psal. 2 I... I das auch yetzt etlich erst recht anfangen, ir volck zu st8̈cken, plöcken, schinden und schaben I... I und peynigen und todten schmalich die iren und frembden aufs allerscherpffst, das auch Got nach dem ringen der auBerwelten den yammer nit lenger wirt ktinnen und mâgen ansehen I...I. ${ }^{4}$

An anderer Stelle heißt es, bezogen auf Vers 2 und 8 :

Man siecht itzt hubsch, wie sich die 8 le und schlangen zusammen vorunkeuschen auff einem hauffen. Die pfaffen und alle bôse geistlichen seint schlangen I...I und die weltlichen herren und regenten seint fle I...I. Do haben sich die reich des teufels mit tone beschmiret. Ach lieben herren, wie hubsch wirt der Herr do unter die alten tôpf schmeissen mit einer eysern stangen, Psal. 2.48

Die Reiche des Teufels: das Reich des Kaisers und des Papstes, nach Müntzers Argumentation in seiner AUSLEGUNG DES UNTERSCHIEDS DANIELIS 49 die tönern-eisernen Füße von Nebukadnezars Traumfigur, werden durch den Stein, das Reich Christi, der ohne menschliches Zutun vom Berg gerissen wird, zerstört werden. 50 Ohne menschliches Zutun ("an handt") bedeutet aber für Müntzer nicht, daß der irdische Entscheidungskampf gegen diese Reiche ohne Waffen geführt werden so11. Die Zerstörung der Gottlosen ist die Aufgabe weltlicher Macht, schließt er aus dem 13. Kapitel des Römerbriefes. ${ }^{51}$ Wo aber die weltlichen Herrscher mit dem "römischen Antichrist" verbündet sind, muß, wie in den mythischen Zeiten Nebukadnezars ein "neuer Danie1" aufstehen und sie auf ihre eschatologische Aufgabe hinweisen. Wenn sie sich jedoch dieser Aufgabe und den Warnungen des neuen Danie1, a1so Müntzers, widersetzen, so müssen sie ohne Gnade vernichtet werden durch die "ernsten Knechte Gottes" 52 Die Revolution und die Vorbereitungen für das bevorstehende Millennium fallen letztlich nach Müntzers Daniel-Auslegung ihm und seinen Anhängern $z u$, wenn die Fürsten ihre eschatologische Rolle nicht spielen wollen.

"Wir w81len zurbrechen yren bundt." Mythos und Realität vermischen sich in Müntzers Sprache zur utopischen Hoffnung. Utopisch an dieser Hoffnung ist jedoch nicht ihre historisch bedingte eschatologische Komponente, sondern ihr sozialkritischer Aspekt, der immer dort mitschwingt, wo Müntzer gegen die Herrschenden für das Volk, die Städter, Handwerker und Bauern spricht. Das "wir" in Vers 3 der Müntzerschen Psalmenübersetzung auf ihn und seine Anhänger zu beziehen, ist zumindest eine nicht unwahrscheinliche Deutungsmöglichkeit. Müntzer ist in seiner Allstedter Gottesdienstordnung von 1523, als Luther noch keine deutschsprachige Messe für Wittenberg in Druck gegeben hatte 53 , vorsichtig genung, bei seinen Psalmenübersetzungen mehrere Deutungsmöglichkeiten offen zu lassen. Erst in seiner Fürstenpredigt vom 1.Juli 1524 gibt er eindeutige Kommentare, u.a. auch zu diesem Psalm. Zu fragen ist, ob es ein Merkmal der praktischen Sprache der Utopie gegenüber ihrem zeitgenössischen Sprachhintergrund ist, zunächst mehrdeutig $\mathrm{zu}$ bleiben und erst mit dem Fortschreiten utopischer Gewißheit schärfere semantische Konturen $z u$ zeichnen. Auch Thomas Morus versteckte sich, was die praktische Anwendbarkeit seines Modellstaates betrifft, hinter einer mehrdeutigen Ironie, die bis heute einen Interpretationsstreit darüber hervorgerufen hat, ob die UTOPIA ein satirischer Humanistenspaß oder ein ernstgemeintes Revo1utionsmode11 sei. Bei Luther gibt es derartige Interpretationsvarianten in seiner Obersetzung nicht. Obera11, wo Müntzer Bibeltexte als Belege für seine"Theorie"der Revolution anführt, versteht Luther dieselben Texte eindeutig gerade als das Gegenteil, nämlich als Aufforderung zum geduldigen Ertragen welticher Tyrannei und zum Warten auf die Rache aus der Transzendenz, der alle Veränderung der Verhältnisse überlassen werden so11. Sein Danielkommentar ${ }^{54}$ klingt anders als der Müntzers. Wo Müntzer den zerstörenden Stein des Nebukadnezar-Traumes als revolutionäre Gewalt im Dienst der göttlichen Kraft und Rache interpretiert ("sie haben das lant nicht durch das schwert gewonnen, sonder durch die krafft Gottis, aber das schwert war das mitte1" ${ }^{55}$, billigt Luther die Rache allein der göttlichen Macht $z u$ und verurteilt jedes menschliche Einschreiten gegen die weltichen Zustände als gotteslästerliche Eigenmächtigkeit. Vielmehr habe man sein Los in Geduld zu tragen und sich nicht gegen unhaltbare gesellschaftliche Zustände zu wehren: "Darumb sollen wir solche Tirannen nicht allein gedültiglich leiden / sondern auch vns jres künfftigen vrteils erbarmen / vnd für sie hertzlich bitten."56 
Luther entrückt die Konsequenzen aus seiner Gesellschaftskritik zeitlich und räumlich aus dem menschlichen Verfügungsbereich. Die Emigration in innere Moralität, nicht die Moral der Revolution wird von ihm beschworen. Auf diese Weise werden alle Bibelstellen, die als Aufruf zur Revolte und zur Errichtung besserer Zustände interpretierbar wären, von Luther entschärft und als Hoffnung auf die Utopie jenseits der historischen Wirklichkeit interpretiert. Selbst wenn man bedenkt, welchen hohen Realitätsgrad eine solche Verheißung am Beginn des 16. Jahrhunderts noch oder wieder hatte, war doch eine unmittelbare Gefahr für den gesellschaftlichen status quo daraus nicht abzuleiten. Sie bot eher, realpolitisch gesehen, den Legitimationshintergrund für eine Verurteilung jeglichen revolutionären und utopischen Bewußtseins. Eine solche Verurteilung betreibt Luther 1525 in seiner Schrift WIDER DIE RAUUBERISCHEN UND MORDERISCHEN ROTTEN $D E R$ BAUERN. 57 Seine wiederholte Mahnung "gebt dem Keyser / was des Keysers ist" 58 und seine Interpretation des 13. Römerbriefkapitels zeichnen Luther mit seiner Auslegungsweise deutlich als einen Verteidiger der sich etablierenden Fürstenmächte in Deutschland aus. Thomas Müntzer dagegen leitet aus ebendemselben Kapitel seinen Anspruch auf die Revolutionierung auch der gesellschaftlichen Verhältnisse ab. 59 So dient ihm dieser Text u.a. auch als Belegstelle für seinen Kampfaufruf an die Allstedter vom April 1525.

Dort,wo der gleiche Ausgangstext zwei Interpretationen erfährt, die einander absolut ausschließen und negieren, ist die Sprache seiner Interpreten nicht die gleiche. Hier beginnen die literar-historisch kaum nachvollziehbaren Nuancen der Andersartigkeit einer Sprache der praktischen Utopie. An diesem Punkt aber beginnt auch die Sprache einer Utopie, die ihren neuen Anfang nicht in die Transzendenz oder eine ästhetische Fiktion entrückt, sondern ihn in die Realität von gesellschaftlichen Verhältnissen und deren Sprache mit hineinnimmt, den gegenutopischen Kräften (d.h. denen, die einen bestimmten gesellschaftlichen status quo garantieren) gefährlich $z u$ werden. Zerstören und bauen, war Müntzers utopisches Programm, das er nach seinen Predigten, Briefen und Taten zu urteilen, wörtlich aufgefaßt hat. Luther schreibt $z$ denselben Jeremiasworten als Randkommentar seiner Bibelausgabe von 1545: "(Verstören) Nicht durch krieg / Sondern mit predigen vnd weissagen."60 Aus dieser grundsätzlich verschiedenen Haltung zum Problem der ge- sellschaftlichen Veränderung ergeben sich alle weiteren semantischen wie grammatischen Unterschiede in der Obersetzung und Interpretation des zweiten Psalms durch die beiden Reformatoren. Müntzer führt in seiner Obersetzung des Psalms wie auch in anderen Bibe1zitaten alle erzählten Ereignisse direkt auf seine Gegenwart zurück, während Luther in seinen Vorworten und im Bibeltext zunächst mehr auf die historische Situation besonders der alttestamentlichen Texte hinweist, ehe er sie in seine Polemik gegen die Papstkirche mit einbezieht. So schreibt er in Vers 2: "Die Könige im Lande", und meint damit das Land Israel des Alten Testaments. 61 Müntzer spricht dagegen von den "Königen und Fürsten der Erde", also von allen, auch den gegenwärtigen. Man beachte weiter den unterschiedlichen Gebrauch des Tempus: Müntzer sagt: sie haben sich verschworen, Luther: sie Zehnen sich auf. Luthers Präsens kann im Zusammenhang mit seiner Interpretation (vg1.Anm.61) durchaus als historisches Präsens aufgefaßt werden. Müntzers Perfekt läßt jedoch neben Luthers Interpretation auch die Möglichkeit einer gegenwärtig geschehenen Handlung $\mathrm{zu}$. Seine Obersetzung ist so angelegt, daß der Psalmtext im historischen Rahmen des Alten Testaments, aber auch aktuell interpretiert werden kann. Trotz oft fast gleichlautendem Text beider Obersetzungen wird im folgenden der Sinnunterschied immer größer. Für Luther ist der Spott Gottes in Vers 4 über die Verschwörung gegen ihn ein Trost für alle Gläubigen: Gott wird sie rächen; sie aber müssen alle "Obel der Welt" solange geduldig ertragen, bis "sein Tag kommt". Schon hier schließt Luther also die Möglichkeit eigenen historischen Handelns vollkommen aus. Für Müntzer aber ist dieser Satz im Zusammenhang mit seiner vorausgegangenen Obersetzung nur eine Bestätigung dafür, daß Gott mit einem babylonischen Urteil gegen die fürstlichen Gottesfeinde ("er wird sie in seinem Grimm aerstreuen") auf der Seite des Aufstandes stehen wird. Der Hinweis auf Babylon fehlt bei Luther. Statt zerstreuen übersetzt er schrecken und interpretiert: "denn äußerlich wird er sie im Kampf " (allerdings ohne menschliche Hilfe), "innerlich durch Furcht verzehren." Auch für Müntzer sind die Fürsten eine Geißel Gottes zur Bestrafung für ein unchristliches Leben des Volkes. 62 Während Luther jedoch nur diesen einseitigen Weg indirekter Gottesstrafe kennt, 63 läßt Müntzer umgekehrt auch das Volk als Strafe für die gottlosen Regenten auftreten. 64 Dieses Gottesgericht geschieht bei Luther in unbe- 
stimmter Zeit: morgen oder einst. ${ }^{65}$ Bei Müntzer fehlt das einst in Vers 5 , und sein reines Futurum rückt das eschatologische Geschehen näher an die historische Wirklichkeit.

Die Verse 6 bis 9 beziehen sich auf Christus und seine eschatologische Reichsutopie. Müntzer $1 \ddot{\beta}$ t Christus in diesen Versen durchgehend sprechen. Bei Luther wechselt die Rede zwischen Gott und Christus. Allein durch die verschiedene Verteilung der Sprechrollen ergeben sich erhebliche Interpretationsunterschiede, die sich auf die gegensätzlichen theologischen Positionen der beiden Reformatoren beziehen. In Vers 8 und 9 läßt Müntzer dem Satzsinn nach Christus mit Gott sprechen, bei Luther redet Gott mit Christus. Daraus ergibt sich als Subjekt von Vers 9 bei Müntzer Gott, bei Luther Christus. In Müntzers Obersetzung fordert Christus Gott auf, sie, die Feinde, mit einer "eisernen Stange zu zerknirschen". In Luthers Text fordert umgekehrt Gott Christus auf, die Feinde mit seinem "Zepter" zu zersch1agen, und er kommentiert:

Hier muß man wiederum die Träume des Fleisches weit weg tun, daß nicht jemand sich einbilde, das Reich Christi könne mit Eisen und Waffen bereitet oder erhalten werden, wo doch geschrieben steht I...I 2.Kor.10 (4): unsere Waffen sind nicht fleischlich. I...IOder warum verfolgen wir dann nicht auch die Bösen in unseren eigenen Reihen mit dem Schwert, vor allem die großen Hansen unter den Völkern? Aber das sei ferne!66

Luther faßt den Satz: "Du sollst sie mit einem eisernen Zepter zerschlagen", vollständig als Allegorie auf und deutet den Begriff "Zepter" a1s Wort Gottes, "mit dem Gott die Erde d.h. die, die nach Irdischem trachten, schlägt." Zerstörung wird vom Gewaltakt zur geistigen Wandlung uminterpretiert, und Luther versteht darunter Umwandlung einer "schlechten Gestalt in eine Gott wohlgefällige (geistige oder moralische) Gestalt." Einen Aufstand gegen weltliche Zustände lehnt er (bereits 1519)67 ausdrücklich ab. Dadurch daß Luther Christus a1s Satzsubjekt setzt, ergibt sich sinngemäß, daß Gott Christus bereits den Auftrag zur Zerstörung, d.h. zur Umwandlung der Gottlosen, und zur Bestimmung des Endgerichts ("So will ich dir der Welt Ende zum Eigentum geben") gegeben hat. Keiner also außer Christus ist im Auftrag Gottes handlungsberechtigt zur Veränderung irdischer Zustände. Diese z.T. neutestamentlich orientierte Interpretation des Psalmtextes ermöglicht es Luther, gegen jede Revolution, die von weltlicher Seite ausgeht, fürstliche Vergeltungsschläge als Ordnungsmaßnahme im Sinne göttlicher Zucht $z u$ rechtfertigen.

Müntzer setzt Gott als Satzsubjekt ein und erhält so einen von Luthers Interpretation sehr verschiedenen Sinn: Christus bittet in Müntzers Obersetzungsvariante, Gott solle die Feinde mit einer eisernen stange zerbrechen. Damit bleibt Christus in einer Vermittlerrolle und das Zerstörungswerk in der Hand Gottes. Der bedient sich allerdings nach Müntzers Danie1Auslegung des Menschen, d.h. einer auserwäh1ten Schar "wahrer" Christen. Sie sind Gottes "eiserne Stange", die die Revolution - den Begriff der Zerstörung nimmt Müntzer wörtlich - im Auftrag Gottes auf der Erde beginnen, um das Reich Christi zu errichten.

Man muß das unkraut Idie gottlosen Regenten und Pfaffen I außreuffen auß dem weingarten Gottis in der zceyt der erndten I...I Die engel aber wilche yre sicheln darzu scherffen, seint die ernsten Knechte Gottis, die den eyfer gotlicher weysheit volfüren, Malachie 3.68

Kurz vor der entscheidenden Schlacht bei Frankenhausen, die den Bauernaufstand in Thüringen blutig beendet, schreibt Müntzer am 12. Mai 1525 an Graf Enst von Mansfeld:

Das du auch wissest, das wyrs gestrackten bevell haben, sage ich: Der ewigke lebendige Got hatz geheissen, dich von dem stull mit gewalt uns gegeben $z$ u stossen I...I.69 Der Auftrag zur "Revolution" ist nicht wie bei Luther an Christus, sondern an die Auserwäh1ten des Müntzerschen Bundes gegangen. Ihnen ist die Errichtung der Utopie aufgetragen, und in diesem chiliastischen Bewußtsein bewegt sich die Sprache Thomas Müntzers. Ein gleiches oder zumindest ähnliches sprachliches Bild (eisernes Zepter, eiserne Stange) funktioniert in zwei verschiedenen semantischen Kontexten, einmal als Allegorie der inneren Reinigung und einmal als utopisches Symbol der Revolution. Die Drohung in Vers 10 und den Schluß des Psalms interpretiert Müntzer seiner Deutung entsprechend folgerichtig: Seht euch vor, ihr Herrschenden, daß ihr gerecht seid gegenüber euren Untertanen ("recht urteil fellen") . Wenn ihr nicht die "zucht ergreyfft", d.h., wenn ihr euch nicht belehren laßt (züchtigen = erziehen, lehren $)^{70}$ und Gott mit Furcht dient, dann wird sein Zorn und sein Gericht über euch in kurzer Zeit losbrechen. Luther deutet den Sinn des Psalmschlusses folgendermaßen: "Sorgt, daß ihr gläubig werdet" und "küsset den Sohn, daß er nicht zürne. Denn sein Zorn (nicht Gottes) wird bald anbrennen"(vg1. Lutherkommentar). Nicht Gott richtet hier durch Menschenhand, sondern Christus allein, aber der Tag seines Gerichts ist nicht sicher bestimmbar. 71 Müntzer dagegen handelt jetzt und sofort im Bewußtsein des "utopischen Augenblicks", d.h. in der Gewißheit, daß das Millennium jeden Moment anbrechen müsse und er zu dessen Errichtung' durch Ånderung der gesellschaft1ichen Verhältnisse auf Befehl Gottes beizutragen habe. In seiner Sprache, das zeigt der semantische 
Hintergrund seiner Psalmübersetzung und anderer Bibelstellen deutlich, versteht sich die chiliastische Utopie als vor allem auch diesseitiges "sozialrevolutionäres" Ereignis..$^{72}$ Eine Verlegung der Utopie in ein versprochenes Jenseits lassen die Semantik von Müntzers Sprache und seine Deutung mythisch-christlicher Bilder nicht $z u$, was nicht bedeuten muß, daß Müntzer die Existenz eines Jenseits bezweifelt hätte. Seine Gewißheit schafft eine Sprache, deren Semantik auf Veränderung der bestehenden Verhältnisse abzielt. Sie setzt die oben interpretierten Psalmzeilen in die Sprache einer anhebenden Utopie um. Es ist dieser "revolutionäre" Sinn seiner Sprache, die im Gottesdienst gesungen und gelernt werden sol1, der seine deutschen Messen zu "verbotenen" Messen werden 1 äßt. ${ }^{73}$

Die praktische Sprache der Utopie hat die Realisierung des utopischen Zustandes direkt vor Augen. Sie muß ihn nicht erst literarisch ins Bild setzen. Sie sieht deshalb keine Veranlassung, ihn näher zu definieren, wie es der utopische Roman in seinen Beschreibungen versucht. Sie selbst ist ein schon realisierter Teil der Utopie. Bei Morus übernahm das "utopische Symbol" die Funktion der Bedeutungserweiterung von Wörtern. Diese Symbole sprengten die "horizontale einfache Satzsemantik" durch das Abrufen von Erinnerungen an Mythen, die bestimmte gesellschaftliche Wunschvorstellungen treffen. In den Müntzerschen Texten wird die semantische Erweiterung von Wörtern - abgesehen von der Einbeziehung der biblischen Mythen - durch das Bewußtsein des Autors bewirkt, im Auftrag einer alles beherrschenden, überirdischen Macht und in einem besonderen historischen und heilsgeschichtlichen Augenblick zu handeln. Aber bereits die semantische Erweiterung von Wörtern, wenn diese Erweiterung auf soziale Veränderung zielt, kann als Strukturprinzip utopischer Sprache angesehen werden. Inhaltlich beliebige sprachliche Bedeutungserweiterungen von Wörtern sind dagegen Merkmale jeder literarischen Sprache und müssen nicht unbedingt utopisch sein.

Die Interpretation der biblischen Mythen durch Müntzer zeigt bis in die Einzelheiten der Wortsemantik seine spezielle utopische Auffassung vom biblischen Vokabular. Am deutlichsten wird der Unterschied zwischen Müntzers utopischer Sprache und Luthers Sprache in der Bedeutung, die beide dem Wort "Zerstörung" beimessen. Bei dem einen bedeutet es die Realisierung historisch-gesel1schaftlicher Veränderung im Hin- blick auf eine größere soziale Gerechtigkeit. Der andere interpretiert es als inneren Sinneswandel. Die Semantik der Sprache der Revolution und die der Sprache des Establishments ${ }^{74}$ benutzen beide das gleiche Zeichensystem, ein Umstand, der aus Gründen der Profilierung des jeweils eigenen Standpunkts gegenüber dem gegnerischen die Denunziation der gegnerischen Meinungen erheblich verschärft. Auch das mag ein tieferer Grund für die kräftigen, für uns nur noch mit Vergnügen $z u$ lesenden gegenseitigen Beschimpfungen der beiden Reformatoren sein.

In der Sprache der Müntzerschen Utopie wird mythisches Geschehen als zu bestimmten Zeiten wiederholbar verstanden. Das ist ein gegenüber der historischen Konstellation des Thüringischen Aufstandes allerdings nicht wesentlicher Grund für Müntzers Scheitern. Vielleicht erklärt es aber seine zuweilen unerklärliche Fehleinschätzung der historischen Situation. Im Kampf für die konkreten Einzelbelange der verschiedenen aufständischen Gruppen von 1525 , von denen einige nachdrücklicher von Müntzers Müh1hausener Mitstreiter Heinrich Pfeiffer vertreten wurden, ${ }^{75}$ gingen Müntzers globalere Pläne in der konkreten Situation des Kampfes weitgehend verloren (er beabsichtigte die Organisierung eines überregionalen, zentral geleiteten Aufstandes, der sich schließlich über die gesamte Christenheit erstrecken sollte $)^{76}$. Auch Müntzer wußte woh1, daß sich, realpolitisch gesehen, mythisches Geschehen nicht direkt realisieren läßt, wohl aber eine Änderung sozialer Verhältnisse unter dem zeitgemäßen Aspekt einer mythisch-utopischen Heilsgeschichte.Das erste ist der historisch-subjektive Teil der Müntzscherschen Hoffnung. Das zweite ihre eigentlich utopische Seite. Die Sprache der Müntzerschen Utopie, die entsprechend seiner Entwicklung zum offenen Revolutionär, einen neuen Daniel, einen neuen Jeremias und zuletzt einen neuen Gideon beschwört, verliert nie ihren sozialpolitischen Bezug. Allerdings zielt sie auf einen Horizont, der für seine Mitstreiter kaum in seiner ganzen antizipatorischen Dimension erfaßbar war. Sein atemloser Ruf an die Allstedter und die mansfeldischen Berggesellen zum Kampf für die Errichtung der Utopie ist in einer Sprache geschrieben, die beide Seiten seiner Hoffnung, die utopische und die historisch bedingte, deutlich akzentuiert.

Wie lange schlaft ir? I... I fanget an und streytet den streyt des Herren! Es ist hoch zeyth I...I der meyster will spiel machen, die böBwichter mussen dran. I...I Wan euer nuhr drey ist, die in Gott gelassen allein 
seynen nahmen und lehre suchen, werdet ir hundert tausent nit furchten. Nuhn dran, dran, dran, es ist zeyt I... Es ist uber dye mas hoch hoch von noethen. Dran, dran dran! I...I Wir mussen nit lenger slaffen. I...I Ir must dran, dran, es ist zeyt. I...Igehet forne an den tanz! I...I Dran, dran, dyweyl das feuer hay $B$ ist. Lasset euer schwerth nit kalt werden, lasset nit vorlehmen! Schmiedet pinkepanke auf den anbossen Nymroths werfet ihne den thorm zu bodem! Es ist nit mugelich, weyl sie leben, das ir der menschlichen forcht soltet lehr werden. I...I Dran, dran, weyl ir tag hebt, Gott gehet euch vor, volget, volget! $[$...I es ist nit euer, sondern des herrn streyt I...I. ${ }^{74}$

Diese Sprache rüttelt wach. Sie treibt ins Mythisch-prophetische, zeigt dauernd auf die anbrechende Utopie. Ein leichtes Spiel scheint da die Umwandlung aller irdischen Verhältnisse. Dagegen aber finden sich konkretere Stellen, die klar sagen, was das Wachrütteln sol1: "Schmiedet pinkepanke auf den Ambossen Nimrodd". Auch hier ist biblischer Mythos ins Bild gesetzt, aber die Ambosse Nimrods sind nicht mehr die Geschlechter und Fürsten aus den alttestamentlichen Reichen, 78 sondern die deutschen Fürsten, und der babylonische Turm ist das Symbol ihrer Macht.

Die soziale Revolution Müntzers bleibt untrennbar mit seinem mythisch-chiliastischen Traum verbunden. Sie scheitert weniger an der Einbeziehung des Mythos in seine revolutionäre Konzeption, sondern an den erst aus der historischen Entfernung überschaubar werdenden historischen Umständen.$^{79}$ Seine Sprache zeigt seinen Weg von der Revolution der Theologie in den Messübersetzungen zur Theologie der Revolution in seinen letzten Briefen. Die Entwicklung einer Sprache der Utopie, des utopischen Augenblicks, außerhalb des Romans, die historisch wirksam werden konnte, ohne in ein ästhetisch kalkuliertes Medium verpackt $z u$ werden, war ihm für den Augenblick gelungen. Diejenigen, die er ansprach, hörten ihm $z u$, verbündeten sich mit ihm zum Kampf für eine bessere Welt oder verschworen sich gegen ihn. Damit werden die Reaktionen auf seine Sprache für lange Zeit zum Indikator für utopisches oder gegenutopisches Bewußtsein.

Der historische Augenblick war für die Sprache Müntzers, für die Sprache seiner Utopie, günstig, allerdings nicht für ihre ziele. Dennoch, in keiner späteren Revolution, auch nicht im gleichen Maß in der Französischen, hat Sprache eine ähnlich unmittelbare Wirkung erzielen können.

Utopisches Sprechen kann zum einen revolutionäres Handeln begleiten und zum anderen im Bereich der Ästhetik 1iterarische Bilder zu utopischen Bildern machen. In der "Predigt" wie im Roman stützt es sich auf mythische
Bilder. Sie durchziehen unabhängig von der außeren Gattung ihrer Kontexte, konstant in ihrer Intention, die gesamte utopische Literatur bis zur Gegenwart. Sie können aber auch vö1lig abgelöst von eindeutig utopischen Texten in allen möglichen textlichen Zeugnissen auftreten. In Romanen von Goethe und Eichendorff bis hin zum modernen, zeitgenössischen Roman treffen wir auf diese Symbole, immer wieder anders ausgestaltet, aber immer wieder auf das gleiche zielend. 


\section{ANMERKUNGEN. (I.Thomas Morus)}

1. Max Horkheimer: Die Utopie. In: Anfänge der bürger lichen Geschichtsphilosophie. Frankfurt 1971, S. 64: "In der Tat hat die Utopie zwei Seiten; sie ist die Kritik dessen, was ist, und die Darstellung dessen, was sein soll. Die Bedeutung liegt wesentlich im ersten Moment beschlossen. Aus den Wünschen eines Menschen kann man auf seine wirkliche Lage schließen; durch das glückliche Utopien des Morus scheint der Zustand der Massen in England hindurch, deren Sehnsucht der humane Kanzler gestaltet hat."

2. Nach den Romanpoetiken vor allem des 18.Jh.s muB auch die Darstellung einer utopischen Welt wahrscheinlich bleiben. (Vgl. dazu W.Voßkamp: Theorie und Praxis der literarischen Fiktion in J.G.Schnabels Roman "Die Insel Felsenburg". In: GRM NF 18,1968, 131-152 und Peter Uwe Hohendahl: Zum Erzählproblem des utopischen Romans im 18.Jh. In: Gestaltungsgeschichte und Gesellschaftsgeschichte. Hrsg.v. K.Hamburger und H. Kreuzer. Stuttgart 1969.) Der Reisende hat im utopischen Roman die Funktion eines erzählerisch wahrscheinlichen Verbindungsgliedes zwischen utopischer und realer Welt. (Zur Funktion des Reisenden im utopischen Roman vgl. u.a. Hans Ulrich Seeber: Wandlungen der Form in der literarischen Utopie. Göppingen 1970.)

3. Vgl. dazu: The Complete Works of St. Thomas More. Bd.4: Utopia. Hrsg.v. E.Surtz u.J.H.Hexter. New Haven, London 1965 , S. 301

4. Thomas Morus: Utopia. tbers.v.Gerhard Ritter. Mit einer Einleitung v.Hermann Oncken. Darmstadt 1964 S.10-11

5. Platon: Politeia, Buch V, Kap.18: $473 c-d$

6. Morus: Utopia/Ritter, a.a.0., S.28-35

7. Dass., a.a.0.,S.35-38

8. Platon: Gorgias .Sämtl.Werke, Hieron .Muller.Lpz.1854, Bd.2, SS.497,504 (521ff).

9. Platon: Phaidros, ebd.,Bd.4,S.155 (274): "Vermöchten wir aber selbst Das Idas Wahrel aufzufinden I...I."

10. Isokrates: $\rightarrow$ Seigel, S.XV. To Niccocles 41; Loeb. Edn. I,63. In: J.E.Seigel: Rhetoric and Philosophy in Renaissance Humanism. Princeton 1968, S.XV.

11. Morus: Utopia/Ritter, a.a.0.,S.38

12. Vgl. dazu u.a. die gegensätzlichen Interpretationen von Surtz und Kautsky: E.Surtz: Utopia as a Work of Literary Art. - Sources, Parallels, and Influences. - J.H.Hexter: Utopia and Its Historical Milieu. In: Thomas Morus. The Complete Works, etc. Bd.4, Introduction. - Karl Kautsky: Thomas More und seine Utopie. Mit einer historischen Einleitung. Suttgart 1888, Neuaufl. Berlin 1947, weitere Neuauflagen.

13. Morus: Complete Works, Bd.4: Utopia, a.a.0.,S.110

14. Dass., a.a.0.,S.385

15. Vgl. dazu Leone L. Halkin: Mithra dans I'"Utopie". In: Moreana, 31-32,1971, S.157-159

16. Vgl. dazu Porphyrios: Schriften zu Religion und

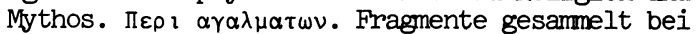
Bidez: Vie de Porphyrios. Pauly-Wissowa, 22,1; 275313

16a.Siehe Anm.4, Kap.II.

17. Morus: Utopia/Ritter, a.a.0.,S.16-19

18. Dass., a.a.0.,S.20

19. Ebd.,S.111

20. Ebd.,S.113: "Als Raphael so erzählt hatte, kam mir vielerlei in den Sinn, was mir an den Sitten und Gesetzen jenes Volkes überaus sonderbar erschienen war I...I vor allem auch in dem, was die eigentliche Grundlage ihrer ganzen Verfassung ist, nämlich in ihrem gemeinschaftlichen Leben und der gemeinschaftlichen Beschaffung des Lebensunterhaltes ohne allen Geldverkehr. Wird doch allein schon durch diese eine Verfassungsbestimmung aller Adel, alle Pracht, aller Glanz, alle Würde und Majestät I...I des staatlichen
Lebens von Grund auf umgesturrzt."

21. Desiderius Erasmus: Mörias enkömion seu laus stultitiae. Straßburg 1511.- Dt.: Das Lob der Torheit. Eingel.u.m.Arm.vers.v. Wendelin Schmidt-Dengler. In: Erasmus-Studienausgabe. Bd.II. Darmstadt 1975

22. Vgl. Zitat u.Arm.2O

23. Edward L.Surtz: The defense of pleasure in More's Utopia. In: Studies in Philology, XIVI, 1949. Ders.: Epicurus in Utopia. In: English Literary History, Baltimore 1949. - Neuerdings vgl. auch M.-M. Lacombe: La sagesse d'Epicure dans l'Utopie de More. In: Moreana 31-32,1971, 169-182

24. Morus: Utopia/Ritter, a.a.0.,S.58

25. Dass. ,a.a.0., , .72

26. Ebd. ,S.73

27. Ebd. , S. 75

28. Ebd., S. 76

29. "Epikur findet es nicht richtig, daß sie Idie MenschenI ihre Güter gemeinsam besitzen sollen, wie es die Grundsätze des Pythagoras über den Besitz bei Freunden verlangen." (Vgl. dazu E.Surtz: The praise of fleasure. Cambridge 1957) - Zu Epikur vgl. Pauly-Wissowa 61,154-55: "Staat und Gesellschaft wuirden sich vortrefflich befinden, wenn nur alle ihre Mitglieder zielbewußte und virtuose Egoisten wären. Dann wären Gesetze überhaupt nicht erforderlich." - Diese grundlegende Auffassung Epikurs vom Staat schließt an sich schon jede kollektivistische Konzeption aus.

30. Morus: Utopia/Ritter, a.a.0.,S.69

31. Herbert Marcuse: Triebstruktur und Gesellschaft. Frankfurt 1955; 1971,S.152

32. Morus: Utopia/Ritter, a.a.0.,S.65

33. Dass., a.a.0., s.62-64

34. Amerigo Vespucci: Cosmographiae introductio. Insuper quatuor Americi Vespucii navigationes. St. Dié 1507

35. Amerigo Vespucci, ebd., I, sig. c1v. (tbers.v.Verf.)

36. Pietro Martire d'Anghiera: De rebus oceanicis et orbe novo. Granada 1516, Decad. I,3. (thbers.v.Verf.)

37. Die amerikanische Entdeckungsgeschichte ist voll von diesen"Mißverständnissen". So zog der Aztekenkönig Montezuma II. (1502-1520) persönlich und ohne Waffen seinem Eroberer Cortés entgegen, um irm zu huldigen. Er hielt inn für den Gott und Priester der gefiederten Schlange, Quetzalcoatl, der einst über das Meer geflohen war, aber nach der Sage versprochen hatte, eines Tages von dort zurulckzukehren. Der Stadthalter des Cortés, Pedro de Alvarada, richtete kurze Zeit darauf in der den Spanierm von Montezuma kampflos überlassenen Hauptstadt, Tenochtitlán, ein Blutbad an, um sich der goldenen Halsketten und Armbänder der Einwohner zu bemächtigen.

38. Morus: Complete Works, Bd.4: Utopia, a.a.0.,S.150, 152,154

39. Ernst Bloch: Gesamtausgabe Bd. 13: Tübinger Einleitung in die Philosophie. Frankfurt 1977, S.99 (: Utopie in Archetypen und Werken)

40. Morus: Complete Works, Bd.4: Utopia, a.a.0. ,S.18-19 (Übers.v.Verf.); vgl. die Abb. vor S.VII

41. Vgl. dazu Hans Georg Soeffner: Der geplante Mythos. Hamburg 1974

42. Morus: Utopia/Ritter, a.a.0., S.78: "Ich denke mir nämlich, dieses Volk muß von den Griechen abstarmen, weil ihre Sprache, die im übrigen fast persisch klingt, noch einige Spuren der griechischen Sprache

43. Morus: Utopia/Ritter, a.a.0.,S.10

44. Nicolas Edme Restif de la Bretonne: La découverte australe par un homme-volant. Paris 1781

45. Louis Sébastien Mercier: L'an deux-mille-quatre-centquarante. Rêve s'il en fût jamais. London, Paris 1770. 
46. Cuccagna - Cocagna - Cocagne oder Cocaigne: dem Schlaraffenland ähnlicher, märchenhafter Ort des Utberflusses in den italienischen, spanischen und französischen Volkssagen.

47. Morus: Utopia/Ritter; Einleitung v.H.Oncken, a.a.0.,S. 32* und Text, S. 43, Anm.1

48. Morus: Utopia/Ritter, a.a.0.,S.43

49. Dass., a.a.0.,S.43: "Ubrigens war dieses Land, wie berichtet wird und wie der Augenschein deutlich zeigt, in alter Zeit noch nicht rings vom Meere umgeben. Vielmehr hat erst Utopus I...I das Land zur Insel gemacht."

50. Zum Motiv und Symbolcharakter der Insel in der Literatur vgl. Horst Brunner: Die poetische Insel. Inseln und Inselvorstellungen in der deutschen Literatur. Stuttgart 1967

51. Paul Watzlawick, Janet H.Beavin, Don D.Jackson: Menschliche Kommunikation. Formen, Störungen, Paradoxien. Berm, Stuttgart, Wien 31972; hier: digitale und analoge Kommunikation S.61-68

52. Hans-Georg Soeffner: Der geplante Mythos, a.a.0., S.170. - Vgl. dazu auch den gesamten Abschnitt 3. "Digitale" und "analoge" Sinnübermittlung dieser vielleicht interessantesten Arbeit zur Utopie in den letzten Jahren. - Vgl. dazu ebenfalls Jürgen Habermas: Der Universalitätsanspruch der Hermeneutik. In: Theorie-Diskussion. Hermeneutik und Ideologiekritik. Frankfurt 1975, S.120-159; hier: Zur Funktion der Paläosymbole, S.142-150: "Paläosymbole sind nicht in ein grammatisches Regelsystem eingefugt. Sie sind keine geordneten Elemente und treten nicht in Zusammenhängen auf, die grammatisch transformiert werden können. Man hat deshalb die Funktionsweise dieser vorsprachlichen Symbole mit der von Analogierechnerm im Unterschied zu der von Digitalrechnerm verglichen. Schon Freud hat in seiner Traumanalyse das Fehlen der logischen Beziehungen bemerkt. Er weist insbesondere auf die Oppositionsworte hin, die auf sprachlichem Niveau noch die genetisch ältere Eigentümlichkeit einer Vereinigung logisch unvereinbarer, nämlich konträrer Bedeutungen bewahrt haben. I...I Obgleich die Paläosymbole eine vorsprachliche Grundlage der Intersubjektivität des Zusammenlebens und Miteinanderhandelns darstellen, erlauben sie keine im strikten Sinne öffentliche Kommunikation. Denn die Konstanz der Bedeutungen ist gering und die privaten Bedeutungsanteile erheblich: sie verbürgen noch keine intersubjektiv verbindliche Identităt der Bedeutungen."

53. Hans-Georg Soeffner: Der geplante Mythos, a.a.0., S.184-185

54. Als Säulen des Herkules gelten nach der griechischen Mythologie die Felsen von Gibraltar und Ceuta am Ausgang des Mittelmeeres, das in der Antike auch das Ende der Welt war. Ebenfalls als Säulen des Herkules werden zwei Säulen im Tempel von Cadiz bezeichnet. Die Warnung: "Non plus ultra" auf den Säulen war für diejenigen bestimmt, die es wagen sollten, aus dem bekannten Weltkreis ins Unbekannte, in den westlichen Ozean vorzudringen.

55. Francis Bacon: Instauratio magna. London 1620. Das Frontispiz -des Werkes zeigt ein Schiff, das im Begriff ist durch die Säulen des Herkules hindurch nach Westen zu fahren. Das Bild ist hier als Symbol für die Erforschung des Unbekannten zu deuten, als das Wesen der Antizipation.

56. Morus: Utopia/Ritter, a.a.0.,S.17

\section{(II. Thomas Mintzer)}

1. Die vom Papst verweigerte Scheidung von seiner ersten Gemahlin, Katharina von Aragon, wird für den anfangs streng katholischen König Heinrich VIII., der vom Papst den Titel "Defensor fidei" erhält für seine gegen Luther gerichtete und 1521 erschienene Schrift "Assertio septem sacramentorum", Anlaß und Grund zur Trennung der englischen Kirche vom Heiligen Stuhl. 1534 macht der König sich selber zum Oberhaupt der Englischen Kirche mit seiner beruihmten "Suprematsakte", die besagt, "daß der König 'justly and rightfully is and ought to be Supreme Head of the Church of England'. Fortan gab es keinen Papst mehr, man sprach nur mehr von dem Bischof von Rom. Im übrigen bedeutete die Trennung von Rom und die jurisdiktionelle Rolle des Königs als Oberhaupt der englischen Kirche keine sichtbare Veränderung der kirchlichen Organisation und der liturgisch-theologischen Substanz." (Heinrich Lutz: Der politische und religiöse Aufbruch Europas. In: Propyläen-Weltgeschichte. Berlin 1964, Bd.7, S.62-63.)

2. Philipp Melanchton: Histori Thome Muntzers des anfengers der Döringischen vffrur, seer nutzlich zulesen. Hagenaw, Durch J.Secerium Getruck (1525?)

3. Vrl. dazu vor allem die Auseinandersetzung Morus' mit Luther in Morus' "Responsio ad Lutherum". In: The Copl.Works of T.More. Bd.5. New Haven,Ldn. 1969

4. In einem Brief Morus' an Erasmus (Opus epistolarum Desideri Erasmi Roterodami. Hrsg.v.P.S.Allen u.a. Oxford 1906-1958, Bd.2, S.502) von 1516 schreibt er von einem Traum: "Du kannst Dir nicht vorstellen, wie ergriffen ich bin; ich fühle meinen Geist erweitert, und ich gehe erhobenen Hauptes einher, denn in meinen Träumen haben mich meine Utopier auserwählt, für immer ihr König zu sein; ich sehe mich nun einhergehen, gekrönt mit einem Weizendiadem, sehr eindrucksvoll in meinem Franziskanerrock, während ich, umdrängt von einem vormehmen Gefolge von Amaurotianern, ein Weizenbündel als heiligstes Zepter trage." (Zit.n. Morus, Complete Works, Bd.4, S.Ixxviii: J.H.Hexter, Utopia and Its Historical Milieu. - Ubers. v.Verf.) - Zu den Zeichen der Fürstenwürde in Utopia vgl. auch Morus: Utopia/Ritter, a.a.0.,S.85

5. Mintzer an Graf Ernst von Mansfeld. Frankenhausen, 12. Mai 1525. In: Thomas Miintzer. Schriften und Briefe. Kritische Gesamtausgabe. Unter Mitarbeit von Paul Kirm hrsg.v. Günther Franz. Gütersloh 1968, $\mathrm{Nr} .88, \mathrm{~S} .467-469$

6. Bekenntnis Thomas Mïntzers: Bekenntnis und Widerruf. 16.Mai 1525. In: Schriften und Briefe/Franz, a.a.0., S. 548

7. Bekentnus Erm Thomas Muntzers etwa pfarner zu Alstedt und itzo in dem uffrurischen haufen zu Frangkenhausen befunden, gescheen in der gute dinstags nach Cantate 1525. In: Schriften und Briefe/Franz, a.a.O. ,S.543550

8. Vgl. dazu Manfred Bensing: Thomas Müntzer und der Thüringer Aufstand 1525. Berlin 1966,S.138-39: "Miintzers Programm, nach dem während des Aufstandes gehandelt wurde, ist nicht schriftlich fixiert worden. Wir sind darauf angewiesen, die wichtigsten Grundsätze und Forderungen den Schriften und Briefen Mintzers sowie den späteren Geständnissen zu entnehmen. I... I Miintzers Gesamtprogrammatik läßt deutlich drei Teile erkennen: 1. eine Art 'Maximalprogramm', das mit dem vielumstrittenen 'Omnia sunt communia' umrissen ist, im praktischen Kampf aber keine Rolle gespielt hat; 2. eine Art 'Minimalprogramm', das für Müntzer ein zu erreichendes Durchgangsstadium absteckte und in der Forderung nach thergang der politischen Gewalt in die Hand des 'gemeinen Mannes', des Volkes, die grundlegende These besaß. Sein übergangscharakter zeigte sich in einer ganzen Reihe politischer und sozialer Maßnahmen, die das gegenwärtig Mögliche in Rechnung stellten, so beispielsweise in Zugeständnissen an jene Fürsten und Adligen, die sich dem Bund unterwarfen, die Ver- 
teilung konfiszierten Kirchengutes nicht nur an die Armen und Bedürftigen, sonderm auch an den politisch entmachteten Adel. Das alles zeigt, daß weniger die soziale Frage, als vielmehr die politische Machtfrage fur Mintzer im Vordergrund gestanden hat I...I 3. ein taktisches Program, das die Mittel und Wege zum erstrebten Zustand nannte."

Zu Miintzers utopischem Programm vgl. auch Carl Hinrichs, der mehr den urchristlich-mythischen Aspekt der müntzerschen Zielvorstellungen betont und weniger eine Differenzierung des müntzerschen Programms in einen utopischen und einen realpolitischen Teil vornimmt (Luther und Mintzer. Berlin 1952,S.20-21): "So ist Thomas Miintzer selbst offenbar der einzige geblieben, der peinlich befragt worden ist. Er hat über die Artikel, die die Bundesgenossen hätten 'auf die Wege richten wollen', also über das Programm, ausgesagt: 'Omnia sunt communia I...I'. Miintzer hat damit offenbar eine vorhergehende Ausssage erläutert, die dahin ging, er habe die Empörung darum gemacht, 'daß die Christenheit sollt alle gleich werden'. Obgleich es sich hier um Ausssagen handelt, die unter Gewaltanwendung erpreßt sind, leuchten sie doch nach Form und Inhalt als Zubehör, als notwendige Konsequenz und Schlußstein des ganzen Denkens Mißntzers derartig ein, daß man sie als Zeugnis nicht wird verwerfen dürfen. Für Müntzer war alles, was sich über Zweck und Ziel des Bundes der auserwählten wahren Gläubigen aussagen ließ, in einigen Versen der Apostelgeschichte enthalten, deren Vulgatatext in seiner Ausssage noch deutlich zu erkennen ist: 'Ormes etiam qui credebant, erant pariter et habebant omnia communia. I.... I'. IApostelgéschichte 2,44-45I I...I In diesem Bund der in gleichem Glauben verbundenen Auserwählten kann nur völlige Gleichheit und Gütergemeinschaft herrschen, eine Brulderlichkeit, die Reiche und Bedürftige nicht nebeneinander duldet. Und das nicht etwa, weil es die Autorität der Schrift so verlangt, sonderm weil der bewährte, ungedichtete Glaube, anders als der selbstsüchtige, ungeprüfte Scheinund Larvenglaube der 'Gottlosen', der aus Buchstaben der Schrift zurechtgemacht ist, und zur Sicherung der bestehenden Verhältnisse dient, sich nicht neben den Ordnungen der Welt einrichtet, um sie auf sich beruhen zu lassen, sonderm weil er als ein unittelbar von Gott bewirkter Glaube auch eine neue Wirklichkeit im Zusammenleben der Menschen hervorruft. Die Schrift bestätigt nur die aus dem neuen wahren Glauben sich von selbst ergebende Sozialverfassung, sie zeigt an, daß sich dieser Glaube der Auserwählten in tbereinstimung befindet mit der Liebes- und Brüderlichkeitsgesinnung des noch unverfälschten ersten Christenglaubens I... I Dazu gehört aber Geringachtung von Wohlleben und Besitz, auf den man $\mathrm{zu}$ verzichten I...I imstande sein mu. Das gilt auch für die Fürsten, die, wenn sie der Mahnung von Mintzers Predigt folgen, als einfache Mitglieder des Bundes mit ihren Brüderm gleichberechtigt sein werden."

9. Mïntzer an die Allstedter. Mihlhausen ca.26.od.27. April 1525. In: Schriften und Briefe/Franz, a.a.0., Nr.75, S. $455-456$

10. Vgl. dazu M.Bensing, Müntzer und der Thüringer Aufstand, a.a.0.,S.109: "Die Konzentration von Gesinnungsgenossen bei Mihlhausen spiegelt lediglich eine Seite des Bemühens wider, ein tbergewicht der eigenen Partei zu erlangen. Mit ihr war nicht mehr als ein Mittel gegeben, die weitaus kompliziertere Aufgabe zu lösen: die Massen zu gewinnen. Miintzer hat stets seiner Fähigkeit vertraut, sie zu aktivieren. I...I Der Gegner aber, dem er jetzt Inach seiner Flucht aus Allstedt in MühlhausenI gegenüberstand: Heinrich Pfeiffer Ider "Ideologe der gemäßigten bürgerlichen Oppositionsbewegung" in Mithlhausen (Bensing,S.75)I, war anderer Art. Er bediente sich der Argumente Mïntzers, knüpfte wie dieser an die gegenständlichen Wünsche und Bedürfnisse der Aufständischen an, aber er erhob zugleich deren Erfüllung und Befriedigung zum letzten Zweck des Aufstandes. Und darin konnte und durfte ihm Mintzer nicht zustimmen. Hier liegt der eigentliche tragische Konflikt des Thüringer Aufstands verborgen, der sich nicht nur äußerlich als ein solcher zwischen zwei Personen darstellte. Er resultierte tatsächlich aus der schreienden Diskrepanz zwischen den unausgereiften Verhältnissen und den
Ideen Mïntzers, zwischen dem historisch Möglichen und dem geschichtlich Notwendigen. Diesem Notwendigen kam Miintzer sehr viel näher als Pfeiffer, wenn er den Blick über die Mauern der Stadt, über die enge Landschaft hin auf ganz Deutschland und die ganze Christenheit lenkte. So sehr seine fürstenund adelsfeindlichen Predigten zündeten - der arme Bauersmann, Handwerker und Lohnarbeiter verstand Pfeiffer besser, der nicht den Adel, sondern die Berlepsch, Bültzingslöwen, Entzenberg, Westermhagen und Wintzingerode, nicht die Schlösser oder Adelsnester, sondern die Harburg und den Scharfenstein, nicht die Klöster oder Hurenhäuser, sondern die Klöster Reifenstein, Beuren und Teistungenburg zu vermichten aufrief, der nicht forderte, ferm vom eigenen Dorf, in fremden Fürstentümern für die Gerechtigkeit Gottes zu streiten, sonderm in der vertrauten Umgebung, aus der man die Beute leicht nach Hause tragen konnte."

11. Mintzer an Graf Ernst von Mansfeld. Frankenhausen, 12. Mai 1525. In: Schriften und Briefe/Franz, a.a. 0. ,Nr.88, S. 468

12. Außgetrückte emplössung des falschen Glaubens der ungetrewen welt/durchs gezeugnus des Euangelions Luce/vorgetragen der elenden erbermlichen Christenheyt/zur innerung jres irsals. Ezechie am 8.Cap. Lieben gesellen last vns auch das loch weytter machen auff das alle wellt sehen vnnd greyffen mÊ/wer vnser grosse Hansen sind/die Got also lesterlich zum gemalten mendleyn gemacht haben. Jere. am 23. Cap. Thomas Muntzer mit dem hammer Mihllhausen MDXXIIII. In: Th.Mïntzer. Schriften und Briefe/Franz, a.a.0., $\mathrm{Nr} .8$, S.265-319

13. Jeremias 23,29 (Utbers.v.1545). In: D.Martin Luthers Deutsche Bibel 1522-1546, Bd.11,1: Die Ubersetzung des Prophetenteils des Alten Testaments. (Die Propheten Jesaja bis Hesekiel). D.Martin Luthers Werke. Kritische Gesamtausgabe. Die Deutsche Bibel. Bd. 11,1. Weimar 1960,S.268-269

14. Außlegung des anderm unterschyds Danielis, deß propheten, gepredigt auffm Schlos zu Alstet vor den tetigen, thewren herzcogen und vorsteherm zu Sachsen durch Thomam Mîntzer, diener des wordt Gottes. Alstedt MDXXIIII. In: Th.Mintzer. Schriften und Briefe/Franz, a.a.0.,Nr.7, S.241-263

15. Mintzer hatte zu seiner Ausgedrückten Entblößung eine gekürzte Bearbeitung - etwas weniger scharf im Ton - verfaßt, die in einer Handschrift am 1.August 1524 in Weimar zur Zensur eingereicht wurde. Die Abschrift davon wurde am 6.8. 1524 von Herzog Johann an seinen Bruder, Kurfürst Friedrich, gesandt und trägt den Titel: Gezeugnus des erstenn Capitels des Euangelion Luce durch Thomam Munczer, der ganczenn cristenheit furgetragen zurichtenn. - Mach das loch weiter vnnd las sie alle sehenn, wer die grossen Henße seint. Ezechielis.8. Vgl. dazu Th. Mïntzer. Schriften und Briefe/Franz, a.a.0.,Nr.8B, S.266-319

16. Daniel-Auslegung. Schriften und Briefe/Franz, a.a.o., Nr.7, S.261

17. Vgl. dazu Daniel 7,27: "Aber das Reich, Gewalt vnd macht, vnter dem gantzen Himel wird dem herligen Volck des Höhesten gegeben werden, des Reich ewig ist, vnd alle Gewalt wird jm dienen vnd gehorchen." In: D.Martin Luthers Werke. Kritische Gesamtausgabe. Die Deutsche Bibel. Bd.11,2. Weimar, 1960, S.162-63

18. 1. Müntzer an Friedrich den Weisen. Allstedt,4.Okt. 1523. In: Schriften und Briefe/Franz, a.a.0.,Nr.45, SS.395-397; hier S.396-97: "Die fursten seyn den frummen nicht erschecklich. Und wen sich das wirt vorwenden, so wirt das swert yhn genommen werden und wirt dem ynbrunstigen volke gegeben werden zum untergange der gotlosen, Danielis 7 I...I." 2. Muintzer an den Schösser Zeiß. Allstedt, 22.Juli 1524. In: Schriften und Briefe/Franz, a.a.O. ,Nr.57, S.416-419; hier S.417: "Dan es ist clerlich am tage, das sye Idie TyrannenI vom christenglauben ganz und gar nichts halten. Do hat yhr gewalt auch eyn ende, sye wyrt in kurzer zeyt dem gemeinen volk gegeben werden."

3. Müntzer an die Eisenacher. Mühlhausen, 9.Mai 1525. 
In: Schriften und Briefe/Franz, a.a.0.,Nr.84, S.463464; hier S.463: "Nachdem Gott ytzt dye ganze welt sonderlich fast bewegt zu erkentmus gottlicher war heit und dieselbige sich beweyset mit dem aller ernsten eifer uber dye tyramen, wie das clerlich Daniel am VII. underschied sagt, das die gewalt soll gegeben werden dem gemeinen volk, auch ists angezaygt Apoca. am XI. ca., das das reych dieser welt soll Christo zustendigk sein."

19. Ausgedrückte Entblößung. Schriften und Briefe/Franz, a.a.0.,Nr.8A, S.267

20. Helmut Brackert: Bauernkrieg und Literatur. Frankfurt 1975, S.46-47

21. Vgl. Miuntzers Brief an die Allstedter. Mihlhausen ca. 26. od.27.April 1525. In: Schriften und Briefe/ Franz, a.a.0.,Nr.75, S.454-456

22. Vgl. dazu Buch der Richter 6 und 7; hier besonders 7, 15-23. In: D.Martin Luthers Werke. Kritische Gesamtausgabe. Die Deutsche Bibel. Bd.9,1. Weimar 1939, S.112-113: "Vnd in dem die drey hundert Man bliesen die Posaunen, schafft der HERR, das im gantzen Heer eines jglichen Schwert wider den andern war. Vnd das Heer floh bis gen Betha Sitta I...I Vnd die menner Israel I...I schrien vnd jagten den Midianiterm nach."

23. Ausgedrückte Entblößung. Schriften und Briefe/Franz, a.a.0.,Nr.8A, S.273

24. Zur zensierten Fassung der "Entblößung" vgl. Anm. 15

25. Zum Allstedter Bund Miintzers vgl. Carl Hinrichs, Luther und Mintzer, a.a.0.,S.2 u. 11ff.: "Mintzer wollte das kleine Ackerstädtchen Allstedt, das einst eine Residenz der sächsischen Kaiser gewesen war, und dessen Magistrat inn gegen Ostern 1523 zum Prediger gewählt hatte, zu einem mit dem Evangelium nach seiner Auffassung wirklich Ernst machenden religiöspolitischen Zentrum, zu einem Gegen-Wittenberg machen, von dem aus nicht nur die Volksmassen, sonderm I...I auch die kursächsische Obrigkeit für eine gewaltsame Umgestaltung aller Lebensverhältnisse nach Maßgabe des von Mïntzer ausgelegten Wortes Gottes gewonnen werden sollten. Und von dieser eroberten kursăchsischen Basis aus sollte dann schließlich die religiöse und soziale Revolutioniemung ganz Deutschlands ausgehen, wobei das Beispiel und die Macht, sowie das Ansehen, das die ermestinischen Füsten I...I auch beim 'gemeinen Mann' besaßen, zweifellos mit in Rechnung gestellt wurden. I... I Das Organ seiner Reformation ist ein geistlich-revolutionärer Bund von wahren 'Auserwählten' ohne Rücksicht auf Herkunft, Beruf und Vor bildung, die den 'Geist Christi' als einen menschenund weltumfassenden Geist unmittelbar, ohne Buchstaben, Schrift und Lehre, aus der Erfahrung des Leidens, des Kreuzes, in einem einmaligen, abschliessenden Akt I...I in sich erzeugen und dadurch zum Werkzeug einer wahrhaften, endgültigen Reformation werden. Diese revolutionäre Sekte mit ihrem 'freiheitlichen', gegenüber jeder auf Tradition und Schrift gegmindeten Autoritätskirche als Sprengmittel wirkenden I...I Prinzip, dem Prinzip des sog. 'inneren Geistes', des 'inneren Lichtes' oder auch des 'inneren Wortes', dieser Bund hatte seinen Ursprung und Mittelpunkt in Allstedt." (Hinrichs, S.1-3) - "Der Kampf gegen die Mallerbacher Marienverehrung, der im ubrigen ganz in der Linie der vorjährigen bilderstürmerischen Wittenberger Unruhen [1522] lag, ist für Mintzer aber nur der Hebel für die Begründung einer eigenen revolutionären Organisation, des 'Bundes der Auserwählten'. Denn das 'Verbündnis' einer aus ungefähr dreißig Teilnehmern bestehenden Versammlung, die eines unbekannten Tages in dem trockenen Bett des Allstedter Stadtgrabens zusammentrat, lautete: 'Bei dem Evangelio zu stehen, Mönchen und Nonnen keinen Zins mehr zu geben und dieselben helfen zerstören und vertreiben'. Wenn es also dazu kam, daß am 24. März I1524I im Beisein Müntzers die Kapelle zerstört wurde und in

Flammen aufging, so ist hier unschwer die erste Aktion jenes neugegründeten Bundes zu erkennen, der also offenbar kurz vor dem 24. begründet sein dürfte I...I." (Hinrichs, S.12)
26. Ausgedrückte Entblößung. Schriften und Briefe/Franz, a.a.0.,Nr.8A, S. 300

27. Den Begriff des "ästhetischen Mehrwerts" gebraucht Christoph Siegrist in seiner Abhandlung uber das "Lehrgedicht der Aufklärung" (Suttgart, 1974, S.72). Er meint vor allem damit die sinnliche Konkretisierung abstrakter Sachverhalte durch literarische Bilder und eine poetische Sprache, die Grundbedingung fir jede Lehrdichtung ist und ebenso Miintzers und auch Luthers Predigen auszeichnet. "Wichtigstes Mittel, Generelles in Poetisches, philosophisches Sprechen in dichterisches zu transponieren, ist die Versinnlichung in ihren verschiedenen Modi. I... I Der Mehrwert, den die Asthetisierung herausarbeitet, stellt die Rechtfertigung der Gattung ILehrgedichtI dar I.... IDas Einzelne regt die assoziative Motorik ungleich stärker an; bietet ihr mehr Ausgangspunkte als die leeren Begriffe; vom einen zum andern, besonders aber vam Unterbegriff zum Oberbegriff lauft der angeregte Verstand; Ver bindungen nach allen Seiten hin eröffnend, eignet dem poetischen Text eine Vielschichtigkeit, die ihn von der Gradlinigkeit eines diskursiven logischen Textes unterscheidet." (Siegrist, S.72-73)

28. Deutsch Euangelisch Messze etwann durch die Bepstischē pfaffen im latein zu grossem nachteyl des Christen glaubens vor ein opffer gehandelt I...I Thomas Muntzer Alstedt M.D.XXiiij. Vorrede yns buch disser lobgesänge. In: Schriften und Briefe/ Franz, a.a.0.,Nr.3, S.161-165; hier S.163-65

29. Vgl. dazu RGG I, 31957, 1201-1202 (IV. Deutsche Bibelübersetzungen): "Die erste germanische B.Ủ. war die des Westgoten Ulfilas. Ausschließlich auf der Vulg. beruht die mittelalterliche deutsche B.U., deren sich auf den Psalter und die Evangelien beschränkende erste Anfänge durch die christlichkulturellen Bestrebungen Karls d.Gr. veranlaßt waren. I...I Nach I...I wenigen Vorlăuferm aus althochdeutscher Zeit (Tatian, Otfried, Notker, Williram) beginnt die eigentliche Geschichte der deutschen B.t. erst mit dem 14.Jh. Die in großer Zahl unabhängig voneinander entstandenen, meist anonymen U.en, die aber weiteren Kreisen unzugänglich blieben, enthalten zum geringeren Teil einen vollständigen B.text, in den weitaus meisten Fällen dagegen nur Teile der B. oder einzelne biblische Bücher I...I Stellen auch die erhaltenen Hss. mur einen Bruchteil der einst vorhandenen dar, so zeigt doch ihre verhältnismäßig kleine $\mathrm{Zahl}$, daß die deutsche $\mathrm{B}$. im MA nicht sehr weit verbreitet war. Eine Änderung trat erst in der 2. Hälfte des 15 . Jh.s ein, als 1466 Johann Mentelin in Straßburg mit Hilfe des Buchdrucks eine in Bayerm entstandene (ca. 100 Jahre alte) U. des vollständigen $B$.textes herausbrachte. Bis 1490 wurde sie elfmal I...I nachgedruckt. Die im Wortschatz stark veraltete und textlich oft fehlerhafte oder ungeschickte $t$. unterzog man hauptsächlich in den Ausgaben von ca. 1475 (G.Zainer, Augsburg) und 1483 (A.Koberger, Nürmberg; Auflagenhöhe wohl 1000-1500 Expl.) einer Revision. Sehr gering war - abgesehen vom Psalter - die Zahl der damaligen hochdeutschen biblischen Teildrucke. I...I war die deutsche B. im ausgehenden MA - auch infolge der Plenare, Historienbibeln, Armenbibeln u.s.w. in breiten Kreisen des deutschen Volkes auch kein völlig unbekanntes Buch, so waren sie doch sowohl wegen der sprachlichen Unvollkommenheit wie auch wegen des hohen Preises der gedruckten B.n weit davon entfermt, ein wirkliches Volksbuch zu sein, wie sie es erst durch Martin Luthers $U$. wurde."

30. Martin Luther: Eyn Sermon von dem newen Testament. das ist von der heylige Messe Doct. Mar. L. Aug. Wittenbergk. IAm Ende:I Gedruckt zu Wittenbergk durch Johan. Grunenberg Nach Christ Geburt tausent fünffhundert vnd Zwantzigsten JAR. In: D.Martin Luthers Werke. Kritische Gesamtausgabe. Bd.6. Weimar 1966, S.349-378

31. Luther: Sermon von der heiligen Messe, a.a.0., S. 362 (16) u. S.375 (34): (16.) "Nu sich was haben sie vns auß der messe gemacht. Zum ersten/haben sie vns diße wort des testaments vorporgen/vnd geleret/ man sol sie den leyen nit sagen/es seyen heymliche 
wort/allein in der messe/vō dem priester zu sprechen. I...I wilcher teuffel hat yhn doch gesagt/das die wort die die aller gemeynsten/aller offentlichsten sein sollen/bey allen Christen/priester vnd leyen/ mann und weyben/iung vnd allt/sollen aller heymlichst vorporgen sein? I...I Aber wolt gott/das wir deutschen meß zu deutsch leßen/vñ die heymlichsten wort auffs aller hohist sungen I...I (34) Wo wollen aber die elenden pffaffen unnd leyen bleyben/die von dem vorstandt der messen vnd glauben/Bo weyt kümen seyn/das sie gleych eyn tzeuberey drauß gemacht haben I...I Hie schweygt yderman still vnd lassen das volck eynher gehen/vmb des vorfluchten schendlichen pfennigs wille / /er durch Bo mancherley namen vnd tugent der meß/mit hauffen zu gehet/I...I."

32. Luther: Deudsche Messe vnd ordnung Gottisdiensts. Wittemberg. IAm Ende:I Martinus Luther. Gedruckt zu Wittemberg. M.D.XXVI. In: D.Martin Luthers Werke. Kritische Gesamtausgabe. Bd.19. Weimar 1964, S.44113; hier: Vorrede, S.73: "Aber umb der willen mus man solche ordnunge haben, die noch Christen sollen werden odder stercker werden. I...I Aller meyst aber geschichts umb der eynfeltigen und des jungen volcks willen, wilchs sol und mus teglich ynn der schrifft und Gottis wort geubt und erzogen werden, das sie der schrifft gewonet, geschickt, leuffig und kundig drynnen werden, yhren glauben zu vertretten und andere mit der zeyt zu leren und das reych Christi helffen mehren; I...I." - Vgl. dazu auch: D.Martin Luthers Psalmen-Auslegung. Hrsg.v.Erwin Mulhaupt. Göttingen 1959, Bd.1., S.5-6: 3.Vorrede zum Neuburger Psalter 1545: "Billig sollt ein jeder Christ, der beten und andächtig sein will, den Psalter sein täglich Betbüchlein sein lassen. Und wäre wohl auch gut, daß ein jeglicher Christ denselben so übte und so geläufig drin wirde, daß er ihn von Wort zu Wort auswendig könnte I...I."

33. Luther: Deutsche Messe/1526, a.a.0.,S.72-113 (s.o. $\mathrm{Nr}$.32.)

34. Luther: dass., a.a.0., S.95

35. Vgl. dazu folgende Schriften Luthers: 1. An den Christlichen Adel deutscher Nation: von des Christlichen Standes besserung: D.Martinus Luther. Vuittenberg. IMelchior Lotther 1520I In: Werke/krit. Gesamtausg. Bd.6. Weimar 1966, S.381-469

2. Eyn trew vormanung Martini Luther tzu allen Christen. Sich tzu vorhuten fur auffruhr vind Emporung. Vuittemberg. IMelchior Lotther 1522I In: Werke/krit.Gesamtausg. Bd.8. Weimar 1966, S.670-687 3. Uon welltlicher vberkeytt wie weytt man yhr gehorsam schuldig sey. Mart. Luther Uuittemberg. M. D.XXIII. In: Werke/krit.Gesamtausg. Bd.11. Weimar 1966, S.229-281

4. Eyn brieff an die Fursten zu Sachsen von dem auffrurischen geyst. Martinus Luther. Wittemberg 1524. In: Werke/krit.Gesamtausg. Bd.15. Weimar 1966, S.199-221

5. Ermanunge zum fride auff die zwelf artikel der Bawrschafft ymn Schwaben. Mart. Luther. Wittemberg 1525. In: Werke/krit.Gesamtausg. Bd.18. Weimar 1964, S. 279-334

6. Ermanunge zum fride auff die zwelff artickel der Bawrschafft ynn Schwaben. Auch widder die reubischen vnd mordisschen rotten der andern bawren. Mart. Luther. Wittemberg. 1525. In: Werke/krit.Gesamtausg. Bd.18. Weimar 1966, S. 344-361

7. Eyn Schrecklich geschicht vnd gericht Gotes vber Thomas Muntzer, darynn Gott offentlich desselbigen geyst luggenstrafft vnd verdamet. Mart. Luther. IWittenberg, Joseph Klug 1525I In: Werke/krit.Gesamtausg. Bd.18. Weimar 1964, S.362-374 - Luther druckt hier zwei Mintzerbriefe ab (Brief an die Allstedter, Franz, Nr.75 und Brief an Graf Ernst von Mansfeld, Franz, Nr.88) und kormentiert sie. Besonders aus diesen Kormentaren wird die Stellung Luthers zu Mintzer nach dem Aufstand von 1525 deutlich.

36. Die gegensätzlichen theologischen und politischen Positionen zwischen Luther und Milintzer arbeitet sehr deutlich Carl Hinrichs heraus in seiner bereits zitierten Abhandlung: Luther und Miintzer. Ihre Auseinandersetzung über Obrigkeit und Widerstandsrecht. Berlin 1952
37. Ernst Bloch: Thomas Muintzer als Theologe der Revolution. In: Gesamtausgabe. Frankfurt 1977, Bd.2, S.194-195

38. Ernst Bloch, dass., a.a.0., S.195-196

39. 1. Thomas Muintzer: Deutzsch Kirchē ampt vorordnet, auffzuheben den hinterlistigen deckel unter welchem das Liecht der welt/vorhalte war/welchs yetzt widerumb erscheynt mit dysen Lobgesengen/und Gottichen Psalmen/die do erbawen die zunemenden Christēheyt/ nach gottis unwandelbarn willen/zum untergang aller prechtigen geperde der gotlosen. Alstedt. IErlenburg, Nikolaus Widemar 1523I In: Schriften und Briefe/Franz, a.a.0.,Nr.2, S.25-155; hier: Das ampt auff das Osterfest. Psalm 2, S.104.

2. Martin Luther: Der Psalter. In: Werke/krit.Gesamtausg. Die Deutsche Bibel. Bd.10,1. Weimar 1956; hier nebeneinander abgedruckt die thersetzungsfassungen von 1524, 1531 und 1545. Psalm 2, S.108-111. Der zitierte Text der Lutherübersetzung folgt der Fassung von 1545.

3. Mart in Luther: Psalmen-Auslegung. Hrsg.v. Erwin Millhaupt. Göttingen 1959, Bd.1; Psalm 2, S.26-44

40. Zu Luthers Psalmenübersetzung von 1545 siehe Anm. 39. - Die Unterstreichungen sind vom Verf. Die Lutherubersetzung ist kursiv gesetzt. - Der Text der Mintzerübersetzung folgt der Ausgabe des Deutschen Kirchenamts bei Franz (s.o.Anm.39).

41. $\mathrm{Zu}$ Luthers Psalmenkormentar vgl. die Ausgabe von E.Milhaupt, s.o.Anm.39. - Unterstreichungen vam Verf.

42. Im Wolfenbütteler (Herzog-August Bibliothek) Exemplar der Druckausgabe des Deutschen Kirchenamts von Thomas Mintzer aus dem Jahr 1523 wird nach: "I...I Got vñ seynen gesalbten" ein Absatz gemacht, so daß der nächste Satz im Druckbild als selbständiger Vers erscheint. Daraus ergeben sich in der Verszählung 13 statt 12 (Luther) Abschnitte bei Muintzer. Franz, a.a.0., S.104 druckt diesen Absatz nicht mit.

43. Vgl. dazu Martin Luther: Der Psalter. In: Werke/krit. Gesamtausgabe. Deutsche Bibel. Bd.10,1. Weimar 1956, S.109-111

44. Müntzer übersetzt in seiner Deutsch-Evangelischen Messe, Jes.11,4 (Franz, a.a.0.,Nr.3, S.169): "Eyne ruthe wirt außgehn von der wortzeln Jesse und ein blut IBlütel wirt auffsteigen von yrer wortzeln I... I und es wirt der geist der forcht des Herm die blǘeth erfullen. Die blueth wirt yhr urteyl nicht vollfuren nach dem ansehen der leute, und yre straff vorenden, nachdem die welt germe horet, sunder wirt urteylen die dorfftigen in der gerechtigkeyt und wirt straffen die sanfftmutigen der erden in der billigkeyt, und wirt schlahen das ertreich mit der ruthen yres mundes, und mit dem geyst yrer lyppen wirt sie todten den gottlosen, und die gerechtigkeit wirt yr ein gorttel an den lenden sein, und der glaube ein schurtz yrer nyren."

45. "vertragen": sich mit jemandem vertragers: übereinkommen, einen Vertrag oder Frieden schließen. Vgl. dazu Matthias Lexer: Mittelhochdeutsches Handwörterbuch. Leipzig 1878, Bd.3, Sp.273. - In der Ausgedrückten Entblößung (Franz, a.a.0., Nr.8A, S.283) steht hier sogar der Plural: "Wie bey unsern zeyten nu Gott seyn liecht in die welt schickt, wirt beweyset der gottlosen, unsinnigen menschen regiment und Oberkeyt nach allem mâtwillen mit allem eusserlichem toben und wutten auffs allerhochst wider Got und alle seyne gesalbten, psal.2 I...I." Die ẗbersetzung bedeutet, daß unter "Gesalbten" nicht mehr Christus allein verstanden wird, sondern die Auserwählten Gottes, also im Kontext der Ausgedrückten Entblößung Miintzer und seine Anhänger.

46. "beschweren": Last auflegen; beswaeren: drücken, belästigen, betrüben. Vgl. dazu Lexer, Mhd.Handwb. Lpz. 1872, Bd.1, Sp.232

47. Müntzer: Ausgedrückte Entblößung. In: Schriften und Briefe/Franz, a.a.0., Nr.8A, S.283

48. Muintzer: Danielauslegung (Fürstenpredigt). In: Schriften und Briefe/Franz, a.a.0.,Nr.7, S.256

49. Zum Titel der Fürstenpredigt s.o.Anm.14 
50. Zu Nebukadnezars Traumbild vgl. Daniel 2,31-36

51. Vgl. dazu Müntzer, Danielauslegung (Franz, a.a.O., S.259): "Drumb lasset die ubeltheter nit lenger leben, die uns von Gott abwenden, Deut.13., dann ein gottloser mensch hat kein recht zcu leben, wo er die frumen vorhindert. Exodi am 22. capitel saget Got: 'Du solt die ubeltheter nicht leben lassen.' Das meynet auch sant Paulus, do er vom schwerdt saget der regenten, das es zcur rache der bosen vorlihen sey und schutz der frumen, Roma. am 13.capitel." Vgl. dazu Römer 13,4 (Luther. Gesamtausg. Dt.Bibel, Bd.7,2. Weimar 1931, S.69): "Denn sie Idie Obrigkeit I ist Gottes Dienerin, dir zu gut. Thustu aber boses, so furchte dich, Denn sie tregt das Schwerdt nicht vmbsonst, Sie ist Gottes Dienerin, eine Racherin zur straffe vber den, der boses thut."

52. Vgl. dazu Mintzer, Danielauslegung (Franz, a.a.O., S.261-262): "Sie haben das lant nicht durch das schwerdt gewonnen, sonder durch die krafft Gottis, aber das schwerdt war das mittel, wie uns essen und trincken ein mittel ist zu leben. Also notlich ist auch das schwerdt, die gotlosen zu vertilgen, Rom. am 13. Das aber dasselbige nw redlicher weyse und fuglich geschee, so sollen das unser thewren veter, die fursten, thun, die Christum mit uns bekennen. Wo sie aber das nicht thun, so wirt yhn das schwerdt genommen werden. Danielis am 7.capitel I...I Wo sie aber das widderspiel treiben, das man sie erwurge on alle gnade wie Ißkias, Josias, Cirus, Daniel, Helias, 3. Regum 18, die pfaffen Baal vorst8ret haben. Anders mag die christliche kirche zcu yrem ursprung nicht widder kummen. Man muß das unkraut außreuffen auß dem weingarten Gottis in der zceyt der ermaten, dann wirt der schone rothe weytz bestendige wortzeln gewinnen und recht auffgehn, Matth.13. Die engel aber, wilche yre sicheln darzu scherffen, seint die ermsten knechte Gottis, die den eyfer gotlicher weyßheit volfuren, Malachie 3."

53. Luthers "Deutsche Messe und Ordnung Gottesdienstes zu Wittenberg furgenommen" ist erst 1526 erschienen. Offensichtlich war Luther, nach der Aussage Mintzers auf dessen Allstedter gedrucktes "Deutsches Kirchen amt" (1523) und die "Deutsch-Evangelische Messe" (1524) - beide bei Franz, a.a.0.,Nr.2 u.3 - eifersüchtig ("heylig"). Dazu schreibt Müntzer in seiner "Hochverursachten Schutzrede" (Franz, a.a.0.,Nr.9, S.321-343), die als Antwort auf Luthers Schmähschrift gegen ihn (Ein Brief an die Fürsten zu Sachsen von dem aufrührischen Geist, s.0.Anm.35, 4.) konzipiert war: "Es ist nit anders in der warheit, wie mir das gantze landt gezeügnuß gibt, das arme dürstige volck begerte der warheit also fleyssig, daß auch alle strasse vol leüte waren von allen orten, anzuhoren, wie das ampt, die biblien zu singen und zu predigen, zu Alstedt angerichtet wart. Solte er ILutherI auch zuprechen, so konte erß zư Wittenberg nit thun, man sichts in seyner teütschen meß wol, wie heylig IeifersüchtigI er darauff war, welches den Luther also sere verdroß, daß er zum ersten bey seinen fürsten zưweg prachte, das mein ampt nit solte in truck geen." Miintzer bezieht sich hier auf die Pläne Luthers, bei Herzog Johann und Friedrich dem Weisen mit seinem "Brief an die Fürsten zu Sachsen" zu erwirken, daß die Messen und Predigten Muintzers (u.a. auch Karlstadts in Orlamünde) abgeschafft würden, wenn sie zu offenem Aufrubr beitragen. Vgl. dazu auch C.Hinrichs, Luther und Mintzer, a.a.0.,S.144-150 und 183-185: "Er ILutherI habe diesen Brief Ian die Fürsten zu Sachsenl allein aus der Ursache geschrieben, weil er vermommen, und auch 'aus ihrer Schrift' verstanden habe, 'als wollt derselb Geist die Sache nicht im Wort lassen bleiben, sonderm gedenke sich mit der Faust dreinzubegeben, und wolle sich mit Gewalt setzen wider die Oberkeit und stracks daher einen leiblichen Aufrubr anrichten'." (Hinrichs, S.145)

54. Vgl. den Danielkommentar Luthers: Vorrede vber den Propheten Daniel. (1545) In: Werke/Gesamtausgabe. Deutsche Bibel. Bd.11,2. Weimar 1960, S.2-131; hier Vorrede. Fassungen 1530 und 1545
55. Miintzer: Danielauslegung. In: Schriften und Briefe/ Franz, a.a.O.,Nr.7, S.261

56. Luther: Vorrede über den Propheten Daniel. In: Werke/ Gesamtausgabe. Deutsche Bibel. Bd.11,2. Weimar 1960, S. 9

57. Zum Titel dieser Schrift vgl. die Arm.35, 6.

58. Zur unterschiedlichen Auffassung des 13. Römerbriefkapitels bei Luther und Muntzer vgl. Hinrichs, Luther und Mïntzer, a.a.0., S.33-36. - Im Römerbrief, Kap. 13, 7-8, kurz nach den oben zitierten Stelle, übersetzt Luther weiter: "So gebet nu jederman, was jr schuldig seja, Schos, dem der schos geburt, Zol, dem der zol geburt, Furcht, dem die furcht geburt, Ehre, dem die ehre geburt. Seid niemand nichts schuldig, denn das jr euch vntereinander liebet." - Vgl. dazu auch Luthers Kommentar zum 13. Römerkapitel (Werke/ Gesamtausg. Deutsche Bibel. Bd.7. Weimar 1931, S.25 (Vorrede) und S.70-71 (Römer 13): "Im Xiij. Leret er das weltlich Regiment ehren vnd gehorsam sein, welches darumb eingesetzt ist, obs wol die Leute nicht from machet für Gott, so schaffets doch so viel, das die Frommen eusserlich fride vnd schutz haben, vnd die Bosen on furcht oder mit friede vnd ruge nicht konnen frey vbels thun. Darumb es zu ehren ist auch den Frommen I...I." (Vorrede auf die Epistel S.Pauli an die Römer)

59. Vgl. dazu Miuntzers Interpretation zum 13. Römerbriefkapitel (Danielauslegung. In: Schriften und Briefe/ Franz, a.a.0.,Nr.7, S.261): "Sie haben das lant nicht durch das schwerdt gewonnen, sonderm durch die krafft Gottis, aber das schwerdt war das mittel", etc. s.o. Arm. 52

60. Der Prophet Jeremia $(1,10)$. In: Luther, Werke/Gesamtausg. Deutsche Bibel. Bd.11,1. Weimar 1960, S.197

61. Vgl. dazu Luthers Psalmenauslegung (Ps.2). In: Psalmen-Auslegung. Hrsg.v.E.Mülhaupt, a.a.0., Bd.1, S.27: "Daß dieser Psalm von David gemacht ist und von Christus redet, erzwingt die Autorität der ältesten Kirche, von der Lukas Apg. 4 (,24-28) schreibt: sie hoben ihre Stimme einmüig auf zu Gott und sprachen: Herr, der du bist der Gott, der Himmel und Erde und das Meer und alles, was darinne ist, gemacht hat, der du durch den Mund Davids, deinen Knecht gesagt hast: warum empören sich die Heiden und die Völker nehmen vor, was umsonst ist? die Könige der Erde treten zusammen und die Fürsten versameln sich zuhauf wider den Herrm und wider seinen Christus. Wahrlich, ja, sie haben sich versammelt über deinen heiligen Knecht Jesus, welchen du gesalbt hast, Herodes und Pontius Pilatus mit den Heiden und dem Volk Israel, zu tun, was deine Hand und dein Rat zuvor bedacht hat, daß es geschehen sollte I...I."

62. Vgl. dazu das Zitat aus Miintzers Danielauslegung, s.0.Arm. 52

63. Vgl. dazu das Zitat aus Luthers Vorrede zum Römerbrief, s.o.Anm. 58

64. Vgl. das Zitat aus Mintzers Danielauslegung, s.o. Anm.52: "Wo sie aber das nicht thun, so wirt yhn das schwerdt genommen werden."

65. In seiner Psalmenauslegung (Millhaupt, a.a.O. ,Bd.1, S.36-37) schreibt Luther dazu: "Der Sinn ist also: betet Christus eilend und schnell an, damit ihr nicht durch seinen Zorn vergeht und euch nicht selber täuschet, als wäre er noch weit entfermt; wisset, daß es schnell und in Kürze entbrennen wird; plötzlich, wenn ihrs nicht denket, wird er kommen I...I Des gleichen heißt es auch Spr. 1 (,27): wenn über euch kommt wie ein Sturm, was ihr fürchtet, und 1.Tess. 5 (,2f.): ihr wisset gewi $\beta$, daß der Tag des Herm wird kommen wie ein Dieb in der Nacht; denn, wenn sie werden sagen, 'es j.st Friede, es hat keine Gefahr', so wird sie das Verderben schnell überfallen." Das Jüngste Gericht bleibt also für Luther in seinem Termin ungewiß.

66. Luther: Psalmenauslegung/Millhaupt, a.a.0., Bd.1, S. 31

67. Vgl. dazu das Zitat unter Nr.66. - Der Kommentar stammt aus der zweiten Psalmenvorlesung von 1519. 
68. Müntzer: Danielauslegung. In: Schriften und Briefe/ Franz, a.a.0.,Nr.7, S.261-62

69. Müntzer an Graf Ernst von Mansfeld. Frankenhausen, 12.Mai 1525. In: Schriften und Briefe/Franz, a.a.O., Nr. 88, S. 468

70. "züchtigen": erziehen, lehren; zühten: nären, auferziehen, züchten. VgI. dazu Lexer, Mhd.Handwb. Lpz. 1878, Bd.3, Sp.1172

71. Vgl. dazu das Zitat unter Anm. 65.

72. Mintzers Aufruf zur Revolution in seinem Brief an die Allstedter zeigt das deutlich (vgl. dazu das Zitat im Text unter $\mathrm{Nr} .77$ ). Daß die sozialrevolutionären Ziele Müntzers aber dennoch untrennbar mit einer inneren, geistlichen Umwälzung des Menschen zum guten Menschen verbunden ist, geht aus Müntzers Ausgedrüickter Entblößung klar hervor. Carl Hinrichs (Luther und Muintzer, a.a.0.,S.52-53) schreibt dazu: "Aber beim Volk kommt nun noch etwas anderes hinzu, wodurch es an der wahren Seligkeit verhindert wird: das ist der harte Druck, der infolge der Pracht und des Reichtums der Besitzenden auf ihm liegt, so daß der arme Mann 'vor Bekümmernis der Nahrung' nicht einmal Zeit hat, lesen zu lermen IAusgedrückte EntblößungI, womit ihm der Weg zur neuen Lehre versperrt ist. Deshalb muß man die 'wuchersüchtigen Bösewichter' beseitigen, damit auch das 'arme gemeine Volk' des 'Geistes' innewerden kann Iebd.I I...I Die Beseitigung des Druckes, der auf den unteren Klassen lastet, ihre Befreiung aus ihrer elenden Lage, ist also für Müntzer nicht Selbstzweck, seine soziale Revolution hat einen über das Materielle hinausreichenden letzten Sinn I...I Der Sinn der Revolution ist, den Menschen seiner wahren Bestimmung zuzuführen. Diese erblickt Milntzer in seiner tiefen Religiosität in einem Leben mit und in Gott. Die Umwälzung der bisherigen politisch-sozialen Verhältnisse soll die Möglichkeit schaffen zur Erlösung der Menschheit vom Bösen. Die äußere Erneuerung der menschlichen Lebensverhältnisse zielt auf die innere."

73. Spätestens seit 1524 tritt Luther offen in einem Brief an den Kurprinzen Johann Friedrich (18.Juni) und später in seinem "Brief an die Fürsten zu Sachsen" scharf gegen Mintzer und Karlstadt auf und bittet die Obrigkeit, Miintzer zur Verantwortung zu ziehen und ihn und seine Lehren unschädlich zu machen. In seinem Brief an Johann Friedrich nutzte Luther die Gelegenheit zu einem neuen Vorstoß gegen Müntzer; "er bittet den Kurprinzen, es dahin zu bringen, daß Mintzer zur Verantwortung seiner Lehre nach Wittenberg kommen müsse." (Hinrichs, Luther und Muintzer, a.a.0.,S.31) "Auch von Wittenberg her verstärkte sich der Druck auf die Landesherrschaft, zwischen der lutherischen Richtung und dem Radikalismus Müntzers und Karlstadts, durch den jene ihre evangelische Sache kompromittiert sah, einen klaren Trennungsstrich zu ziehen. In der zweiten Julihälfte war Luthers Kampfschrift gegen Müntzer I...I erschienen. Anfang August beantragte der Rektor der Wittenberger Universität beim Kurfürsten, er möge den Herzog Johann zur Entfernung Karlstadts aus Orlamünde veranlassen." (Hinrichs, ebd.,S.138) Ähnliche Absichten in bezug auf Mintzer werden auch aus Luthers "Brief an die Fürsten zu Sachsen" deutlich. Die immer noch schwankenden Fürsten beauftragten Luther zunächst, eine Visitationsreise in die "gefährdeten" Ortschaften Thüringens zu unternehmen, bei der Luther aber nicht viel ausrichtete. Eine Disputation der radikalen und gemäßigten Parteien wurde von Luther vereitelt. So gelang es inm schließlich, die Obrigkeit noch vor dem offenen Bruch Mintzers mit den Fürsten auf seine Seite zu ziehen und damit seine eigene Lehre durch die staatliche Macht zu sanktionieren und die Mintzers als "obrigkeitsfeindlich" abstempeln zu lassen. Damit wird die gesamte revolutionäre Tendenz von Mintzers Theologie in die Illegalität abgedrängt, während Luthers Lehre offiziell legalisiert wurde.

74. Im Sinne der Stärkung der fürstlichen Regionalmacht gegenüber dem mittelalterlichen Römischen Kaiserreich handelt Luther durchaus als ein "frühbürgerlicher" Reformator gegen ein historisch überlebtes Gesellschaftsgefüge. Unter diesem Aspekt ist Luthers
Sprache nicht als die Sprache des eigentlichen Establishments anzusehen, sondern als die einer adligbürgerlichen Oppositionsbewegung, die selbst gegen das längst ausgehöhlte Machtgefüge von Kaiser und Papst antritt. Mintzers Revolution zielt dagegen weiter auf eine keineswegs "modern", sondern urchristlich gemeinte Gleichstellung von Adel, Bünger und Bauer und geht damit zumindest realpolitisch an den historischen gesellschaftlichen Entwicklungsmöglichkeiten vorbei, wenn sie auch von einem größeren antizipatorischen Weitblick zeugt.

75. Vgl. dazu Anm.10.

76. Vgl. dazu M.Bensing, Thomas Müntzer und der Thüringer Aufstand, a.a.0., S.107: "Milntzer gestand: 'Woe es ime recht gangen nach seynem synne und wye er furgehapt, sey das seyn meynunge gewest, es habens auch gemeynigklichen alle von der gemeyne seynes bundes gwust, das er wolle das land uff 10 meyl weges umb Molhawsen eyngenommen haben und das land zu Hessen und mit den fursten und herm verfaren, wye oben angezeygt. I...I.' Hier bestätigt Müntzer die bereits für die Zeit vor Aufstandsbeginn registrierte Tendenz, von Mihhlhausen aus und mit der Kraft der Mihlhäuser ganz Thüringen den Fürsten und dem Adel zu entreißen und so ein Zentrum zu schaffen, von dem aus der Aufstand auch in andere Teile Deutschlands getragen werden konnte."

77. Müntzer an die Allstedter. Mühlhausen, ca.26. od. 27.April 1525. In: Schriften und Briefe/Franz, a.a. $0 ., \mathrm{Nr} .75, \mathrm{~S} .454-456$

78. Vgl. dazu RGG IV, ${ }^{3} 1960$, 1496: "Nimrod: nach der Völkertafel in Gen. 10,8-12 Sohn des Kusch, Gewaltherrscher auf Erden I...I als solcher wurde er sprichwörtlich in Israel und noch bei uns. Sein Reich soll von Babel, Erech/Uruk, Akkad und Kalue I...I ausgehend auf Assyrien übergeriffen haben."

79. Vgl. dazu M.Bensing, Thomas Muintzer, etc., a.a.0., S. 193-194: "Unzweifelhaft hat die allgemeine Schwäche des Bauernkrieges den Erfolg der Fürsten begünstigt. Dennoch resultierte die Niederlage der thüringischen Bewegung in erster Linie aus den ihr innewohnenden Schwächen. Sie äußerten sich einmal in der Unmöglichkeit, die Isolierung der Aufstandszentren zu überwinden und das große Reservoire an Menschen und Waffen an den Brennpunkten der Auseinandersetzung konzentriert einzusetzen. Die Lokalborniertheit, die Tendenz, revolutionäre Erfolge allein im lokalen oder provinziellen Interesse zu nutzen, erwies sich als der größte Hemmschuh. Zudem half sie gemäßigte Unterströmungen nähren, die nach den ersten Erfolgen und bei Ausbleiben neuer Aufgaben notwendig an Bedeutung gewinnen mußten. Lokale Beschränktheit trug schließlich auch die Hauptschuld daran, daß es nicht gelang, die wichtigsten Städte Thüringens für die Insurrektion zu gewinnen, sie für die Verteidigung des Aufstandes gegenüber den Fürsten zu nutzen. I... I Der anfängliche Vorzug des Thüringer Aufstandes, die verschiedensten sozialen Elemente in einem Lager vereint zu haben, mußte ins Gegenteil umschlagen, als die Abwehr der Fürstenheere von der Zentralisation der Bewegung abhing. Die meisten Bauern vermochten aus eigener Kraft die ihnen eigene Lokalborniertheit nicht zu überwinden, und wo sie sich der Führung lokalbeschränkter städtischer Kräfte anvertrauten, wurde ihre Schwäche nur vermehrt. Gegen diesen potenzierten Provinzialismus vermochte auch Thomas Mintzer nichts auszurichten." - Vgl. auch die Anm.Nr.10. und 74. 


\section{TYPOLOGIE UND BIBLIOGRAPHIE LITERARISCHER UTOPIEN}

\begin{abstract}
Die Wirklichkeit ist so unendlich verschiedenartig, im Vergleich mit allen, selbst den raffiniertesten Ergebnissen des abstrakten Denkens, und duldet keine verallgemeinernden und scharf abgrenzenden Unterschiede. Die Wirklichkeit strebt zur Auflösung in lauter Einzelfälle.

Fëdor M. Dostoevskij: Aufzeichnungen aus einem Totenhaus. Moskau, Petersburg 1860-62.
\end{abstract}

\section{EINLEITUNG}

Bibliographie und Typologie. Die Schwierigkeiten der bibliographischen Bestandsaufnahme thematisch und gattungstheoretisch nicht eindeutig eingrenzbarer Textgruppen, deren $\mathrm{Zu}-$ ordnung $z u$ einem Oberbegriff einer Vielzahl von subjektiven und historisch bedingten Variationen unterliegt, die ihrerseits in die Rezeptions- und Definitionsgeschichte dieses Oberbegriffs verwoben sind, lassen sich mit den herkömmlichen bibliographischen Zuordnungsmethoden kaum bewältigen. Mehrere bereits unternommene Versuche, eine Bibliographie zum Begriff der Ziterarischen Utopie, d.h. der textlich fixierten Sozialutopie zusammenzustellen, können daher ohne Zweifel als gescheitert angesehen werden. Der allgemein als ein unbedingtes Gütezeichen geforderte bibliographische Anspruch auf vollständige Erfassung erweist sich in diesem Fall so lange àls unerfüllbar, wie es keine e i n d e u $t i g$ e Definition zum Begriff Utopie gibt. Jede "eindeutige" Definition des Utopiebegriffs würde aber zugleich eine Einengung des zuzuordnenden Textkanons bedeuten, die jederzeit kritisierbar und korrigierbar bleibt. Hiermit sei nur kurz auf die hermeneutische Grundschwierigkeit hingewiesen, der sich jeder Versuch aussetzt, der einem nur vage und vorläufig definierten Utopiebegriff eine bestimmte, abgegrenzte Anzahl von Texten als zuge- hörig oder nicht zugehörig zuzuordnen hat. Eine Bibliographie der utopischen Literatur muß daher notgedrungen "Auswahlbibliographie" oder Bibliographie mit Auswahlcharakter bleiben, eine Auswahl allerdings, die in diesem Fa11 durch die Wah1 der Definitionsgrenzen des Begriffs Sozialutopie (= textlich fixiertes, direkt oder indirekt dargestelltes Bild von einem idealen Staatswesen oder einer idealen menschlichen Gemeinschaft, dem die Negation der vom Autor als negativ empfundenen Verhältnisse seiner politischen und sozialen historischen Realität zugrundeliegt) bestimmt wird. So werden manche von einem anderen Vorverständnis aus gesuchte Texte hier vermißt, andere als nicht zugehörig kritisiert werden. Trotzdem wird versucht, einen grundsätzlichen Uberblick über die Vielfalt der unter dem Begriff der Sozialutopie mit einigem Recht subsumierbaren Texte zu geben. Die typologische Sichtung der auf den ersten Blick kaum homogenen Textliste ist dabei unumgänglich und erscheint als geeignete Methode, den Gesamtkomplex der utopischen Literatur wenigstens ansatzweise in den Griff $z u$ bekommen, ein Gesamtkomplex, der sich vom antiken Märchen über scholastische Spekulationen zum Tausendjährigen Reich, über Seereiseabenteuer und satirische Beschreibungen exotischer Phantasieländer, über Rechtstexte 
und Verfassungsstatuten, über Sozialprogramme und philosophische Abhandlungen, über Flugschriften und Schauspiele bis hin zu Elementen von Utopie und Science-Fiction im modernen Roman des 20. Jh.s erstreckt. Nur so, unter dem Aspekt einer typologischen Entflechtung dieser Textmasse nach dem Charakter der Utopie und dem Charakter ihrer literarischen Präsentationsform erhält das aufgeführte Textmaterial einen gewissen exemplarischen Wert und kann u.U. auch für nicht aufgeführte Texte sprechen. Aus den verschiedensten Gründen entstandene Lücken werden auf diese Weise zwar nicht mit bibliographischen Einzelheiten gefüllt, wenigstens aber typologisch überdeckt, so daß Texte, die hier übersehen wurden, mindestens leicht in den Gesamtzusammenhang nachträglich eingeordnet werden können. Das betrifft insbesondere die Randgebiete der utopischen Literatur: die Prognostika, die Kaiserprophetien, die Fürstenspiege1, die Arkadiendichtungen, die politisch-satirischen Schriften, die Robinsonaden und Swiftiaden, die "Anti-Utopien", manche philosophischen Denksysteme, die Science-Fiction Texte, etc. Wenn aus diesen und anderen Randgruppen hier jeweils nur einige typische Texte vertreten sind, so seien die entstehenden Lücken mit der Nutzlosigkeit einer ins Uferlose aufgeschwemmten und dadurch typologisch konturlosen und unübersichtlichen Bibliographie entschuldigt. Von größerem Nutzen ist hier, besonders bei den Randgruppen, eine typologische Orientierung, die, anstatt alle den einzelnen Gruppen zugeordneten Texte aufzuführen, vordringlich Wert darauf legt, angesichts einiger weniger typischer Texte, das grundsätzliche Verhältnis der gesamten Gruppe zur Sozialutopie typologisch zu klären. Damit ist zwar keine Gewähr für eine vol1ständige Auflistung aller jemals innerhalb der Utopiediskussion dem Begriff zugeordneten Texte gegeben, es bildet sich aber auf diese Weise ein deutliches typologisch-bibliographisches Raster zu einem nicht auf bestimmte Textgattungen festlegbaren Begriff heraus, das das Wesentliche des Utopischen vielleicht eher anzudeuten vermag als die bisherigen, im allgemeinen unsystematisch und zufällig anmutenden bibliographischen Sammlungen utopischer Texte (zuletzt in großem Rahmen bei Pierre Versins: Encyclopedie de 1'Utopie. Paris 1972.).

Eine Typologie der utopischen Literatur, die Einzeltexte in Untergruppen zusammenfaßt und alle Untergruppen auf bestimmte Weise dem Oberbegriff zuordnet, verschafft größere Oberblicke, strukturiert die Gesamttextmasse und erhellt Zusammenhänge zwischen Texten, die auf den ersten Blick kaum etwas miteinander $z u$ tun haben. Trotzdem bleibt der bibliographische Aufbau streng chronologisch. Die Querverweise und typologischen Einzelbestimmungen sind zunächst den Kommentaren zu den Titeln $z u$ entnehmen. Ein typologisches Register, das einen Großteil der Titel dann noch einmal in verschiedenen Untergruppen zusammenfaßt und somit die chronologische Bibliographie typologisch strukturiert, dient anschließend als Oberblick.

Typen der utopischen Literatur sollen in dieser Bibliographie vorgestellt und bibliographisch erschlossen werden, Typen einer bisher kaum überschauten und differenziert strukturierten "Gattung". Anregungen erhielt diese Arbeit u.a. aus Ernst BZochs "Prinzip Hoffnung", aber sie legt sich nicht fest auf die wenig differenzierenden Gegensatzpaare, mit denen Gruppen utopischer Texte bisher gern strukturiert wurden. Konstruktionen wie Utopie und Antiutopie, archistische und anarchistische Utopie, Utopie des Raumes und der Zeit, Utopie der Ordnung und Freiheit, konkrete und abstrakte, technische und soziale Utopie u.s.f. gerieten so zu typologischen Grobrastern, die das wesentlich vielseitigere historische Textmaterial zu abstrakt in ein antithetisches Gestaltungsprinzip zwangen. Auch eine auf der Basis der bibliographischen Erschließung des Textmaterials beruhende, genaue Typologie der Repräsentationsformen, der Inhalte, der Motivationen, der historischen Zusammenhänge und Hintergründe und der Rezeptionsweisen utopischer Literatur kann allerdings nicht alle Zusammenhänge aufschlüsseln und den Utopiebegriff vollständig ausschöpfen, aber sie kann als Grundlage für weiterführende Einzelforschungen zur literarischen Utopie dienen und darüber hinaus zu einem etwas stärker als bisher differenzierten Vorverständnis von dem verhelfen, was mit dem Begriff utopische Literatur bezeichnet wird.

Bibliographie und Typologie zwingen in ihrer Kombination $z u$ einer genauen Interpretation jedes einzelnen aufgeführten Textes und erlauben keine willkürlichen Obernahmen aus bereits vorgefundenem bibliographischen Material, 
das allerdings als Wegweiser dienen mußte. Deshalb war es notwendig, den größten Teil der hier aufgeführten Texte mindestens mitte1bar inhaltlich und von seinen historischen Umständen her kennenzulernen. Eine vollständige Klärung des Utopiebegriffs durch dieses Verfahren ist nicht $z u$ erwarten, eher eine bessere Veranschaulichung seiner Struktur. So gesehen dient diese Bibliographie in ihrer typologischen Orientierung zugleich der Verdeutlichung des $B$ e $g$ r $f f s$ Utopie und der näheren Bestimmung der "1 $i \mathrm{t}$ e $\mathrm{r}$ a $\mathrm{r} i$ $\mathrm{s} c \mathrm{~h}$ e $\mathrm{n}$ G a $t \mathrm{t}$ u $\mathrm{n}$ " Utopie. Die Frage, was ist Utopie, was utopische Literatur, scheint mit dem Hinweis auf einzelne, typologisch dem Oberbegriff zugeordnete Textgruppen (z.B. utopische Robinsonade, utopische Seeoder Planetenreise, utopisch-politische Satire, utopisch-arkadischer Roman, utopischer Erziehungsroman, utopisches Sozialprogramm, utopisch-philosophische oder utopisch-architektonische Idealstaatskonstruktion, etc.) im Hinblick auf eine Gattungstheorie eher beantwortbar als mit den kaum an der Vielzahl aller Einzeltexte verifizierbaren allgemeinen Theorien zur utopischen Literatur, die oft nur begrenzte typologisch homogene Textgruppen (wie $z . B$. den utopischen Roman) adäquat erklären. Es kann allerdings kaum der Sinn allgemeiner Theorien sein, immer jeden Einze1- und Sonderfall zu erklären. Von einer typologischen Bibliographie ist das zumindest ansatzweise schon eher zu erwarten.

Die Bibliographie und Typologie der utopischen Literatur versteht sich als Ausgangspunkt zunächst für ergänzende bibliographische Arbeiten, die unter neuen Aspekten weitere Titel anfügen oder aufgenommene ausklammern. Vor allem aber soll sie allen denjenigen, die in das Gebiet der utopischen Literatur eingeführt werden wollen, als Grundlage und Nachschlagewerk und a1len denjenigen, die Einze1heiten vertiefen wollen,als Plattform und Orientierungspunkt dienen. In diesem Sinne war es erforderlich, so offen wie möglich zu bleiben und sich vor subjektiven Werturteilen über einzelne Texte so weit wie möglich zu hüten oder sie wenigstens kritisch zu reflektieren und zur Diskussion zu stellen, ohne jedoch jenem unkritischen Glauben an die "Objektivität" bibliographischer Zusammenste1lungen zu erliegen.

Der Utopiebegriff ist in den letzten Jahren häufig strapaziert worden, weniger wurde zur
Textkenntnis verholfen, vielleicht auch deshalb nicht, weil eine große Anzah1 der utopischen Texte bisher nur in verhältnismäßig "unzugänglichen", meist fremdsprachigen Originaldrucken des 15 . bis 18 .Jh.s vorliegt. Die Science-Fiction Literatur, auch unbekanntere Texte aus dem vorigen Jahrhundert, wird eifrig publiziert und dem Leser in Taschenbuchausgaben leicht zugänglich gemacht; einige utopische Texte des 16 . bis 18 . Jh.s liegen in teuren Reprintausgaben vor, der Rest bleibt nur dem zugänglich, der sich nach langwieriger bibliographischer Sucharbeit an alte Bibliotheksbestände wagt. Kaum werden Texte wie James Harringtons Oceana, London 1656 oder Margaret Cavendishs Blazing World, London 1666, die Popularität von Jonathan Swifts Gulliver, London 1726 oder von Herbert George Wells' Time Machine, New York 1895, erreichen. Trotzdem gehören auch diese Texte unbedingt zum Gesamtbild der utopischen Literatur. Neben Typologie, Gattungs- und Definitionsfrage sieht es diese Bibliographie als eine wichtige Aufgabe an, gerade diese teils "verschollenen" Texte wenigstens bibliographisch erneut zugänglich zu machen und mit den Bibliotheks-Standortangaben den ersten Schritt zu einer erneuten Rezeption zu erleichtern. Ist die utopische Intention auf ein besseres Zusammenleben der Menschen a1s eine historische Konstante der utopischen Literatur anzusehen, so liegen ihre strukturbildenden Elemente gerade nicht in ihrer Intention, sondern in ihren historischen Variablen: einmal in ihrer kritischen Reflexion auf ihre jeweilige historische Realität und zum andern in der Reflexion auf ihre Rezeption, die sich in den verschiedenen literarischen Präsentationsformen widerspiege1t. Diese Varianten gilt es,aus Einzeltexten heraus zu sichten, um damit in einem hermeneutischen Erkenntnisprozeß den Gesamtbegriff wieder um einiges exakter definieren $z u$ können.

Die Kommentare $z u$ den einzelnen Texten konnten nicht in allen Fällen die gesamte neueste und neuere Forschungsliteratur innerhalb der verschiedensten Gebiete berücksichtigen. Das war auch nicht die Aufgabe dieses auf die allgemeine Typologie abzielenden Gesamtüberblicks über die utopische Literatur. Trotzdem wurde die neuere und neueste Literatur zu bekannteren Autoren und vor allem zur Utopie und $z u$ einzelnen Utopisten weitgehend berücksichtigt und im bibliographischen A.nhang vermerkt. 
Die Typologie zur utopischen Literatur 1iefert nach den Ordnungsprinzipien einer durchnummerierten, chronologischen Titelbibliographie für die utopischen Texte vorwiegend des europäischen Raums in einem bibliographischen und einem Kommentar-Teil zu jedem aufgeführten utopischen Text a11e wichtigen bibliographischen, historischen, inhaltlichen und gattungstypologischen Informationen sowie eine Einordnung des jeweiligen Textes in den sozialgeschichtlichen und literarhistorischen $\mathrm{Ge}-$ samtzusammenhang der utopischen Literatur. So gibt die Typologie insgesamt einen detaillierten, aber nicht lückenlosen Oberblick über den gesamten textlich dokumentierten Bereich des utopischen Denkens. Kulturgeschichtliche, gattungstheoretische und sozialgeschichtliche Zusammenhänge zwischen verschiedenen aufgeführten Texten werden innerhalb der Kommentare, wo erforder1ich, durch Querverweise angedeutet, so daß "typologische Gruppen" von verschiedenartigen, zeitlich und sprachlich auseinanderliegenden Texten, die dann unter einem bestimten, gattungstheoretischen, kultur- oder sozialgeschichtlichen Aspekt zusammengefaßt werden können, für den Leser sichtbar werden. Als Oberblick über bestimmte typologische Raster, die den Gesamtbereich der utopischen Literatur strukturieren, dienen das typologische Register und die typologische Tabelle im Anhang. Das Textmateria1 und die Kommentare werden durch weitere Register erschlossen: zunächst durch ein alphabetisches Autorenregister, in dem alle Hauptautoren aufgeführt sind. Es folgt ein alphabetisches Titelregister, das alle Haupttitel aufführt und u.a. von deutschen Titelübersetzungen auf die Originaltitel verweist. An dritter Stelle steht das Namenregister, in das u.a. ein Register der Drucker für die Drucke vom 15.bis zum 18. Jahrhundert und ein Register weiterer, in den Kommentaren genannter Autoren utopischer, nicht-utopischer und sekundärere Texte eingearbeitet sind. Das Sachregister schließlich verzeichnet neben den wichtigsten Sachbegriffen die Titel von utopischen und nicht utopischen Texten, die in den Kommentaren oder im Einleitungsteil erwähnt wurden und nicht bereits im Titelregister aufgeführt sind.

Titelaufnahme. Bibliographie. Kommentar.

Nach der Ordnungszah1, die die chronologische Reihenfolge der Texte bestimmt, steht, in kursiv, das Erscheinungsjahr des Textes, bzw. das Entstehungsjahr bei antiken und mittelalter1ichen Texten. Dahinter folgen Name und Vornamen des Autors. Es folgt die genaue typographische Wiedergabe des Titelblattes des Originaltextes mit Zeilenspiegel für Texte vom 15. bis zum 18. Jahrhundert, wo dem Verfasser die Originale vorlagen. (Hochgestelltes kursives $f$, das eine Textpassage einsch1ießt, bedeutet, daß dieser Textabschnitt im Original in Fraktur gesetzt ist. Hochgestelltes ${ }^{k}$ bedeutet, daß die bezeichnete Passage in kursiv gesetzt ist. Sperrung bedeutet Rotdruck im Original.) A1le anderen Titel erscheinen normalisiert aber möglichst in vollem Wortlaut und in der originalen Schreibweise der Vorlage, in der Reihenfolge: Titeltext, evt1. Herausgeber, Obersetzer, etc., Ort, Ver$1 \mathrm{ag} /$ Drucker, Jahr, Umfang. Titel aus der Antike und dem Mittelalter werden grundsätz1ich in möglichst modernen, wissenschaftlichen Ausgaben des 19. und 20. Jahrhunderts aufgeführt. Für Titel nach 1800 fällt die Formatangabe fort. Titel innerhalb der Kommentare und bibliographischen Angaben erscheinen je nach ihrer Wichtigkeit in vollem Wortlaut normalisiert, gekürzt oder als Wiedergabe der Originale mit Zeilenspiegel. Alle Zusätze des Verfassers innerhalb der Titel sind in eckige Klammern I I gesetzt und kursiv. Alle Angaben vom Verfasser zum Titel erscheinen kursiv. Nach dem Titel folgen, wenn nicht angegeben, Druckort und Jahr, evt1. Drucker, danach Umfang und Gliederung des Inhalts des Originals. (Frontisp.=Frontispiz; Tb.=Titelblatt; Kurzt.= Kurztite1; bei eingeklammertem (Tb.) ist das Tb. in der Seitenzählung des Originals mitgezäh1t.) Nach diesen Angaben folgen eventuelle Abweichungen weiterer Titelblätter vom aufgeführten Tb. (nur bei Texten des 15.-18.Jh.s), $z . B$. bei mehrbändigen Werken. Es folgt jeweils am Ende der Umfangsangabe eines Bandes das Format $\left(2^{\circ}, 4^{\circ}, 8^{\circ}, 12^{\circ}\right)$. Einzelne Bände eines mehrbändigen Werkes sind gekennzeichnet mit $1 .: ; 2 .:$; etc. Danach werden, wenn notwendig, weitere Angaben zum Originaltitel verzeichnet, etwa nicht erreichbare frühere Ausgaben, Entstehungsdaten, Auflösungen von Anonyma, etc. Dann wird für Texte des 15. bis 18. Jahrhunderts und seltenere Texte aus späterer Zeit der Bibliotheksstandort der Bibliotheken mit dem Verweis "Bibl.:" angegeben, in denen der 
Verfasser das Original selbst eingesehen hat. ( $\mathrm{BM}=\mathrm{British}$ Museum; $\mathrm{BN}=\mathrm{Bibliotheque} \mathrm{Nationale;}$ LoC=Library of Congress; $23=$ Herzog August Bibliothek, Wolfenbütte1; 7=Niedersächsische Staats - und Universitätsbibliothek, Göttingen; $12=$ Staatsbib1iothek, München; 24=Landesbibliothek, Stuttgart; 21=Universitätsbibliothek, Tübingen; etc.) Nach der Nummer der Bibliothek folgt die Buchsignatur. Alle vom Verfasser zusammengetragenen Daten und Anmerkungen, sowie alle Kommentare des Verfassers in diesem wie in den folgenden Abschnitten sind kursiv gesetzt. Alle Autorennamen in den bibliographischen Angaben sind ebenfalls kursiv. In normalen Typen erscheinen Titel und Zitate.

Nach der Titelaufnahme werden weitere Ausgaben des Werkes in der Originalsprache angegeben. Diese Angaben beschränken sich durchweg auf wichtigere Ausgaben bis zur Gegenwart, soweit sie dem Verfasser bekannt geworden sind. Bibliographische Vollständigkeit wird hier und bei den Obersetzungen nicht angestrebt. Es schließen sich Verweise auf Spezialbibliographien, wenn vorhanden, zu Autor und Werk an. Danach folgen die Übersetzungen. Vorwiegend werden nur die deutschen Obersetzungen berücksichtigt, wenn nicht obersetzungen in andere Sprachen inhaltlich oder literarhistorisch von Bedeutung sind. Sie stehen dann vor den deutschen Obersetzungen. Die Tite1aufnahme geschieht hier je nach wichtigkeit nach den oben angeführten Kriterien. Von den Obersetzungen werden auch nur die wichtigsten bis zur Gegenwart angegeben, soweit sie dem Verfasser bekannt geworden sind. Es folgen weitere Hinweise $z u$ bibliographischen Quellen oder $\mathrm{zu}$ wichtigen Untersuchungen über Autor und Werk, die keinesfalls Vollständigkeit anstreben. Im übrigen ist es nicht Aufgabe dieser Bibliographie, einen Uberblick über den gesamten Forschungsstand $z u$ jedem einzelnen Autor $z u$ geben. Wenn vorhanden, werden dem Verfasser bekannt gewordene Fortsetzungen und Nachahmungen des Originals angegeben, z.B. bei Defoe oder Swift. Daneben erscheinen an dieser Stelle weitere Titel, die einer gleichen typologischen Untergruppe zur Utopie zugehören, z.B. Fürstenspiegel, Arkadiendichtungen, Prognostika, etc. Diese Gruppen werden nicht vollständig bibliographiert, sondern es wird lediglich auf ihre typologische Zugehörigkeit zum Gesamtkomplex hingewiesen. Es erscheinen hier stellvertretend für die gesamte Gruppe nur die wichtigsten Titel vom 16 . bis 18 .Jahrhundert, die eindeutig utopische Züge aufweisen. Daneben erscheinen auch solche Primärtitel, die selbst nicht utopischen Inhalts sind, aber wichtige Informationen $z u$ den Originaltexten und ihrem historischen Hintergrund enthalten oder direkt auf utopische Texte eingewirkt haben, wie $z . B$. Texte von Macchiave11i, Kopernikus, Galilei, Buffon, etc. Diese Ausgaben erscheinen ebenfalls nach Erscheinen chronologisch in Unterpunkte (a,b,c,etc.) geordnet und sind im Titelregister verzeichnet. Je nach Wichtigkeit und Erreichbarkeit der Originale werden diese Titel wie die Originaltite1 behandelt oder mit normalisiertem oder gekürztem Titeltext und allen weiteren Angaben bis hin $z u$ Obersetzungen verzeichnet.

Am Beginn des Kommentarteils stehen Zitate über den Inhalt des $z u$ kommentierenden Textes aus allgemeinen Lexika (Kindlers Literaturlexikon, etc.) oder speziellen Untersuchungen zur utopischen Literatur (Gibson, Dupont, Begley, etc., s.u. bibliographischer Anhang). Es folgt der Kommentar zu Originaltext und Autor, in den, wenn es wichtig erscheint, auch eventuelle Bearbeitungen, Fortsetzungen und Obersetzungen mit einbezogen werden. Der Kommentar konzentriert sich auf Inhalt, biographische Informationen, Textinterpretation, sozialgeschicht1iche und 1iterar- und ku1turgeschichtliche Zusammenhänge und auf typologische und gattungstheoretische Erörterungen und Einordnungen. Am Schluß des Kommentars wird die häufiger zitierte Sekundärliteratur noch einmal erwähnt. Die zitierte Sekundärliteratur $z u$ den einzelnen Titeln erscheint nach Autoren alphabetisch zusammengefaßt noch einmal im bibliographischen Anhang. Die Zitate aus den Originaltexten und aus der Sekundärliteratur erscheinen z.T. in der Obersetzung des Verfassers.

Ihre zentrale Aufmerksamkeit widmet diese Typologie und Bibliographie der utopischen Literatur auf die Zeit vom 16. bis zur Mitte des 19. Jahrhunderts, also auf jene Epochen, die die meisten sozialutopischen Texte hervorbrachten(hier besonders das 18.Jh.). Aus diesem Grund sind für diesen Zeitraum die Kommentare wesentlich ausführlicher gehalten als zu antiken oder mittelalterlichen Texten. 


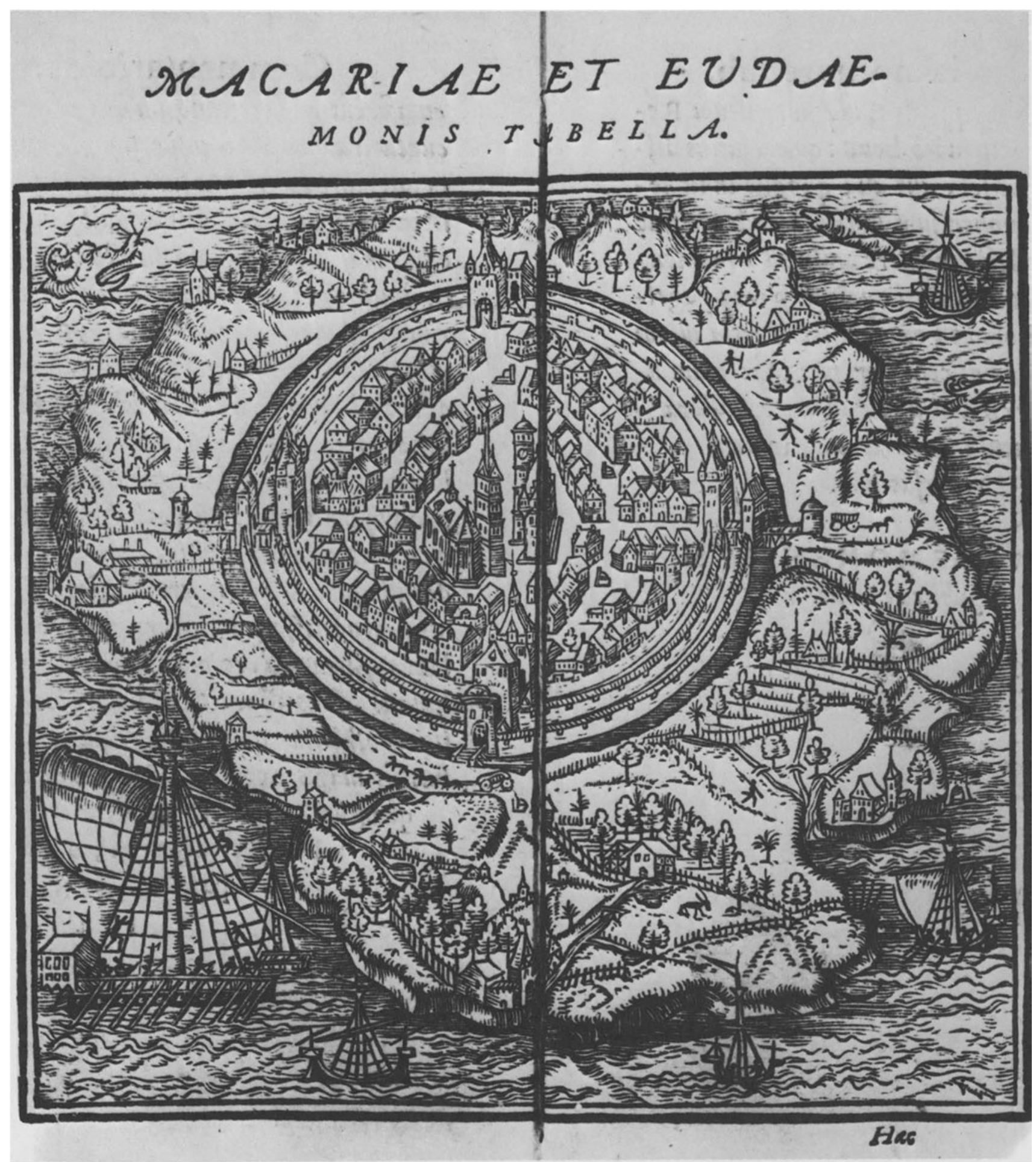

Gaspar Stiblin: Commentariolus de Eudaemonensium Republica. Basel 1555. - Bibl.: 23: 1198.9 Theol.80: Abbildung der Insel und der Stadt: "Macariae et Eudaemonis Tabella." - Vgl. dazu S.38,2 


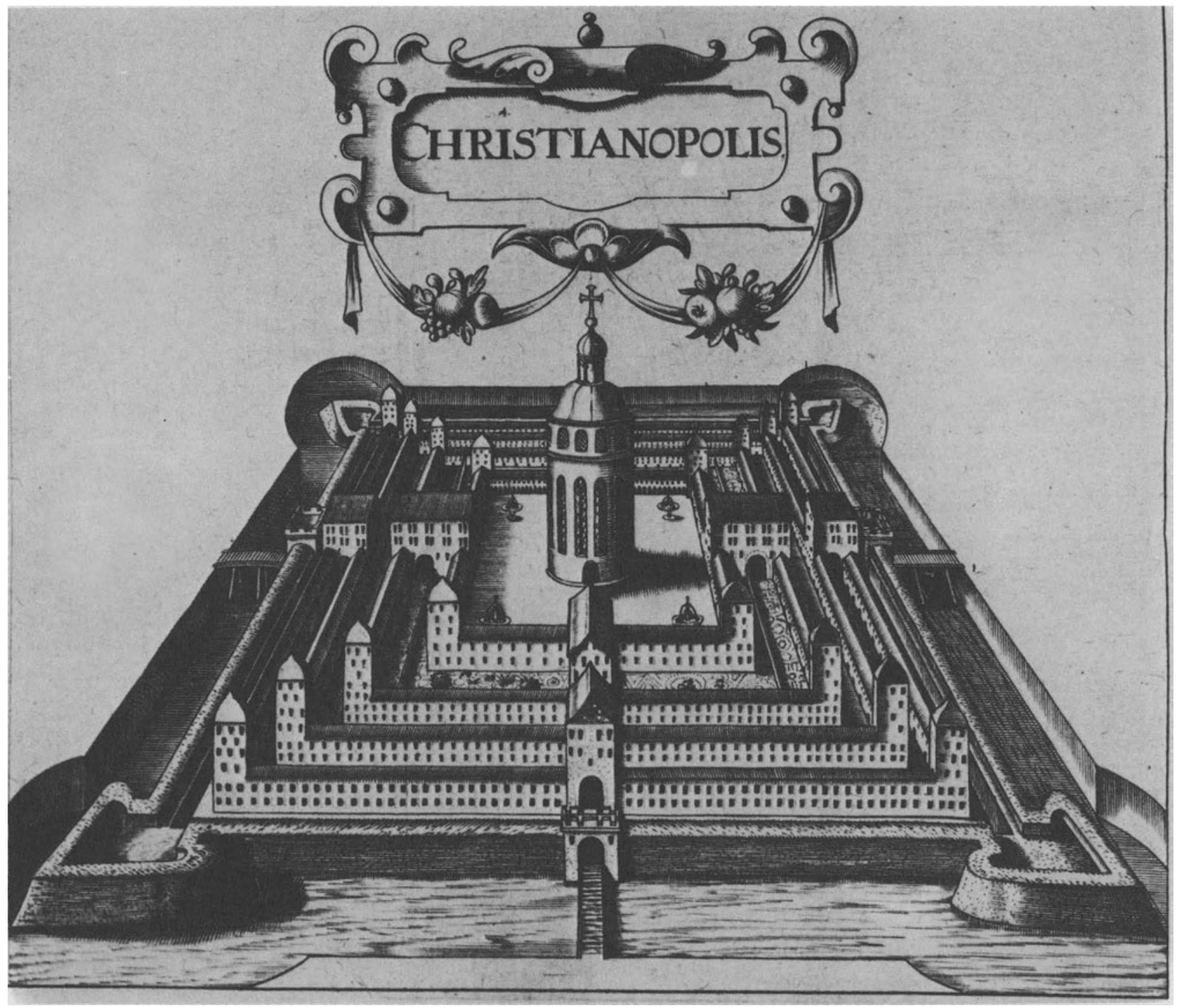

Johann Valentin Andreae: Reipublicae Christianopolitanae descriptio. Straßburg 1619. - Bibl.: 23: 1265.2 Theol (1): Abbildung der Stadt: "Christianopolis", nach S.120. - Vgl. dazu S.50,1 


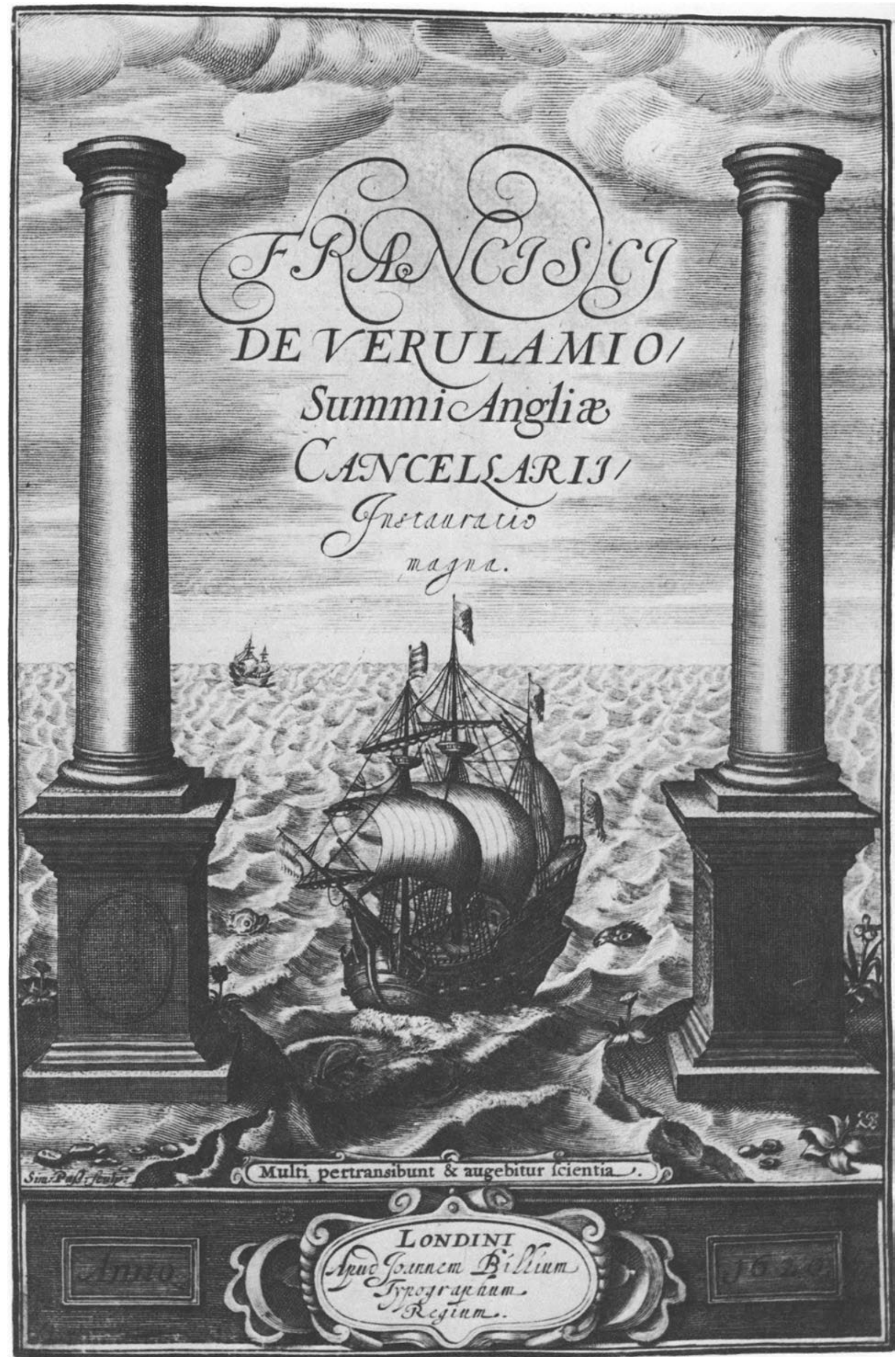

Francis Bacon: Instauratio magna. London 1620. - Bibl.: 23: $157.1 \mathrm{Qu}$ (fol.): Titelblatt. - Vgl. dazu S.XXIX,1; S. XLVI,1, Anm. 55; S.51,1 